\title{
Drugged Out: How Cognitive Bias Hurts Drug Innovation
}

\author{
CYNTHIA M. HO*
}

TABLE OF CONTENTS

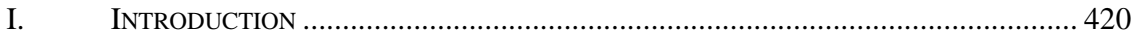

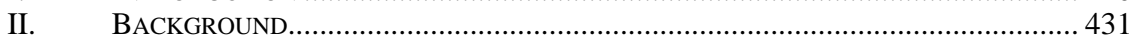

A. Pharmaceutical Development and Commercialization ........................... 431

1. Types of Drugs.................................................................................... 431

2. Patent Theory and Practice: The Case of Drugs ............................. 433

B. $\quad$ The Existence and Importance of Schemas ............................................. 436

1. Individuals and Groups View Information Through

Schemas....

2. Schemas Are Maintained Through Confirmation Bias .................... 438

a. Seeing What We Want To See: Confirmation Bias...................... 438

b. Schemas Are Resistant To Change ............................................ 442

C. Schemas Can Propagate to Those Who Are Not Initially

Interested in the Schemas.

1. Repetition of Schemas Makes Them Seem Real ................................ 443

2. Compelling Stories That Are Repeated Are

Especially Memorable

* (C) 2014 Cynthia M. Ho. Associate Dean of Faculty Research and Development, Clifford E. Vickrey Research Professor, and Director of the Intellectual Property Program, Loyola University Chicago School of Law. I would like to thank Colleen Chien, Jeanne Fromer, Leah Chan Grinvald, Christi Guerrini, Yaniv Heled, Nancy Kim, Peter Lee, Irina Manta, Angela Upchurch, and Liza Vertinsky for their comments on earlier drafts. This Article also benefited from the 2013 IP Scholars Conference, the 2012 Works-in-Progress Intellectual Property Colloquium, and the 2013 Patent Conference, PatCon 3. In addition, many thanks to the assistance of Librarians Patricia Scott and Nan Norton, as well as Research Assistants Michelle Arvans, Jean Liu, Guthrie Weinstock, and Eric Yarnell for their excellent help. 
III. ReveAling Three Key Schemas Impacting Pharmaceutical

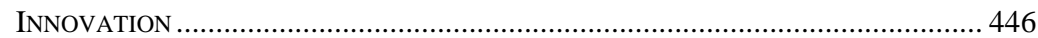

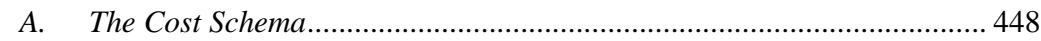

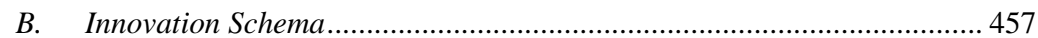

1. Contesting the Methodology of a Study that Challenges This Schema ..................................................................... 460

2. Supporting and Reinforcing Schema via Selective Listening ........................................................................................... 463

C. Strong Patent Schema .......................................................................... 466

1. The Assumption That Strong Patents Are Desirable To Promote Any Drugs ........................................................................ 467

2. Supporting the Schema Through Selective Consideration of International Evidence.

3. Supporting the Schema Through Selective Reliance on Supposed Value of Incremental Innovation................................... 474

IV. ADDRESSING THE POLICY IMPLICATIONS OF PHARMACEUTICAL INNOVATION

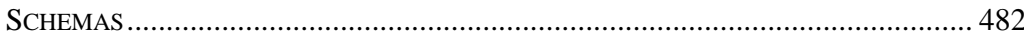

A. $\quad$ Addressing Existing Schemas............................................................... 482

1. Avoiding Unintentionally Propagating Problematic Schemas

2. Combating Current Schemas ............................................................... 485

B. Less Is More: Patent Policy Should Consider Promoting

More Innovative Drugs...

C. Schemas for Further Consideration ......................................................... 499

1. Is There a Cultural Belief That Newer Is Better? ........................... 499

2. Exploring Other Patent Schemas? .................................................... 505

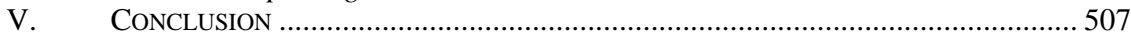

\section{INTRODUCTION}

Three blind men inspect an elephant. Each touches a different part of the elephant and comes to a different conclusion about what the elephant "looks like." Although they are each correct—in part-their conclusions seem to represent very different beasts. This story shows that what is "true" is a function of what one sees. But, what about more complex events and information where it may be challenging for an individual to see the entire "animal"? Just as the blind men are missing the big picture because they lack complete vision, individuals may be "blind" to a bigger picture because of cognitive biases that studies repeatedly show all individuals have. ${ }^{1}$ Although there are many biases, the primary focus

1. The issue of cognitive biases has recently infiltrated popular discussion. E.g., Malcolm GladWell, BlinK: The Power of Thinking Without THINKING (2005); Daniel KAHNEMAN, THINKING, FAST AND SLOW (2011). 
here is on seeing what we want to see consistent with our original views-a phenomenon called "confirmation bias."2

This Article focuses on certain beliefs concerning patents and pharmaceutical innovation that are reinforced through confirmation bias. This focus is an attempt to explain two distinct, yet different, views. On the one hand, scholars who focus on patent theory frequently hail the pharmaceutical industry as an example of how patents work as intended. ${ }^{3}$ These scholars note that because development costs are high and imitation is inexpensive, patents are essential and effective in promoting innovation that would otherwise be unlikely to occur. ${ }^{4}$ Accordingly, they either resist changes to the current system, ${ }^{5}$ or they argue for increased patent and related protection. ${ }^{6}$ On the other hand, scholars who focus on

\section{See infra Part II.B.2.}

3. See, e.g., Robert P. Merges, Justifying Intellectual Property 282 (2011) ("If there is one industry where the conventional 'incentive theory' of patents is actually true, it is the pharmaceutical industry.").

4. See, e.g., ADAM B. JAFFE \& JOSH LERNER, INNOVATION AND ITS DISCONTENTS: How Our Broken Patent System Is ENDANGERing InNovation AND PROgRess, and WhAt To Do ABOUT Iт 42-43 (2004) (explaining that unlike a business that builds a new factory, a pharmaceutical business is building an intangible asset that is easier to steal); see also Laura Magazzini et al., Patent Disclosure and $R \& D$ Competition in Pharmaceuticals, 18 Econ. InNovation \& New TECH. 467, 467 (2009) ("The pharmaceutical industry is a textbook example ... for which patent protection assures appropriability, thus providing incentives for innovation.”).

5. For example, in the recent discussion of the need for major patent reform, pharmaceuticals were considered one of the few areas not in need of change. See, e.g., Nat'l Research Council, A Patent System for the 21st Century 41 (Stephen A. Merrill et al. eds., 2004).

6. Although patents are technically only one aspect of legal protection for drugs, they are the most well-known and thus the focus of this Article. However, there are related protections such as data exclusivity and patent linkage, explained in more detail in Part IV. Scholars familiar with the protection of drugs often advocate increasing all of these protections. See, e.g., Shamnad Basheer, The Invention of an Investment Incentive for Pharmaceutical Innovation, 15 J. WORLD INTELL. Prop. 305, 305 (2012); Dan L. Burk \& Mark A. Lemley, Policy Levers in Patent Law, 89 VA. L. Rev. 1575, 1615-17 (2003); Dana P. Goldman et al., The Benefits from Giving Makers of Conventional "Small Molecule” Drugs Longer Exclusivity over Clinical Trial Data, 30 HeALTH AfF. 84, 89 (2011); Henry G. Grabowski et al., Evolving Brand-Name and Generic Drug Competition May Warrant a Revision of the Hatch-Waxman Act, 30 HeALTH AfF. 2157, 2164 (2011); Christopher M. Holman, Unpredictability in Patent Law and Its Effect on Pharmaceutical Innovation, 76 Mo. L. REv. 645, 645 (2011); Benjamin N. Roin, Unpatentable Drugs and the Standards of Patentability, 87 TEX. L. REV. 503, 557 (2009); see also John M. Golden, Innovation Dynamics, Patents, and Dynamic-Elasticity Tests for 
how patents impact access to low-cost medicine tend to criticize patents as both failing to incentivize drugs for unprofitable treatments as well as overincentivizing development of minimally innovative drugs. ${ }^{7}$ These scholars generally do not aim to modify the patent system but instead suggest solutions beyond the patent system to promote the desired innovation. $^{8}$

This seeming disconnect in discussions prompted this Author to look for a reason why this might be the case. ${ }^{9}$ Cognitive biases provide an explanation for why there are different views as well as why each side may be blind to considering that there is another side. In addition, such biases may provide a more productive explanation for the beliefs and actions of self-interested companies, rather than the usual assumption that they are greedy companies that place profits ahead of patients. This Article is not interested in adding to the thus far unproductive phenomenon of blaming profit-based companies for not operating more like humanitarian organizations. ${ }^{10}$

the Promotion of Progress, 24 HARV. J.L. \& TECH. 47, 50 (2010) (suggesting stronger patent rights to speed technological progress, albeit recognizing this would impose costs on followon innovators). But see Brian J. Love, Interring the Pioneer Invention Doctrine, 90 N.C. L. REV. 379, 446-47 (2012) (suggesting that although some have argued for broader patent rights for pharmaceutical and biomedical inventions, these inventions already have broad rights).

7. See, e.g., Comm’n on Intell. Prop. Rights, Innovation \& Pub. Health, World Health Org., Public Health, Innovation and Intellectual Property RighTS 5, 8, 11-12 (2006); Amy Kapczynski et al., Addressing Global Health Inequities: An Open Licensing Approach for University Innovations, 20 BERKELEY TECH. L.J. 1031, 1038-39 (2005); Aaron S. Kesselheim, Using Market-Exclusivity Incentives To Promote Pharmaceutical Innovation, 363 NEW ENG. J. MED. 1855, 1855 (2010); Aidan Hollis, An Efficient Reward System for Pharmaceutical Innovation (June 10, 2004) (unpublished paper) (on file with the World Health Organization), available at http://www.who.int/intellectual property/news/Submission-Hollis6-Oct.pdf.

8. See, e.g., Stan Finkelstein \& Peter Temin, Reasonable Rx: Solving the DRUG PRICE CRISIS xvi (2008) (suggesting a major structural reform of the drug industry); Brita Pekarsky, Should Financial Incentives Be Used To Differentially Reward “Me-Too" and Innovative Drugs?, 28 PharmacoEconomics 1, 7-8 (2010) (discussing reference pricing, modifications in regulatory approval, and prizes); James Love \& Tim Hubbard, Comment, The Big Idea: Prizes To Stimulate R\&D for New Medicines, 82 CHI.-KENT L. REV. 1519, 1520 (2007) (suggesting offering prizes in lieu of patents).

9. At one point, this Author considered framing the issue as myths. However, after further investigation, grounding the discussion in cognitive biases seemed more intellectually robust. A myth suggests that there is no basis, whereas the beliefs here are not completely unsubstantiated. In addition, cognitive bias theory explains why these beliefs have propagated - a phenomenon that is not explained by labeling something a myth.

10. See, e.g., Sarah Joseph, Pharmaceutical Corporations and Access to Drugs: The "Fourth Wave" of Corporate Human Rights Scrutiny, 25 HuM. RTS. Q. 425, 426 
Each of the views concerning patents and pharmaceutical innovation could be considered one side of the elephant because each is true, yet incomplete. For example, although it is true that there are many studies showing that patents are important to investments in pharmaceutical research, the data is more ambiguous on whether more patent protection produces more innovation. In fact, those that argue for stronger patents often do not cite such data and instead only reference studies that compare patent protection versus no patents at all. ${ }^{11}$ Moreover, there is the question of what type of innovation patents produce. Whereas many scholars do not evaluate what type of innovation patents seem to produce in the area of pharmaceuticals, there is data that most innovation is in fact incremental and of limited medical significance. This has been noted by some scholars and policymakers but minimized by others. ${ }^{12}$ Some scholars and policymakers may consider this of no moment because they argue that innovation in all areas is incremental. ${ }^{13}$ However, pharmaceutical innovation is different. This is an area with implications for public health, as recognized by some outside the field of patents, such as the Food and Drug Administration (FDA) and the President's Council of Advisors on Science and Technology, which have recommended steps to move away from producing more drugs of minimal therapeutic value. ${ }^{14}$ In addition, unlike most other areas, there is actual data that most pharmaceutical innovation is incremental. ${ }^{15}$

This Article builds upon a growing literature concerning cognitive biases, as well as world views, referred to here as "schemas,"16 and their

(2003); Rhona MacDonald \& Gavin Yamey, Op-Ed., The Cost to Global Health of Drug Company Profits, 174 W. J. MED. 302, 302 (2001); Emmanuel Kolawole Oke, Using the Right to Health To Enforce the Corporate Responsibilities of Pharmaceutical Companies with Regard to Access to Medicines, 1 J. HeALTH DipL. 1, 1 (2013).

11. See infra Part III.C.2.

12. See infra Part III.B.

13. See infra Part III.C.3.

14. See 21 U.S.C. § 356 (2012) (providing expedited approval for certain "breakthrough" treatments); PRESIDENT's COUNCIL OF ADVISORS ON SCI. \& TECH., REPORT TO the President on Propelling InNovation in Drug Discovery, Development, AND EVALUATION (2012) [hereinafter PCAST REPORT].

15. See infra Part III.B.

16. This Article uses the term schema broadly to refer to any organizing principle, hypothesis, script, or prototype that functions as a mental organizing system. See, e.g., MARTha Augoustinos et AL., Social Cognition: An InTEgrated InTROduction 68 
implications for law and policy. Although there is a robust body of scholarship concerning cognitive biases in the form of stereotypes such as race or gender, ${ }^{17}$ scholarship concerning cognitive biases relating to intellectual property is more limited. In addition, intellectual property articles have thus far focused on aspects of judicial decisionmaking, such as hindsight bias. ${ }^{18}$ This Article, in contrast, focuses on schemas and cognitive biases that exist long before there is any legal case to adjudicate. Although there are some scholars who have identified schemas with legal implications, no scholars have previously identified schemas in the area of patents and pharmaceutical innovation. ${ }^{19}$

This Article suggests that brand name pharmaceutical companies, such as Pfizer and Eli Lilly, act consistently with research showing that individuals and entities have self-interest biases, which shape their world view and, in turn, results in them processing information consistent with that view. These individual companies, as well as Pharmaceutical Research and Manufacturers of America (PhRMA), the lobbying group that represents the companies, ${ }^{20}$ act consistently with cognitive bias studies.

(2d ed. 2006); Reid Hastie, Schematic Principles in Human Memory, in 1 Social Cognition: THE ONTARIO SyMposium 39, 39-47 (E. Tory Higgins et al. eds., 1981).

17. See, e.g., Christine Jolls \& Cass R. Sunstein, The Law of Implicit Bias, 94 Calif. L. Rev. 969 (2006); Jerry Kang, Trojan Horses of Race, 118 HARV. L. Rev. 1489 (2005); Justin D. Levinson, Forgotten Racial Equality: Implicit Bias, Decisionmaking, and Misremembering, 57 DUKE L.J. 345 (2007).

18. See, e.g., Gregory N. Mandel, Patently Non-Obvious: Empirical Demonstration that the Hindsight Bias Renders Patent Decisions Irrational, 67 OHIO ST. L.J. 1391 (2006); Irina D. Manta, Reasonable Copyright, 53 B.C. L. REV. 1303 (2012).

19. See, e.g., Derek E. Bambauer, Shopping Badly: Cognitive Biases, Communications, and the Fallacy of the Marketplace of Ideas, 77 U. CoLO. L. REV. 649 (2006); Ronald Chen \& Jon Hanson, Categorically Biased: The Influence of Knowledge Structures on Law and Legal Theory, 77 S. CAL. L. REV. 1103 (2004) [hereinafter Categorically Biased]; Ronald Chen \& Jon Hanson, The Illusion of Law: The Legitimating Schemas of Modern Policy and Corporate Law, 103 Mich. L. Rev. 1 (2004) [hereinafter The Illusion of Law]; Stephen J. Choi \& A.C. Pritchard, Behavioral Economics and the SEC, 56 STAN. L. REV. 1 (2003); Donald C. Langevoort, Organized Illusions: A Behavioral Theory of Why Corporations Mislead Stock Market Investors (and Cause Other Social Harms), 146 U. PA. L. REV. 101 (1998). In addition, some scholars have started to focus on confirmation bias in certain realms beyond the judicial arena. See, e.g., Matthew S. Hirshberg, The Self-Perpetuating National Self-Image: Cognitive Biases in Perceptions of International Interventions, 14 PoL. Psychol. 77 (1993); Brett McDonnell \& Daniel Schwarcz, Regulatory Contrarians, 89 N.C. L. REV. 1629 (2011); Susanna Kim Ripken, The Dangers and Drawbacks of the Disclosure Antidote: Toward a More Substantive Approach to Securities Regulation, 58 BAYLOR L. REV. 139 (2006).

20. See AвоUт PhRMA, http://www.phrma.org/about (last visited May 20, 2014). This Article will refer to PhRMA interchangeably with the pharmaceutical industry or 
In particular, studies repeatedly show that individuals presented with information contrary to their beliefs may actually become more entrenched in their beliefs. ${ }^{21}$

Although the actions and statements of companies and lobbying organizations could be more cynically viewed as misrepresentation, cognitive bias provides an alternative and more productive explanation. If companies are simply misrepresenting, the natural reaction is to simply accuse them of bad will. Studies, however, suggest that this may cause further polarization and thus would be the worst possible approach. ${ }^{22}$ Also, even if there is some intentional misrepresentation, it could stem from differing underlying world views (schemas), such that consideration of cognitive bias makes sense.

In addition, regardless of the explanation for the public statements of companies and PhRMA, these statements result in important, yet thus far unacknowledged, cognitive biases of scholars and policymakers. In particular, scholars' and policymakers' repetition of industry views have combined to contribute to a largely uncritical view of the impact of

pharmaceutical companies because PhRMA represents these companies. Of course, it should be noted that for the general thesis of this Article, the industry is treated as acting similarly, when in fact, companies occasionally take different action. In particular, Andrew Witty, the Chief Executive Officer of GlaxoSmithKline has challenged one of the schemas noted here, stating that the oft-cited cost of each new drug is "one of the great myths of the industry" and that drugs can in fact be priced lower. Ben Hirschler, GlaxoSmithKline Boss Says New Drugs Can Be Cheaper, ReuTERs (Mar. 14, 2013, 11:15 AM), http://www.reuters.com/ article/2013/03/14/us-glaxosmithkline-prices-idUSBRE92D0RM20130314. The uniqueness of this statement is underscored by the fact that it was challenged on a blog post. Derek Lowe, GlaxoSmithKline's CEO on the Price of New Drugs, SEEKING AlPHA (Mar. 21, 2013, 10:32 AM), http://seekingalpha.com/article/1292031-glaxosmithklines-ceo-on-the-price-ofnew-drugs.

21. See infra Part II.B.2.

22. See, e.g., Kathleen A. Kennedy \& Emily Pronin, When Disagreement Gets Ugly: Perceptions of Bias and the Escalation of Conflict, 34 PERSONALITY \& SOC. PsyCHOL. BulL. 833 (2008). Although difficult to implement in practice, studies suggest that if the message can be delivered by a perceived "in-group" member, it is much more likely to be tolerated rather than rejected. See, e.g., Matthew J. Hornsey \& Sarah Esposo, Resistance to Group Criticism and Recommendations for Change: Lessons from the Intergroup Sensitivity Effect, 3 Soc. \& Personality Psychol. Compass 275 (2009); Matthew J. Hornsey \& Armin Imani, Criticizing Groups from the Inside and the Outside: An Identity Perspective on the Intergroup Sensitivity Effect, 30 Personality \& Soc. Psychol. Bull. 365 (2004); Dean Morier et al., The Effects of Group Identity, Group Choice, and Strength of Group Identification on Intergroup Sensitivity, 17 Group DyNAMICS: TheOry, RES., \& PRAC. 14 (2013). 
patent law and policy on pharmaceutical innovation. At the same time, cognitive biases explain why arguments criticizing the effectiveness of the patent system in promoting more socially beneficial pharmaceutical innovation are easily ignored. Studies repeatedly show that all individuals tend to reject information and views that are inconsistent with their preexisting views. ${ }^{23}$ In addition, people are prone to believe repeated facts. ${ }^{24}$ Consequently, the pharmaceutical companies' oft-repeated views of pharmaceutical innovation and patent policy are likely generally accepted, rather than critically evaluated. In other words, this Article explains and illustrates a cascade of cognitive biases impacting pharmaceutical innovation and patent policy.

This Article suggests that pharmaceutical companies and some scholars have certain schemas that have been reinforced by confirmation bias and propagated to others, such as policymakers, through repetition. ${ }^{25}$ First, there is the "high cost" schema that suggests that every drug costs $\$ 1$ billion to develop when the reality is that most new drugs cost a fraction of that price. $^{26}$ Admittedly, even a fraction of $\$ 1$ billion is still quite expensive, but the exaggerated number has important implications for how policymakers and scholars consider ways that patent law should be tailored to promote innovation. Second, there is an "innovation" schema that assumes that companies are highly innovative when in reality, most of the "new" drugs they produce are modest improvements that often have little therapeutic value. ${ }^{27}$ Although small innovation is better than none at all, the assumption that most new drugs are highly innovative also implicates patent law and policy. The last schema builds on the first two schemas. In particular, the "strong patent" schema suggests that patent protection should be strong and that there are no net negative social repercussions to such protection. ${ }^{28}$ It is undisputed that patents are valuable and even essential to pharmaceutical companies, unlike other areas of technology, such as software, where other issues, such as first-mover

\footnotetext{
23. See infra Part II.B.2.

24. See infra Part II.C.1.

25. These proposed schemas may admittedly be a result of this Author's own cognitive biases. Nonetheless, this Article aims to provide ample evidence that these proposed schemas are widely held by many and accepted as truth, rather than simply a viewpoint.

26. See infra Part III.A.

27. See infra Part III.B.

28. See infra Part III.C.
} 
advantage, are more important. ${ }^{29}$ However, the value of patents to companies does not necessarily justify the schema that stronger patents will yield more net social benefits. After all, as all scholars recognize, patents always have a "deadweight loss" to the extent that some consumers will not be able to afford the patented drug that is sold at a patent premium. ${ }^{30}$ This is a definite negative repercussion that is generally given short shrift in discussions that advocate stronger patent rights for pharmaceuticals. In addition, this schema assumes that patents promote innovation without considering whether the social cost of a patent is equally justified for less innovative drugs.

None of these schemas are intended to suggest ill will on the part of either companies or scholars. However, recognizing that they are in fact schemas, rather than undisputed facts, is a first step towards recognizing their impact. This Article aims to show that existing cognitive biases perpetuate current laws that mostly promote modest innovation, with unjustified social costs.

This Article is timely in revealing the existence and impact of cognitive biases in pharmaceutical innovation. In particular, the pharmaceutical industry is currently experiencing a crisis in the development of innovative, new drugs. ${ }^{31}$ Although there have been exponential increases in the

29. See, e.g., C.T. TAYlor \& Z.A. Silberston, The Economic ImpaCt of the PATENT System: A STUdy of THE BRITISH ExPERIENCE 231 (1973); Richard C. Levin et al., Appropriating the Returns from Industrial Research and Development, in 3 BROOKINGS PAPERS ON ECONOMIC ACTIVITY 783, 784, 794-95 (Martin Neil Baily \& Clifford Winston eds., 1987); Edwin Mansfield, Patents and Innovation: An Empirical Study, 32 MGMT. SCI., 173, 174 (1986); Wesley M. Cohen et al., Protecting Their Intellectual Assets: Appropriability Conditions and Why U.S. Manufacturing Firms Patent (or Not) 6 (Nat'l Bureau of Econ. Research, Working Paper No. 7552, 2000).

30. See, e.g., C. Scott Hemphill, Paying for Delay: Pharmaceutical Patent Settlement as a Regulatory Design Problem, 81 N.Y.U. L. REv. 1553, 1602 (2006); Clarisa Long, Patent Signals, 69 U. CHI. L. ReV. 625, 633 n.26 (2002); Robert P. Merges \& Richard R. Nelson, On the Complex Economics of Patent Scope, 90 Colum. L. REV. 839, 868 n.124 (1990).

31. See, e,g., PCAST RePORT, supra note 14, at vii; Fabio Pammolli et al., The Productivity Crisis in Pharmaceutical R\&D, 10 NAture ReV. Drug Discovery 428, 429 (2011); Liza Vertinsky, Making Knowledge and Making Drugs? Experimenting with University Innovation Capacity, 62 EMORY L.J. 741, 747-48 (2013); Richard A. Friedman, A Dry Pipeline for Psychiatric Drugs, N.Y. Times, Aug. 20, 2013, at D3, available at http:// www.nytimes.com/2013/08/20/health/a-dry-pipeline-for-psychiatric-drugs.html?_r=0. Although a few have contested this, they are outliers. See, e.g., Donald W. Light \& Joel R. Lexchin, 
amount of money spent on research and development, there has been no corollary increase in new drugs; rather, innovation has generally been stagnant for years. ${ }^{32}$

Brand name pharmaceutical companies may rationally seek more legal protection for drugs, not only to arguably promote more innovation but also to buffer against other financial pressures. In particular, such companies argue that the pending expiration of patents on "blockbuster" drugs, each of which generates over $\$ 1$ billion in sales, together with competition from lower cost generic drugs, erodes their profits, as well as the ability to fund future innovation. ${ }^{33}$ For example, when patent protection for the popular cholesterol-fighting drug Lipitor expired in 2011, Pfizer's sales of Lipitor dropped by seventy-one percent, and

Pharmaceutical Research and Development: What Do We Get for All That Money?, BRIT. MED. J., Aug. 7, 2012, at 1 (claiming innovation crisis is a myth used as a ploy to get government benefit, but nonetheless arguing that there is a crisis with respect to an inadequate number of new drugs that represent a true therapeutic advance); Bernard Munos, Lessons from 60 Years of Pharmaceutical Innovation, 8 NATURE REV. DRUG DisCOVERY 959, 959-60 (2009) (concluding no decline in productivity, using an unduly restrictive data set).

32. See, e.g., PCAST REPORT, supra note 14, at 9-10; Jeff Hewitt et al., Beyond the Shadow of a Drought: The Need for a New Mindset in Pharma R\&D, OLIVER WYMAN 1, 3-4 (2011), http://www.oliverwyman.com/media/OW_EN_HLS_PUBL_2011_Beyond _the_Shadow_of_a_Drought\%283\%29.pdf; Measuring the Return from Innovation: Is R\&D Earning its Investment?, DELOITTE 1, 9 (2011), https://www.deloitte.com/assets/DcomPoland/Local\%20Assets/Documents/Raporty,\%20badania,\%20rankingi/pl_raport_chemiczny _2011.pdf. Although some thought that innovation might be increasing given a fifteenyear record number of thrity-nine new drugs approved in 2012 versus thirty in 2011, there were only twenty-seven new drugs in 2013. See Novel New Drugs: 2013 Summary, U.S. FoOD \& DRUG ADMin. 2-3 (Jan. 2014), http://www.fda.gov/downloads/Drugs/ DevelopmentApprovalProcess/DrugInnovation/UCM381803.pdf. Although some note that the lower numbers are not a cause of concern due to decreased applications, even that can be problematic given that fewer drugs will be unlikely to sustain the drug companies. See, e.g., Bernard Munos, The FDA Approvals of 2013: A Watershed?, FORBES (Jan. 3, 2014, 4:57 PM), http://www.forbes.com/sites/bernardmunos/2014/01/03/the-fda-approvals-of2013-a-watershed (noting that the average output from large pharmaceutical companies in the last five years is not enough to support current sales). Although the U.S. Food and Drug Administration (FDA) notes that the 2013 approval rate is on par with long term averages since 2003, this could still be problematic because the productivity does not match the increased money spent on research. See, e.g., Michael Lanthier et al., An Improved Approach to Measuring Drug Innovation Finds Steady Rates of First-In-Class Pharmaceuticals, 1987-2011, 32 HEALTH AFF. 1433, 1433 (2013) (noting the "sluggish” pace of new molecular entity (NME) approvals since 2000 and concern about the industry output given greatly increased research and development).

33. See, e.g., Grabowski et al., supra note 6, at 2157. In addition, some claim that the costs of developing drugs are also increasing due to more extensive and expensive requirements from the FDA. See, e.g., PCAST REPORT, supra note 14, at 12-13. 
Pfizer's overall revenues dropped by seven percent. ${ }^{34}$ A number of legal and economic scholars are sympathetic to this position because patents are generally considered the primary policy tool to promote innovation. ${ }^{35}$

However, the assumption that stronger patent rights will promote innovation may rest in part on the cognitive biases that perpetuate it. Despite the prevailing view that the pharmaceutical industry is a clear success story for the effectiveness of patents, more protection may not be the best answer. For example, although there are many new drugs to treat erectile dysfunction and obesity, there are not enough drugs that effectively treat conditions such as Alzheimer's disease. ${ }^{36}$ In addition, even in areas where there are a number of drugs, such as treatment for cancer or acid reflux, the drugs may be very similar in terms of how they operate and their side effect profiles. ${ }^{37}$ Granted, having more drug options may be valuable if they have different side effect profiles. Nonetheless, current patent law and policy, in conjunction with existing cognitive biases, contribute to duplication in some areas and inadequate development in others. This inefficiency poses particular problems in the pharmaceutical industry because an increase in the number of similar patented drugs does not necessarily reduce the cost of individual drugs beyond a negligible amount. The cost of patented drugs can be severe for individuals without

34. E.g., Alan Rappeport, Pfizer Feels Impact of End to Lipitor Patent, FIN. TIMES, http://www.ft.com/cms/s/0/9820326a-9398-11e1-8ca8-00144feab49a.html\#axzz2tXPLw8LT (last updated May 1, 2012, 11:01 PM). The issue is not just that companies lose sales, but they lose them quickly. See, e.g., Benjamin G. Druss et al., Listening to Generic Prozac: Winners, Losers, and Sideliners, HeALth AfF., Sept./Oct. 2004, at 210, 213 (noting that whereas generics previously took a year to surpass the original product in market share, this happened less than six months after Prozac's patent expired).

35. See, e.g., supra note 6; see also infra Part IV.B. (suggesting a contrary approach).

36. See Alastair J.J. Wood, A Proposal for Radical Changes in the Drug-Approval Process, 355 New EnG. J. Med. 618, 618-19 (2006).

37. See, e.g., Laura Beil, The Cancer "Breakthroughs" That Cost Too Much and Do Too Little, NEWSWEEK, http://www.newsweek.com/cancer-breakthroughs-cost-toomuch-and-do-too-little-64531 (last updated Sept. 27, 2012, 10:02 PM); Using the Proton Pump Inhibitors To Treat Heartburn and Stomach Acid Reflux: Comparing Effectiveness, Safety, and Price, CONSUMER REPORTS, http://www.consumerreports.org/health/resources /pdf/best-buy-drugs/PPIsUpdate-FINAL.pdf (last updated July 2013) (suggesting that most proton pump inhibitors are similar without significant differences in side effects). 
adequate financial resources and can result in avoidance of necessary medical care. ${ }^{38}$

This Article proceeds in three parts. Part II provides background to understand the three schemas discussed in Parts III and IV. Part II begins with some fundamental concepts of how drugs are developed as well as the relevance of patent protection and the market place to that development. Most of Part II, however, focuses on the rich cognitive bias literature that is necessary to lay the foundation for why patent policy should be reevaluated. In particular, this Part explains schemas and the studies that show how they are reinforced through confirmation bias and repetition.

Part III applies the cognitive bias research to establish three schemas of pharmaceutical innovation and patent protection, and how they have persisted through confirmation bias and repetition. This Part provides evidence of the three schemas outlined above: (i) that the average cost of every drug is $\$ 1$ billion (cost schema), (ii) that the industry is highly innovative (innovation schema), and (iii) that pharmaceuticals should have stronger patent protection because there are no net negative social repercussions (strong patent schema). Although each one of these schemas has some basis in reality, they are not indisputable truths, as will be explained.

Part IV then considers the implications of the revealed schemas. This Part provides concrete suggestions for not only avoiding unintentionally reinforcing the schemas but also more directly challenging them. This Part also advocates for a change in patent policy in light of the fact that previously presumed tenets of patent law and policy are in fact only partially supported schemas. In particular, this Article argues that scholars and policymakers should be more hesitant to provide patent and related protection for drugs; this proposition is strikingly different and is contrary to conventional wisdom. Lastly, this Part considers areas in need of further research as possible additional schemas, followed by a brief conclusion.

38. E.g., Kaiser Health Tracking Poll, The HenRy J. KAISER FAMILY Found. (Apr. 2009), http://kaiserfamilyfoundation.files.wordpress.com/2013/01/7891.pdf (finding that about one-third of patients do not comply with prescriptions because of the cost); see also Kevin Sack, Slump Pushing Cost of Drugs Out of Reach, N.Y. TimES, June 4, 2009, at A1 (noting an increasing number of patients struggling to comply with drug treatments due to lack of finances). 


\section{BACKGROUND}

This Part provides fundamental background to both the development of drugs as well as the operation of cognitive biases that are essential to understanding the schemas discussed in Parts III and IV.

\section{A. Pharmaceutical Development and Commercialization}

This subpart briefly outlines how drugs are developed and commercialized, as well as the role of patent protection. This subpart first explains that there are different types of drugs that may all seem "new" to a consumer but are actually different from a scientific, regulatory, and innovative perspective. Then, this subpart explains the theoretical and practical role of patents in the development of new drugs.

\section{Types of Drugs}

For consumers, there are essentially two categories of prescription drugs: brand name drugs and generic versions of those drugs. As most consumers know, the brand name drugs are priced at a premium while under patent protection. This is because a patent entitles its owner to exclude all others from making or selling the patented drug during its term of protection. ${ }^{39}$ After a term of less than twenty years, ${ }^{40}$ companies can make generic versions, and when there are multiple generic versions, the price drops substantially. ${ }^{41}$

39. See 35 U.S.C. § 271(a) (2012).

40. The patent term is a bit complicated because it is calculated not from the date the patent issues but from the date an application for a patent was filed. 35 U.S.C. § 154(a)(2) (2012). Moreover, the date of patent issuance is often before FDA approval, such that the effective period when a patented drug can be sold is usually shorter than the patent term. See Frequently Asked Questions on Patents and Exclusivity, FDA, http://www.fda.gov/Drugs/ DevelopmentApprovalProcess/ucm079031.htm (last updated Dec. 5, 2012).

41. See, e.g., Richard G. Frank, The Ongoing Regulation of Generic Drugs, 357 New Eng. J. MED. 1993, 1995 (2007) (providing data that the price of a drug drops to ninety-four percent of its original price when a single generic is introduced, to fifty-two percent of its original price with two generic manufacturers, and to a mere third or less of its original price when there are five or more generics). This is particularly true for blockbuster drugs that tend to have more generic entrants. See, e.g., Henry G. Grabowski \& Margaret Kyle, Generic Competition and Market Exclusivity Periods in Pharmaceuticals, 28 
A brand name drug must be developed and extensively tested to show that it is safe and effective, such that it will be approved for sale by the FDA. $^{42}$ This can take a number of years because it can take time to not only first find a promising chemical compound but also test that compound in multiple stages of animal and human clinical trials to ensure that it not only is effective but also is safe. ${ }^{43}$

In contrast, a generic drug has an abbreviated path to market. Indeed, the FDA refers to applications to sell generic drugs as abbreviated applications because much less is required. ${ }^{44}$ First, there is no discovery process because generics generally copy successful brand name drugs that have already been approved. ${ }^{45}$ In addition, although a generic still needs FDA approval, it only needs minimal testing to be approved. The generic only needs to have testing that shows that it is "bioequivalent" to the previously approved brand drug, such that the FDA can infer that the earlier clinical tests for safety and efficacy of the brand name drug also apply to the generic. ${ }^{46}$

In addition, although consumers tend to view a drug as either a brand name or generic, there are in fact two very different scientific categories of brand name drugs. A brand drug can be either a new molecule that was never previously approved for sale or an incremental modification to something that previously existed; the technical terms are new molecular entity (NME) and incremental modification (IMD). ${ }^{47}$ The new molecules take longer to develop but are more likely to result in treatments that are dramatically different. An incremental modification, although potentially of some clinical benefit, is likely to mostly be an improvement of an existing treatment. ${ }^{48}$ For example, a different dosage, or different administrationoral, rather than injection - would be an incremental modification. ${ }^{49}$

MANAGERIAL \& DeCision ECON. 491, 494 (2007) (stating that drugs with over \$500 million in sales are likely to have more than seven competitors after year one).

42. See 21 U.S.C. § 355(a)-(b) (2012).

43. See Fed. Trade Comm'n, To Promote Innovation: The Proper Balance of COMPETITION AND PATENT LAW AND POLICy ch. 3, at 6-7 (2003).

44. See 21 U.S.C. § 355(j)(1) (2012).

45. See Fed. TRAde Comm'n, supra note 43, ch. 3, at 9 n.38.

46. See 21 U.S.C. § 355(j)(2)(iv) (2012).

47. See Fed. TRAdE COMM'N, supra note 43, ch. 3, at 4; WARREn KaPlan ET AL., World Health Org., Priority Medicines for Europe and the World 2013 Update 25-26 (2013).

48. See Fed. TRAde Comm’n, supra note 43, ch. 3, at 8 .

49. Id. 
The FDA classifies drugs based on perceived clinical benefit at the time of application. The FDA has a classification system to give faster "priority" review to drug applications most likely to provide clinical benefit; all others are given "standard" review. ${ }^{50}$ The FDA classifies drugs for priority review if they are perceived to have just one of a number of benefits, such as increased effectiveness, reduced side effects, enhanced patient compliance, or usefulness in a new subpopulation of patients. ${ }^{51}$ Importantly, as will be discussed later, a substantial number of new drugs are labeled as standard review, which means that they do not have increased therapeutic value. $^{52}$

\section{Patent Theory and Practice: The Case of Drugs}

Pharmaceuticals have long been considered the one area where patents function in reality as they do in theory because drugs are expensive to develop but easy to copy. ${ }^{53}$ In fact, there are a number of studies by economists frequently cited by scholars to underscore the importance of patent protection and sometimes to argue for increasing patent or related protection. $^{54}$

Because a patent permits a company to legally exclude all others from making or selling the identical drug, ${ }^{55}$ pharmaceutical companies mostly rely on patents to protect their investment in new drugs and to maintain a

50. Applications designed for priority review are evaluated in six months, rather than the ten months for standard reviews. See, e.g., Susan Thaul, Cong. Research Serv., RS22814, FDA FAST TRACK AND PRIORITY REVIEW PROGRAMS 3 (2008). There is an even faster track given to the most highly valued drugs that address "serious or life-threatening disease[s]," which are a subset of the priority review drugs; however, those are not addressed here because studies do not focus on this much smaller subset. 21 U.S.C. § 356(a)(1) (2012). Moreover, some have questioned whether the current categorization is even appropriate. See, e.g., Courtney Davis \& John Abraham, Rethinking Innovation Accounting in Pharmaceutical Regulation: A Case Study in the Deconstruction of Therapeutic Advance and Therapeutic Breakthrough, 36 SCI. TECH. \& HuM. VALUES 791, 808-10 (2011).

51. CTR. FOR Drug Evaluation \& ReSEarch, U.S. FoOd \& Drug Admin., MANuAL OF POLICIES AND PROCEDURES 6020.3, at 6-7 (2013), available at http://www.fda.gov/down Loads/aboutfda/centersoffices/officeofmedicalproductsandtobacco/cder/manualofpolicies procedures/ucm082000.pdf.

52. See infra Part III.B.

53. See, e.g., NAT'L RESEARCH CounCIL, supra note 5, at 35-36.

54. See infra notes 235-36 and accompanying text.

55. See 35 U.S.C. § 271 (2012). 
competitive advantage. ${ }^{56}$ Of course, competitors may sell a drug that aims to treat the same condition, such as minimizing heartburn. However, the ability to exclude others from making the patented drug generally permits the patent-owning company to sell its drug at a substantial premium. This is true even when there are two or more drugs that treat the same condition in the same way; each drug is usually priced at a substantial premium in contrast to a generic drug. ${ }^{57}$

The importance of patent protection to the business model of pharmaceutical companies is readily underscored by the fact that when patent protection for a given drug ends and there is robust competition from multiple generic companies, the price of the drug drops substantially. ${ }^{58}$

56. See, e.g., NAT'L RESEARCH COUNCIL, supra note 5, at 35-36.

57. Although patented drugs may cost somewhat less when there are more drugs in the same class, so long as a drug is under patent protection, it still sells for much more than a generic version. See, e.g., CONG. BUDGET OfFICE, How INCREASED COMPETITION FROM GeNeriC Drugs Has AfFected PRICES AND RETURNS IN THE PHARMACEUTICAL INDUSTRY 14-15 (1998), available at http://www.cbo.gov/sites/default/files/cbofiles/ftpdocs/ $6 \mathrm{xx} /$ doc655/pharm.pdf. One study noted discounts of "at least 5\%" for some drugs, but no discounts at all for one drug. Joseph A. DiMAsi, Price TrendS FOR PRESCRIPTION PHARMACEUTICALS: 1995-1999 (2000), available at http://aspe.hhs.gov/health/reports/drugpapers/dimassi/dimasi-final.htm.

58. The first generic may be twenty-five percent lower, whereas with multiple generics, the price can fall to one-fifth of the initial generic price. E.g., Panos Kanavos et al., Competition in Off-Patent Drug Markets: Issues, Regulation and Evidence, 23 ECON. POL'y 499, 505 (2008). The price of the brand drug post patent, on the other hand, tends to actually increase to focus on consumers who are price insensitive. E.g., Dong-Churl Suh et al., Effect of Multiple-Source Entry on Price Competition After Patent Expiration in the Pharmaceutical Industry, 35 Health SERV. Res. 529, 529 (2000). Of course, these numbers reflect the situation in the U.S. market, but do not necessarily apply in all markets. Consider India, where there are only a small number of consumers that can pay the price of a branded drug, even the first generic drug is typically priced at a much steeper margin because otherwise there would be inadequate sales for the generic company to make a profit. For example, Bayer was selling a patented cancer drug marketed as Nexavar in India for over $\$ 5000$ a month, but the first generic manufacturer sold the drug for only $\$ 125$ a month-a drop in price of about seventy-five percent. Naazneen Karmali, Indian Tycoon Slashes Costs of Cancer Drugs, Claims More Humanitarian Impact than Gates, Buffett Combined, ForBEs (June 12, 2012, 3:58 AM), http://www.forbes.com/sites/naazneenkarmali/2012/06/12/ciplas-new-battle. This situation is slightly different in that the generic manufacturer was permitted to make the drug during the patent term pursuant to a compulsory license. See Natco Pharma Ltd. v. Bayer Corp., C.L.A. No. 1/2011 (Controller of Patents, Mumbai, Mar. 9, 2012), available at http://www.ipindia.nic.in/ipoNew/compulsory_License_12032012.pdf, aff'd, Bayer Corp. v. Union of India, QA/35/2012/PT/MUM (Intellectual Property Appellate Board, Chennai, Mar. 4, 2013), available at http://www.gnaipr.com/CaseLaws/OA352012PTMUM.pdf (affirming the compulsory license but modifying the royalty rate); see also Vikas Bajaj \& Andrew Pollack, India Orders Bayer To License a Patented Drug, N.Y. Times, Mar. 
For example, the price of the first HIV therapy was originally about $\$ 10,000$, but today it is only about $\$ 100$ because of substantial generic competition. $^{59}$ In addition, generic competition that results in a price drop can happen quickly after patent expiration. ${ }^{60}$ Indeed, in recent years, many industry sympathizers, policymakers, and even the popular press have discussed the "patent cliff" that many companies were facing with the simultaneous expiration of a number of patents, which was predicted to have a substantial and serious impact on the sales of major pharmaceutical companies. $^{61}$

Company revenues are substantially impacted when a patent on a blockbuster drug expires. This is because the current business models of most companies primarily rely on a handful of blockbuster drugs for the majority of their profits, ${ }^{62}$ such that expiration of a single patent will

13, 2012, at B2. However, it nonetheless indicates that it is possible to have more dramatic price drops with a single generic entrant in a country where consumers cannot afford a more modest price drop. Nonetheless, some still suggest that the dramatically lower prices are still too high for many Indian consumers. See, e.g., Nirmalya "Nemo" Dutta, Despite Compulsory Licensing, Generic Cancer Drug Too Costly for the Poor, HEALTHSiTE (Mar. 21, 2012, 9:18 AM), http:/health.india.com/diseases-conditions/despitecompulsory-licensing-generic-cancer-drug-too-costly-for-the-poor.

59. See, e.g., MÉdecins SAns Frontières, Untangling the Web of Antiretroviral Price Reductions 2 (16th ed. 2013).

60. E.g., Richard G. Frank \& David S. Salkever, Generic Entry and the Pricing of Pharmaceuticals, 6 J. ECON. \& MGMT. STRATEgY 75, 83-85 (1997); Henry G. Grabowski \& John M. Vernon, Brand Loyalty, Entry, and Price Competition in Pharmaceuticals After the 1984 Drug Act, 35 J.L. \& ECON. 331, 335-37 (1992).

61. See, e.g., Tony Harris et Al., IP Austl., Pharmaceutical Patents RevieW 13 (2013) (citing Jack DeRuiter \& Pamela L. Holston, Drug Patent Expirations and the "Patent Cliff," U.S. Pharmacist Generic Drug Review Supplement, June 2012, at 12), available at http://www.ipaustralia.gov.au/pdfs/2013-05-27_PPR_Final_Report.pdf [hereinafter Australian REPORT]; Charlotte Harrison, The Patent Cliff Steepens, 10 Nature Rev. Drug Discovery 12, 12-13 (2011); Katie Thomas, U.S. Drug Costs Dropped in 2012, but Rises Loom, N.Y. Times, Mar. 19, 2013, at A1 (noting the "patent cliff" with respect to blockbuster drugs such as Lipitor and Plavix that lost patent protection in recent years). Branded drugs with annual sales of \$32.2 billion in 2011 lost patent protection in 2012, leaving those revenues exposed to cheap generics. EvaluatePharma, Biotech and Pharma 2012 Year IN REVIEw 20 (2013), available at http://info.evaluatepharma.com/rs/evaluatepharmaltd/images/EPV_Review_2012.pdf.

62. See, e.g., PhRMA, Delivering ON THE Promise of PHARMACEUTICAL INNOVATION: The Need To Maintain Strong and Predictable Intellectual Property Rights 9 (2002) [hereinafter PhRMA, Delivering on the Promise]. 
substantially reduce their profits. ${ }^{63}$ In addition, generics aggressively compete on price upon entering the market, such that blockbuster sales can quickly erode in a matter of months after a patent expires. One famous example is that when the patent on Eli Lilly's antidepressant Prozac expired, it lost over seventy percent of market share in less than six months. ${ }^{64}$

Not only are patents an essential tool for the protection of drugs, they also have an impact on what types of drugs are developed. ${ }^{65}$ Importantly, patent law gives the same term of exclusivity for every drug-whether a breakthrough drug or a more modest drug with no increased therapeutic potential over existing drugs. The more modest drugs may be less costly and time intensive to develop; although this is seldom discussed, what limited data that does exist suggests that such drugs cost about a third of what a truly new chemical compound would cost to develop. ${ }^{66}$ Accordingly, it would seem logical that companies focus primarily on incremental innovations; indeed, as will be discussed, the vast majority of drugs are the product of incremental innovations, and the proportion of such drugs is increasing. ${ }^{67}$

\section{B. The Existence and Importance of Schemas}

Research in cognitive science and behavioral economics has repeatedly shown that all individuals are subject to cognitive biases in how they acquire and process information. ${ }^{68}$ Although flawed decisions may be troubling, these mental shortcuts are nonetheless useful to help individuals

63. See Barbara J. Williams, A Prescription for Anxiety: An Analysis of Three BrandName Drug Companies and Delayed Generic Drug Market Entry, 40 New Eng. L. Rev. 1, 1 (2005).

64. Druss et al., supra note 34, at 211.

65. There are of course other potential factors that impact drug development. For example, whether an insurance company or Medicare is likely to reimburse for a drug could potentially also impact innovation. However, discussion of these issues is beyond the focus of this Article.

66. Cong. Budget Office, Pub. No. 2589, Research and Development in the PHARMACEUTICAL INDUSTRY 21 (2006) [hereinafter CBO STUDY] (citing Richard G. Frank, New Estimates of Drug Development Costs, 22 J. HeALTH ECON. 325, 327 (2003) (noting CMR International's 2002 estimate that product line extensions account for thirty percent of research and development, and PhRMA's 1999 estimate that they account for "about eighteen percent” of R\&D expenditures)). Notably, this information is limited and dated.

67. See infra Part III.B.

68. See, e.g., KAHNEMAN, supra note 1; Categorically Biased, supra note 19, at 1131. 
process information efficiently and effectively. ${ }^{69}$ For example, when faced with a dangerous situation, whether it is an impending car crash or a poisonous snake, it is valuable to be able to act quickly and instinctively. The problem, however, is that the same mental shortcuts that enable us to engage in self-protectionism in the face of real danger also play a role in situations where we should be more objective. Although most individuals recognize that there may be judgment flaws active in others, most individuals assume that they are immune from such flaws, thus compounding the problem. ${ }^{70}$ This Part provides fundamental background on the science of social cognition that is essential to understanding the argument in Part IV that there are currently flaws in prevailing thinking about pharmaceutical innovation and the role of patents.

\section{Individuals and Groups View Information Through Schemas}

One type of cognitive bias is a world view through which an individual interprets information. ${ }^{71}$ For example, someone may have a general world view that government regulation is bad. A corporation that does not want government regulation could be expected to have this view; this world view may extend beyond immediate self-interest to color all views of government regulation, even when not directly applicable to the corporation. ${ }^{72}$

Although the term schema may be unfamiliar to some, there are schemas that are commonly known. For example, a racial stereotype-the generalized views about a particular race-is a schema. ${ }^{73}$ There are also other common schemas, such as the schema that lawyers are mercenaries, women are shoppers, or men are resistant to relationships. ${ }^{74}$ Academics have been shown to have a schema that favors complexity, which results in perceiving articles that use more complex language to be superior. ${ }^{75}$ Although some known schemas, such as racial stereotypes,

69. See, e.g., KAHNEMAN, supra note 1; Categorically Biased, supra note 19, at 1128.

70. See, e.g., Categorically Biased, supra note 19, at 1223; see also infra note 76 (describing this phenomenon as "naïve realism" and providing sources).

71. See, e.g., Categorically Biased, supra note 19, at 1143.

72. See, e.g., The Illusion of Law, supra note 19, at 87-89.

73. See, e.g., Categorically Biased, supra note 19, at 1165-66.

74. See, e.g., id. at 1111-12; The Illusion of Law, supra note 19, at 87-89.

75. See, e.g., J. Scott Armstrong, Unintelligible Management Research and Academic Prestige, 10 INTERFACES 80, 84-85 (1980) (finding faculty from several prestigious institutions 
are considered to be bad, schemas are in fact adaptive behaviors for dealing with a world that is highly saturated with information. Essentially, schemas help all individuals and entities make a complex world more manageable.

\section{Schemas Are Maintained Through Confirmation Bias}

\section{a. Seeing What We Want To See: Confirmation Bias}

A major element of cognitive bias is the fact that individuals not only seek information that is consistent with their preexisting schemas but also neglect or reject disconfirming evidence. ${ }^{76}$ In other words, there is a natural tendency to seek and process information to confirm what we believe we know, resulting in a confirmation bias. For example, many individuals choose to watch Fox News or MSNBC to hear information that is consistent with their views. ${ }^{77}$

Although confirmation bias may seem like a major mental flaw, it can be considered a sensible shortcut to permit individuals to make sense of a vast array of information. For example, when information is ambiguous and could be susceptible to different interpretations, confirmation bias helps individuals to confirm an existing view. Indeed, studies show that

had a bias toward more complex language that resulted in rating more complex discussions as superior in quality); Donald H. Naftulin et al., The Doctor Fox Lecture: A Paradigm of Educational Seduction, 48 J. MED. EDUC. 630, 633-34 (1973) (discussing a study in which a highly charismatic actor posing as an academic was rated as a good teacher by educators, even though he was espousing gibberish).

76. This may be compounded by a phenomenon called naïve realism in which individuals assume they are objective and only others are biased. See, e.g., Emily Pronin, Perception and Misperception of Bias in Human Judgment, 11 TRENDS COGNITIVE SCI. 37, 39-40 (2006); Emily Pronin et al., Objectivity in the Eye of the Beholder: Divergent Perceptions of Bias in Self Versus Others, 111 Psychol. ReV. 781, 781-82 (2004); Robert J. Robinson et al., Actual Versus Assumed Differences in Construal: “Naive Realism” in Intergroup Perception and Conflict, 68 J. PERSONALITY \& SOC. PsYCHOL. 404, 404 (1995). For example, in the 2012 presidential election, some Republicans assumed Nate Silver was biased, and thus, his data predicting an Obama win was suspect. See Nate Silver, When Internal Polls Mislead, a Whole Campaign May Be To Blame, FIVETHIRTYEIGHT (Dec. 1, 2012, 6:01 AM), http://fivethirtyeight.blogs.nytimes.com/2012/12/01/wheninternal-polls-mislead-a-whole-campaign-may-be-to-blame.

77. See Stephan Lewandowsky et al., Misinformation and Its Correction: Continued Influence and Successful Debiasing, 13 Psychol. SCI. PUB. INT. 106, 111 (2012); see also Heather L. LaMarre et al., The Irony of Satire: Political Ideology and the Motivation To See What You Want To See in The Colbert Report, 14 InT'L J. PRESS/POL. 212, 222-23 (2009) (suggesting conservatives believe political satirist Stephen Colbert is sincere whereas liberals think he is poking fun at conservatives). 
someone with a preexisting belief is likely to maintain that belief out of proportion with its correctness, and possibly even after later information reveals that the initial belief was incorrect. ${ }^{78}$ Psychologists explain that people are motivated to discredit or ignore inconsistent information to reduce or prevent psychological distress that might otherwise result by dissonance-a phenomenon called "cognitive dissonance.,"79

There are a number of studies that document how confirmation bias impacts how individuals evaluate research results and whether they are persuaded. In particular, confirmation bias may make individuals more critical of studies that contradict their schemas and less likely to be persuaded by such studies. ${ }^{80}$ This is important to understanding PhRMA's criticisms of studies that challenge its world view, as will be discussed in Part III.

Studies have shown that preconceptions, such as schemas, impact the perceived accuracy of studies, as well as whether they are persuasive. ${ }^{81}$ One classic study concerns subjects that were preselected based on their preference for or against capital punishment and were then provided mock studies that reached opposite conclusions concerning whether capital punishment deterred crime. ${ }^{82}$ Subjects were more critical of research methods inconsistent with their beliefs, citing issues such as insufficient sample size, nonrandom sample selection, or absence of control for key

78. See, e.g., Richard E. NisBetT \& LeE Ross, Human INFERENCE: STRATEGIES AND SHORTCOMINGS OF SOCIAL JUDGMENT 169 (1980).

79. E.g., LeOn Festinger, A Theory of Cognitive Dissonance 2-3 (1957).

80. The confirmation bias impact may be relevant not only to schemas but also to information that is simply inconsistent with a self-interest bias. For example, studies have shown that subjects given positive feedback on supposed intelligence tests or social sensitivity tests are more likely to view those tests as valid. See Tom Pyszczynski et al., Maintaining Consistency Between Self-Serving Beliefs and Available Data: A Bias in Information Evaluation, 11 Personality \& Soc. Psychol. Bull. 179, 186 (1985); see also Peter H. Ditto \& David F. Lopez, Motivated Skepticism: Use of Differential Decision Criteria for Preferred and Nonpreferred Conclusions, 63 J. PERSONALITY \& SOC. PsYCHOL. 568, 574-76 (1992) (concluding that subjects given a fictional medical test for a supposedly dangerous deficiency were more likely to scrutinize the test if they tested positive for the problem).

81. See, e.g., Charles G. Lord et al., Biased Assimilation and Attitude Polarization: The Effects of Prior Theories on Subsequently Considered Evidence, 37 J. PERSONALiTY \& SOC. PsYCHOL. 2098, 2098 (1979).

82. Id. at 2100-01. 
variables. ${ }^{83}$ Similar effects have been found on a broad range of issues, such as health risks, ${ }^{84}$ the safety of nuclear power, bans on gays in the military, and theories regarding the John F. Kennedy assassination. ${ }^{85}$

Doctors, who are generally assumed to be objective, are also not immune to confirmation bias. Studies indicate that doctors tend to generate an early hypothesis that impacts subsequent information gathering and may result in a faulty diagnosis. ${ }^{86}$ Some prominent doctors have been susceptible to an assumption that forty to fifty percent of patients are resistant to the off-patent and cheap treatment of aspirin as a diuretic, perhaps consistent with a belief that newer drugs are better, when in fact, a recent study shows that there was no justification at all for this belief. ${ }^{87}$

Scientists are also not immune to confirmation bias. As noted recently, "[s]cientists are humans, and they're susceptible to confirmation bias too." 88

83. Id. at 2103; cf. Ziva Kunda, The Case for Motivated Reasoning, 108 PsychOL. BuLL. 480, 490 (1990) (noting that study subjects with high caffeine consumption were likely to disbelieve an article that supposedly correlated caffeine with a serious disease and consider the research less sound).

84. See, e.g., Harold H. Kassarjian \& Joel B. Cohen, Cognitive Dissonance and Consumer Behavior: Reactions to the Surgeon General's Report on Smoking and Health, 8 CAL. MgmT. Rev. 55, 63 (1965) (concluding that smokers were motivated to disregard evidence of the health risks of smoking); Ziva Kunda, Motivated Inference: Self-Serving Generation and Evaluation of Causal Theories, 53 J. Personality \& Soc. Psychol. 636, 644 (1987) (concluding that heavy caffeine drinkers were more skeptical than low caffeine drinkers about an article that alleged caffeine risks).

85. Geoffrey D. Munro et al., Biased Assimilation of Sociopolitical Arguments: Evaluating the 1996 U.S. Presidential Debate, 24 BASIC \& APPLIED SOC. PsCYHOL. 15, 16 (2002) (citing studies).

86. See, e.g., Elke U. Weber et al., Determinants of Diagnostic Hypothesis Generation: Effects of Information, Base Rates, and Experience, 19 J. EXPERIMENTAL PSYCHOL. 1151, 1151-52 (1993).

87. See Tilo Grosser et al., Drug Resistance and Pseudoresistance: An Unintended Consequence of Enteric Coating Aspirin, 127 CiRCUlATION 377, 382-83 (2013); Katie Thomas, Study Raises Questions on Coating of Aspirin, N.Y. TIMES, Dec. 5, 2012, at B1.

88. Anahad O’Connor, Myths Surround Breakfast and Weight, N.Y. TIMES WeLL BLOG (Sept 10, 2013, 6:00 AM), http://well.blogs.nytimes.com/2013/09/10/mythssurround-breakfast-and-weight (quoting Dr. David B. Allison, Director of the Nutrition Obesity Research Center at the University of Alabama at Birmingham); see also Daniel Engber, Cuckoo for Cocoa Puffs: Why Are We So Sure That Breakfast Is the Most Important Meal of the Day?, SLATE (Sept. 9, 2013, 1:20 PM), http://www.slate.com/ articles/health_and_science/medical_examiner/2013/09/breakfast_and_weight_loss_is_it _really_the_most_important_meal_of_the_day.1.html (noting that University of Minnesota researcher Mark Pereira commented that the "scientific dogma” is a result of people just wanting to be "right," even when not influenced by the private sector or politicians but possibly from overconfidence); Michael Suk-Young Chwe, Scientific Pride and Prejudice, 
Recently, a study debunked the popular conception among not only lay people but also scientists and even the Surgeon General that eating breakfast is important for weight loss and control. ${ }^{89}$ The study found that there have only been a handful of rigorous trials, and even among those, the findings have often been misrepresented. ${ }^{90}$ For example, a seminal 1992 study with mixed results was misinterpreted in fifty subsequent articles, with the majority improperly relying on the study to suggest that eating breakfast protects against weight gain. ${ }^{11}$ Similarly, a 2002 study reporting a correlation between people who lost weight and those who ate breakfast was over-extrapolated by the majority of subsequent citing articles to suggest that breakfast will result in weight loss. ${ }^{92}$ Even famous scientists are not immune. For example, Robert Millikan published a Nobel Prize-winning work concerning electron charges but only published about half of his observations and omitted those that did not fit his hypothesis. $^{93}$

This phenomenon is very important because studies show that even when individuals aim to be objective and are given rewards for accuracy in experimental settings, they are nonetheless subject to confirmation bias. ${ }^{94}$ The problems of confirmation bias are thus likely to be most problematic in situations where there is not only no reward for accuracy but also selfinterest at play.

N.Y TIMES, Feb. 2, 2014, at SR 12 (providing examples of confirmation bias impacting NASA funded researchers, as well as scientists involved in landmark cancer studies).

89. See Andrew W. Brown et al., Belief Beyond the Evidence: Using the Proposed Effect of Breakfast on Obesity To Show 2 Practices That Distort Scientific Evidence, 98 AM. J. CliniCAL NutRition 1298, 1307 (2013). The Surgeon General asserts that eating a "sensible meal" for breakfast may be important to achieving and maintaining a healthy weight. Pub. Health Serv., U.S. Dep’t of Health \& Human Servs., The Surgeon General's Call to Action to PREvent AND DECREASE OverWEIGHT AND OBESiTy (2001), available at http://www.ncbi.nlm.nih.gov/books/NBK44206/pdf/TOC.pdf.

90. See Brown et al., supra note 89, at 1301.

91. See id. at 1304

92. Id.

93. Raymond S. Nickerson, Confirmation Bias: A Ubiquitous Phenomenon in Many Guises, 2 Rev. Gen. Psychol. 175, 194 (1998); see also Suk-Young Chwe, supra note 88, at SR 12 (noting that Millikan's own lab notebooks had comments, such as "Best yet - Beauty - Publish,” which indicated that he excluded inconsistent data).

94. See George Loewenstein et al., Self-Serving Assessments of Fairness and Pretrial Bargaining, 22 J. LEGAL STUD. 135, 139 (1993). 


\section{b. Schemas Are Resistant To Change}

Confirmation bias is difficult to combat. ${ }^{95}$ In particular, when presented with ambiguous or inconsistent information, sometimes this reinforces, rather than eliminates, preexisting beliefs. ${ }^{96}$ Studies repeatedly show that individuals have a motivation to retain existing beliefs that results in the entrenchment of existing beliefs when faced with ambiguous or contrary information. In the previously noted study where subjects received different "evidence" about the deterrent effects of capital punishment, subjects became more entrenched in their views. ${ }^{97}$ The same effect was found in a study concerning the impact of a fictitious report concerning religious resurrection; after reading the same report, believers increased the intensity of their belief, whereas nonbelievers became more skeptical. ${ }^{98}$

Not only does confirmation bias exist with ambiguous evidence but certain tools that most would expect to minimize such bias may not be helpful or even further reinforce the belief. Increased education does not immunize individuals from the effects of confirmation bias. ${ }^{99}$ In addition, providing reasoning to support a position may reinforce, rather than eliminate, confirmation bias. ${ }^{100}$ Moreover, even after information is discredited, it may continue to be believed — and especially so if individuals provide a written explanation. ${ }^{101}$

95. Some studies suggest that confirmation bias may be reduced in experimental settings through techniques such as requiring subjects to consider an alternative possibility or first portray themselves in a positive way before encountering disconfirming evidence. See, e.g., Charles G. Lord et al., Considering the Opposite: A Corrective Strategy for Social Judgment, 47 J. Personality \& Soc. Psychol. 1231, 1231 (1984); David K. Sherman \& Geoffrey L. Cohen, Accepting Threatening Information: Self-Affirmation and the Reduction of Defensive Biases, 11 CuRRENT DireCtions Psychol. SCI. 119, 119, 122 (2002). However, such techniques have limited applicability to real world situations.

96. See, e.g., Sahara Byrne \& Philip S. Hart, The Boomerang Effect: A Synthesis of Findings and a Preliminary Theoretical Framework, in 33 COMMUNICATION YEARBOOK 3 (Christina S. Beck ed., 2009); Brendan Nyhan \& Jason Reifler, When Corrections Fail: The Persistence of Political Misperceptions, 32 PoL. BeHAv. 303, 323 (2010).

97. Lord et al., supra note 81, at 2105.

98. C. Daniel Batson, Rational Processing or Rationalization?: The Effect of Disconfirming Information on a Stated Religious Belief, 32 J. PERSONAlity \& Soc. PSYCHOL. 176, 176 (1975).

99. Lewandowsky et al., supra note 77, at 120.

100. See Shelly Chaiken \& Suzanne Yates, Affective-Cognitive Consistency and Thought-Induced Attitude Polarization, 49 J. Personality \& Soc. Psychol. 1470, 1470, 1477 (1985) (concluding that subjects who had an initial strong view on either capital punishment or censorship developed a stronger view after writing an essay on the topic).

101. See Craig A. Anderson et al., Perseverance of Social Theories: The Role of Explanation in the Persistence of Discredited Information, 39 J. Personality \& Soc. 
Although the persistence of bias in the face of contrary evidence may seem irrational, there is a psychological explanation. Humans are motivated to make sense of their environment, and the motivation can also result in motivated reasoning to support an initial belief. In other words, the same psychological processes at play for confirmation bias also result in the persistence of these biases.

\section{Schemas Can Propagate to Those Who Are Not Initially Interested in the Schemas}

This Part explains how cognitive biases of individuals, such as scholars and policymakers, may make them susceptible to being influenced by the schemas of others. In particular, this Part focuses on how cognitive biases related to repetition of information, as well as biases that function in evaluating the content of that information, are influential. This is an important foundation for schemas that have been extensively repeated by the industry, as documented in greater detail in Part IV.

\section{Repetition of Schemas Makes Them Seem Real}

Most people would not be surprised to hear that repetition is important. After all, we know that marketing campaigns as well as teachers rely on repetition to reinforce messages and learning. This subpart goes beyond basic intuitions to explain how and why repetition is powerful.

Why is repetition so powerful? Some have suggested that when information is repeated, that information is more readily remembered. ${ }^{102}$ Accordingly, repeated information is presumed to be true- this has been shown with trivia, rumors, false news stories, and marketing claims. ${ }^{103}$

Psychol. 1037, 1045 (1980); Lee Ross et al., Social Explanation and Social Expectation: Effects of Real and Hypothetical Explanations on Subjective Likelihood, 35 J. PERSONALITY \& SOC. PSYCHOL. 817, 825-26 (1977).

102. This is referred to as the availability heuristic or fluency effect. E.g., KAHNEMAN, supra note 1 , at $129-35$.

103. See, e.g., Floyd H. Allport \& Milton Lepkin, Wartime Rumors of Waste and Special Privilege: Why Some People Believe Them, 40 J. ABNormal \& Soc. Psychol. 3, 7-8 (1945); Frederick T. Bacon, Credibility of Repeated Statements: Memory for Trivia, 5 J. ExPERIMENTAl PsYCHOL.: HuM. LEARNING \& MEMORY 241, $241-42$ (1979); Scott A. Hawkins et al., Low-Involvement Learning: Repetition and Coherence in Familiarity and Belief, 11 J. CONSUMer Psychol. 1, 9-10 (2001). 
The repeated information is often better remembered than its source. ${ }^{104}$ In addition, when the source is not recalled, repeated information is considered more likely to come from a credible source ${ }^{105}$ or to be widely believed. ${ }^{106}$ In studies, subjects are inclined to assume repeated statements are true, even where explicitly told that repeated statements are no more likely than unrepeated statements to be true, ${ }^{107}$ or that the source of the information is likely to be biased. ${ }^{108}$ The impact of repetition is also particularly powerful when subjects either lack the motivation or the opportunity to scrutinize the validity of the message. ${ }^{109}$ This has important implications for certain schemas repeatedly stated by the pharmaceutical industry-even though many consumers are skeptical about the industry as a whole, they may nonetheless be influenced by repeated industry claims and lack the motivation or even aptitude to carefully evaluate the information. ${ }^{110}$

In addition, although some studies attempt to debunk claims, the format in which they do so may ironically serve to simply reinforce the original message. In particular, studies show that when information is presented in a myth versus fact format, the myth may be reinforced, rather than

104. See Danielle C. Polage, Making Up History: False Memories of Fake News Stories, 8 EUR. J. PsychOL. 245, 248-49 (2012).

105. See Alison R. Fragale \& Chip Heath, Evolving Informational Credentials: The (Mis)Attribution of Believable Facts to Credible Sources, 30 PERSONALITY \& SoC. PSYCHOL. BuLL. 225, 225-26 (2004). In addition, subjects presented with information consistent with their existing schemas are especially likely to believe that the information is from a credible source. Id.

106. See Kimberlee Weaver et al., Inferring the Popularity of an Opinion from Its Familiarity: A Repetitive Voice Can Sound Like a Chorus, 92 J. PersonAlity \& Soc. PSCYHOL. 821, 821-22 (2007).

107. See, e.g., Linda A. Henkel \& Mark E. Mattson, Reading Is Believing: The Truth Effect and Source Credibility, 20 CONSCIOUSNESS \& CogniTION 1705, 1705-06 (2011); see also Bacon, supra note 103, at 241, 251 (showing that repeated statements are more likely to be judged as true, whereas contrary statements are likely to be viewed as false).

108. See Charles H. Cho et al., Astroturfing Global Warming: It Isn't Always Greener on the Other Side of the Fence, 104 J. Bus. Ethics 571, 581 (2011).

109. See Scott A. Hawkins \& Stephen J. Hoch, Low-Involvement Learning: Memory Without Evaluation, 19 J. CONSUMER RES. 212, 212-13 (1992).

110. See, e.g., 84\% Americans Blame Big Pharma for Healthcare Mess, Alliance FOR HumAn Res. Protection (Sept. 21, 2009), http://www.ahrp.org/cms/content/view/ 636/94 (stating that a vast majority of Americans consider companies to engage in price gouging); Huge Improvement in Reputation of the Auto Industry and Big Drop in Reputation of Airlines, PR NEwSwIRE (Sept. 21 2011), http://www.prnewswire.com/news-releases/hugeimprovement-in-reputation-of-the-auto-industry-and-big-drop-in-reputation-of-airlines-13025 7338.html (demonstrating that whereas the majority of consumers thought the drug industry did a good job in 1997, as of 2011, only seventeen percent did). 
challenged - as quickly as fifteen minutes after the repetition - even though subjects could initially distinguish the myth from fact. ${ }^{111}$

\section{Compelling Stories That Are Repeated Are Especially Memorable}

Repetition is clearly powerful on its own, but the content of what is repeated also has independent power. ${ }^{112}$ People are influenced by compelling stories, which are generally simple and coherent, rather than abstract. Individuals are persuaded by compelling stories because a good story seems reasonable. So, what makes a good story? In addition to being simple and coherent, emotional content plays a role. This should seem intuitively clear because vivid information is impactful and persuasive - a known fact effectively utilized by journalists and speakers. Studies have shown that information with higher emotional content is more likely to be remembered, believed, and disseminated, even if there is no factual foundation. ${ }^{113}$ For example, stories about how vaccines injure children have more resonance than information about how vaccines are not injurious. ${ }^{114}$ Similarly, studies consistently show that people assume that

111. See, e.g., Ian Skurnik et al., How Warnings About False Claims Become Recommendations, 31 J. CONSUMER RES. 713, 714 (2004); Norbert Schwarz, Metacognitive Experiences in Consumer Judgment and Decision Making, 14 J. CONSUMER PSYCHOL. 332, 339 (2004) (showing the same phenomenon after a three day delay); see also Lewandowsky et al., supra note 77, at 115 (explaining how repetition results in fluency, which strengthens information in memory and presumed correctness).

112. For example, information with strong fear appeal is more likely to produce a high level of susceptibility and to be more persuasive than information with low or weak fear appeal. Kim Witte \& Mike Allen, A Meta-Analysis of Fear Appeals: Implications for Effective Public Health Campaigns, 27 Health Educ. \& Behav. 591, 591 (2000). The impact of such fear appeal is stronger for those with no prior knowledge. Joshua M. Averbeck et al., Prior Knowledge and Health Messages: An Examination of Affect as Heuristics and Information as Systematic Processing for Fear Appeals, 76 S. Comm. J. 35, 35 (2011).

113. See, e.g., Ellen M. Cotter, Influence of Emotional Content and Perceived Relevance on Spread of Urban Legends: A Pilot Study, 102 Psychol. ReP. 623, 623 (2008); Chip Heath et al., Emotional Selection In Memes: The Case Of Urban Legends, 81 J. PERSONALITY \& SoC. Psychol. 1028, 1028 (2001).

114. See Martin G. Myers \& Diego Pineda, Misinformation About Vaccines, in VACCINES FOR BIODEFENSE AND EMERGING AND NEGLECTED DisEASES 255-56 (Alan D.T. Barrett \& Lawrence R. Stanberry eds., 2009); James M. Pribble et al., Medical News for the Public To Use? What's on Local TV News, 12 Am. J . MANAged CARE 170, 170 (2006). 
more high profile events occur with greater frequency than they do because they are publicized more and thus more "available" for recall. ${ }^{115}$ Accordingly, people may be more fearful of terrorist attacks or shootings in public schools than car accidents, even though statistically, a car accident is much more likely to occur. ${ }^{116}$

\section{REVEALING THREE KEY SCHEMAS IMPACTING PHARMACEUTICAL INNOVATION}

As noted in the introduction, there are three key schemas that deserve recognition and attention: the cost schema, the innovation schema, and the strong patent schema. Under the cost schema, the industry frequently touts a certain number as the average cost to develop all drugs, when the number is at best the highest number for a small fraction of drugs. ${ }^{117}$ To justify the high costs - and sales price of drugs - the innovation schema suggests that the industry produces highly innovative drugs, when in fact, the majority of drugs are not. ${ }^{118}$ Both of these schemas fuel the final schema that strong, or perhaps stronger, patent protection is necessary in light of high costs to produce innovation that is presumably of great benefit to society. ${ }^{119}$

These schemas are distinct, yet they may reinforce each other and may also be tied to the general self interest of companies as well as scholars. Most individuals have a natural tendency to view themselves in a positive light. ${ }^{120}$ Thus, a company, comprised of individuals, would be

115. See, e.g., KAHNEMAN, supra note 1, at 137-45; STUART SUTHERLAND, IRRATIONALITY: WHY WE DON'T THINK STRAIGHT! 16-17 (1994). One commentator has suggested that this basic principle is capitalized on by casinos that reinforce wins with blinking lights and the loud noise of coins dropping, as opposed to the absolute silence that comes with losses, such that there is a perception of more wins. JOHN AllEn PAULOS, INNUMERACY: MATHEMATICAL ILLITERACY AND ITS CONSEQUENCES 44 (2001).

116. Some suggest that this can be explained by the fact that examples are more available psychologically and easier to grasp than statistical information. See, e.g., KAHNEMAN, supra note 1, at 137-45.

117. See infra Part III.A.

118. See infra Part III.B.

119. See infra Part III.C.

120. See, e.g., Justin Kruger \& David Dunning, Unskilled and Unaware of It: How Difficulties in Recognizing One's Own Incompetence Lead to Inflated Self-Assessments, 77 J. Personality \& Soc. Psychol. 1121, 1121 (1999); Ola Svenson, Are We All Less Risky and More Skillful than Our Fellow Drivers?, 47 Acta Psychologica 143, 146 (1981). This tendency is so strong that there is a radio show based on this premiseNational Public Radio has a show called A Prairie Home Companion, which features the hypothetical "Lake Wobegon" where "all the women are strong, all the men are good 
naturally inclined to believe that it is doing valuable work-the innovation schema-and also that it needs more protection to address costs-the strong patent and cost schemas. In addition, some patent and economic scholars may be more prone to the strong patent schema because the pharmaceutical industry is generally held out as the one case where patents actually work as intended, such that this schema would seem consistent with existing beliefs. ${ }^{121}$ Although it may seem inconsistent with the concept of scholarly research to have bias, there is historical evidence showing that even famous scientists have been biased against facts that do not match their theories, such that scholars in other areas would not seem to be immune. ${ }^{122}$ In addition, studies repeatedly show that a wide variety of highly educated professionals not only have cognitive biases but can be overly confident in their judgments. ${ }^{123}$

This subpart explains how the schemas that impact industry as well as some scholars have been maintained and perpetuated through cognitive biases. The schemas are discussed in the order of complexity, beginning with the cost schema, followed by the innovation and strong patent schemas.

looking, and all the children are above average.” A Prairie Home Companion, AMERICAN PUBLIC MEDIA, http://prairiehome.publicradio.org/about/podcast (last visited May 20, 2014). The same effect is true with groups. See, e.g., Albert H. Hastorf \& Hadley Cantril, They Saw a Game: A Case Study, 49 J. ABnormal \& Soc. Psychol. 129, 130-32 (1954) (showing that group allegiances to a team result in viewing controversial calls in favor of group affiliation); Robert P. Vallone et al., The Hostile Media Phenomenon: Biased Perception and Perceptions of Media Bias in Coverage of the Beirut Massacre, $49 \mathrm{~J}$. Personality \& Soc. Psychol. 577, 577 (1985) (finding that pro-Arab and pro-Israeli students watching the same news coverage of a massacre of civilians viewed the coverage as consistent with their preexisting schemas).

121. See MERGES, supra note 3, at 282 and accompanying text.

122. See, e.g., Nickerson, supra note 93, at 194.

123. See, e.g., Dale Griffin \& Amos Tversky, The Weighing of Evidence and the Determinants of Confidence, 24 Cognitive Psychol. 411, 411-12 (1992); John B. Kidd, The Utilization of Subjective Probabilities in Production Planning, 34 ACTA PsYCHOLOGICA 338, 340-41 (1970); John W. Loop \& Lee B. Lusted, American College of Radiology Diagnostic Efficacy Studies, AM. J. RoENTGENOLOGY 173, 175 (1978); Stuart Oskamp, Overconfidence in Case-Study Judgments, 29 J. Consulting Psychol. 261, 261 (1965). For discussions of lawyers, see Jane Goodman-Delahunty et al., Insightful or Wishful: Lawyers' Ability To Predict Case Outcomes, 16 Psychol. PuB. Pol’y \& L. 133, 133 (2010); Elizabeth F. Loftus \& Willem A. Wagenaar, Lawyers' Predictions of Success, 28 JURIMETRICS J. 437, 437 (1988). 


\section{A. The Cost Schema}

A dominant schema is that the average $\operatorname{cost}^{124}$ to develop every drug exceeds $\$ 1$ billion. ${ }^{125}$ PhRMA asserts on its website that the "average [cost] of $\$ 1.2$ billion” makes patent protection crucial. ${ }^{126}$ Similarly, an April 2012 statement by PhRMA to Congress concerning the importance

124. This subpart focuses primarily on the perpetuation of this schema in academic and policy circles; although the schema clearly pervades general interest articles such as newspapers, scholars and policymakers are generally expected to be more thorough in their evaluation and consideration of information. In addition, there is a related schema - that the average time it takes to develop a new drug is fifteen years-that parallels this discussion with respect to the fact that this figure is only for new molecular entities but is frequently noted as the average for all drugs and taken as an uncontested fact that needs no support. E.g., U.S. GOV’T ACCOUNTABILITY OFFICE, GAO-07-49, NEW DRUG DEVELOPMENT: Science, Business, Regulatory, and Intellectual Property Issues Cited as HAMpering Drug DeVElopment EFForts 6 (2006). Even those that are skeptical of the industry may still repeat this figure without citation. E.g., FINKELSTEIN \& TEMIN, supra note 8 , at 66 .

125. E.g., PhRMA, 2013 Biopharmaceutical Research Industry Profile 38 (2013) (citing DiMasi \& Grabowsi, infra note 128, at 469), available at http://www.phrma. org/sites/default/files/pdf/PhRMA\%20Profile\%202013.pdf. A Forbes article recently cited the even higher average number of $\$ 4$ billion, but this number is not based on any empirical research and has not yet become broadly cited, such that it is not considered in this subpart. Matthew Herper, The Truly Staggering Cost of Inventing New Drugs, FORBES, Feb. 10, 2012, at 38, 38. In addition, a recent U.K. study cites a cost consistent with this schema that also is based solely on NMEs, rather than the development cost of all drugs. JORGE Mestre-Ferrandiz et al., Office of Health Economics, The R\&D Cost of a NeW MEDICINE 11-12 (2012). Thus far, the study has only been cited a few times and mentioned on a few blogs. E.g., TONy Hockley, Civitas Policy Analysis CtR., One SMALL STEP FOR THE NHS, BUT ONE GIANT LEAP FOR ITS PRINCIPLES? 4 (2013), available at http://civitas.org.uk/pdf/Hockley_One_Small_Step_NHS.pdf; Julian Clark, Traversing the Valley of Death, in HEALTHCARE: REFORM OR RATION 68 (2013), available at http://www.ceda.com.au/media/302619/healthcarefinal1.pdf; Adam Hill, R\&D Costs Rise Ten-Fold, PhARMAFILE (Apr. 12, 2012, 9:23 AM), http://www.pharmafile.com/news/ 176314/rd-costs-rise-ten-fold; Glyn Moody, Bayer Fights India's Compulsory Licensing of Cancer Drug By Claiming It Spent \$2.5 Billion Developing It, TECHDIRT (Feb. 4, 2013, 5:40 AM), http:/www.techdirt.com/articles/20130123/07494121762/bayer-fights-indiascompulsory-licensing-cancer-drug-claiming-it-spent-25-billion-developing-it.shtml (quoting report from advocate Jamie Love with respect to Bayer's reliance on a U.K. Office of Health Economics (OHE) report and noting that the OHE is not part of the government but an industry-funded firm). The U.K. study is not addressed separately, but the same considerations would likely apply because it mirrored the approach of the U.S. article in focusing exclusively on the cost of the most expensive drugs to develop and basing its findings on proprietary data. See Mestre-Ferrandiz et al., supra, at 11.

126. Intellectual Property Protections Are Vital to Continuing Innovation in the Biopharmaceutical Industry, PHRMA, http://www.phrma.org/innovation/intellectual-property (last visited May 20, 2014). 
of patent protection in the international landscape also began by stating an average cost of over $\$ 1$ billion. ${ }^{127}$

The $\$ 1$ billion figure can be traced to a 2007 study ${ }^{128}$ that updated a 2003 study that estimated the cost as exceeding $\$ 800$ million. ${ }^{129}$ However, the figure in the studies is only for NMEs, which are likely at most a third of all new drugs, whereas the schema uses this figure as the average for all drugs. ${ }^{130}$ Importantly, two-thirds of all new drugs are incremental

127. International Patent Issues: Promoting a Level Playing Field for American Industry Abroad: Hearing Before the Subcomm. on Intellectual Prop., Competition, and the Internet of the H. Comm. on the Judiciary, 112th Cong. 7 (2012) (statement of Roy Waldron, Chief Intellectual Property Counsel, Pfizer, on behalf of PhRMA); see also Hearing on U.S.-India Trade Relations: Opportunities and Challenges Before the Subcomm. on Trade of the H. Comm. on Ways and Means, 113th Cong. 3 (2013) (written statement of Roy Waldron, Chief Intellectual Property Counsel, Pfizer) (“[I]t takes on average more than $\$ 1$ billion . . . to research and develop a new medicine.”).

128. Joseph A. DiMasi \& Henry G. Grabowski, The Cost of Biopharmaceutical R\&D: Is Biotech Different?, 28 MANAGERIAL \& DECISION ECON. 469, 469, 475-76 (2007) (reporting an average capitalized cost of $\$ 1.24$ billion, with $\$ 559$ million out of pocket costs per approved drug). In addition, although a more recent study purports to confirm the 2003 number, it suffers from the same cost schema of focusing solely on NMEs. See Christopher P. Adams \& Van V. Brantner, Estimating the Cost of New Drug Development: Is It Really \$802 Million?, 26 HEALth AfF. 420, 420-21 (2006); see also Mestre-Ferrandiz et al., supra note 125, at 11-12 (suggesting an estimate of \$1.5 billion but still focusing solely on NME and also basing its estimate on proprietary data).

129. Joseph A. DiMasi et al., The Price of Innovation: New Estimates of Drug Development Costs, 22 J. HeAlth Econ. 151, 151 (2003) [hereinafter DiMasi 2003, The Price of Innovation] (reporting the capitalized cost of a new drug as $\$ 802$ million); see also DiMasi et al., Cost of Innovation in the Pharmaceutical Industry, 10 J. HEALTH ECON. 107, 107 (1991) (reporting the capitalized cost of a new drug as \$231 million in 1987 dollars).

130. The one-third number is an approximation because the study does not provide adequate information to assess the number of NMEs in the years evaluated; the study focuses on when clinical trials were initiated, whereas published data from the FDA focuses on the year of drug approval, which is generally later. However, for years after the clinical trials were initiated, the number of NMEs ranged from twenty-two percent to thirty percent. DiMasi \& Grabowski, supra note 128, at 474; Summary of NDA Approvals and Receipts, 1938 to the Present, FDA, http://www.fda.gov/AboutFDA/WhatWeDo/ History/ProductRegulation/SummaryofNDAApprovalsReceipts1938tothepresent/default. htm (last updated Jan. 18, 2013). In addition, the Congressional Budget Office used the one-third number in its study. See CBO STUDY, supra note 66, at $15 \mathrm{n} .28$ (providing data that about one-third of new drugs from 1990-2004 were NMEs). Although the CBO study is somewhat dated, more recent articles state that the rate of new drug approvals is relatively constant. E.g., Munos, supra note 32, at 959, 961. The most current information on FDA approvals, including the last few years, is available only on a monthly, rather than yearly, 
drugs that are much cheaper to develop than NMEs, such that the schema distorts the cost of most drug development. ${ }^{131}$ Moreover, not even all NMEs are represented by the schema. Rather, the number only reflects the fraction of those NMEs that may be the most expensive. ${ }^{132}$ In particular, the study only considered NMEs that were developed by the same company from start to finish, ${ }^{133}$ whereas most new drugs are the result of efforts initially made by others, such as academics, that a company then licenses. ${ }^{134}$ Although the study explains that this was done because of limitations in data collection, this important caveat is never noted by PhRMA. In addition, even for this sliver of NMEs, the number may not be accurate because of methodological issues, as discussed below. Because of these significant limitations, these studies support only a small fraction of drugs and not the schema that every drug has the same costs.

The first published criticism of the 2003 study was an article by Professors Light and Warburton, entitled Extraordinary Claims Require Extraordinary Evidence. ${ }^{135}$ Although these authors may be subject to their own schema, the focus here is on illustrating confirmation bias for the cost schema because it is so widely accepted that most do not realize it is a schema rather than an established fact. In addition, although their critique addressed multiple issues, the discussion here focuses on those most pertinent to the cost schema. ${ }^{136}$

basis at http://www.accessdata.fda.gov/scripts/cder/drugsatfda/index.cfm?fuseaction=Reports. ReportsMenu.

131. See supra note 130.

132. See Donald W. Light \& Rebecca N. Warburton, Extraordinary Claims Require Extraordinary Evidence, 24 J. HEALTH ECON. 1030, 1031-32 (2005) [hereinafter Light \& Warburton, Extraordinary Claims] (stating that the drugs studied are 3.7 times more expensive than drugs licensed from other companies).

133. See DiMasi 2003, The Price of Innovation, supra note 129, at 156 (noting that the compounds were all "self-originated").

134. See, e.g., Robert Kneller, The Importance of New Companies for Drug Discovery: Origins of a Decade of New Drugs, 9 NATURE Rev. Drug DisCOVERY 867, 867, 879 (2010).

135. Light \& Warburton, Extraordinary Claims, supra note 132; see also Roger Collier, Drug Development Cost Estimates Hard to Swallow, 180 CANADIAN MED. Ass'N J. 279, 279 (2009) (describing the study). There are also additional published criticisms, but because these largely relate to the same points, they are not included here. However, for reference, see Donald W. Light, Reply to DiMasi, Hansen, and Grabowski, 33 J. HeALTH Pol. Pol'y \& L. 325 (2008); Donald W. Light \& Rebecca Warburton, Demythologizing the High Costs of Pharmaceutical Research, 6 BIoSociETIES 34 (2011) [hereinafter Light \& Warburton, Demythologizing].

136. E.g., Steve Morgan et al., The Cost of Drug Development: A Systematic Review, 100 Health POL’y 4, 4 (2011) (finding a nine-fold range in estimates of drug 
Light and Warburton challenged the validity of the data because it relied on confidential and proprietary data supplied by the industry. In particular, they questioned the validity of the number because the confidential data could not have been evaluated by independent parties. ${ }^{137}$ They noted that it is impossible to know what the surveyed companies counted as research costs and warned that the companies would, in fact, have an incentive to overstate the costs given that the companies understood the data would be used to estimate the costs of drug development. ${ }^{138}$ They also noted that it is unclear how invited firms were selected, which casts doubt on whether they were selected from all firms, or only ones that might have higher costs. ${ }^{139}$

DiMasi et al.'s reply demonstrates confirmation bias concerning these criticisms. ${ }^{140}$ DiMasi et al. asserted that "[t]here appears to be little reason for firms to fabricate to achieve particular results when the acknowledged reality supports such basic claims" that drug discovery is "uniformly recognize[d as] on average ... costly, risky, and lengthy."141 The statement may reflect confirmation bias in that it does not address

development costs). Other issues not discussed include whether the figure should reflect capitalized cost, instead of solely out of pocket costs. The capitalized cost includes the cost of not investing money that is used for research, rather than solely out of pocket costs. Although a capitalized cost can result in a figure that is roughly twice as high as the out of pocket costs - $\$ 1$ billion versus $\$ 672$ million in the study - that is not the primary focus of discussion here because standard accounting principles often use capitalized costs, although some suggest that it is less clear whether this should apply to drug development. See, e.g., Merrill GoOzner, The \$800 Million Pill: The Truth Behind the Cost OF New Drugs 239-40 (2004) (suggesting that application of accounting principles are not as clear as PhRMA has claimed). In addition, some have criticized the figure for not excluding government subsidies and tax credits and for potentially including costs that are not required to develop a drug, such as costs to help persuade doctors to prescribe a drug. See, e.g., PuBLIC Citizen, RX R\&D MYTHS: THE CASE AgAINST THE DRUG INDUSTRY’s R\&D “SCARE CARD,” i (Frank Clemente et al. eds., 2001), available at http://www.citizen.org/documents/ACFDC.PDF.

137. Light \& Warburton, Extraordinary Claims, supra note 132, at 1031.

138. Id.

139. Id

140. DiMasi et al. also evidence naïve realism in suggesting that Light and Warburton, but not themselves, are biased. For example, they claim that Light and Warburton failed to address the "validation" of their results in alternative sources. Joseph A. DiMasi et al., Reply: Extraordinary Claims Require Extraordinary Evidence, 24 J. HEALTH ECON. 1034, 1034 (2005). However, DiMasi et al. seem blind to considering whether their own "validation" was completely objective.

141. Id. at 1037. 
the critique. For example, even if it is acknowledged that drug discovery is "costly," that does not rebut the concern that companies have an incentive to overstate the costs. In addition, DiMasi et al. assert that companies knew that the results would be subject to "validity checks," such that companies would not be inclined to distort the data. ${ }^{142}$ However, the validity checks would only be done by the authors of the study, who have a track record of publishing articles suggesting a high cost of drug discovery. $^{143}$

The cost schema is likely widely accepted due to extensive repetition. Importantly, the original $\$ 800$ million estimate was first announced in a press release $\mathrm{e}^{144}$ and was repeated by the press for more than a year ${ }^{145}$ before the actual academic paper was published that disclosed the key details that could then be questioned. In other words, for more than a year, the public, as well as scholars, only heard the industry cost schema. Although the eventual paper disclosed that the average cost number was only for a fraction of most new drugs, ${ }^{146}$ there was no press coverage of the published paper, in contrast to the lavish press coverage of the original press release. ${ }^{147}$ In addition, the industry continues to propagate the cost schema, which may be represented as fact by policymakers or even scholars. ${ }^{148}$

\section{Id.}

143. See Donald W. Light \& Rebecca N. Warburton, Setting the Record Straight in the Reply by DiMasi, Hansen and Grabowski, 24 J. HEALTH ECON. 1045, 1045-46 (2005).

144. Press Release, Tufts Ctr. for the Study of Drug Dev., Tufts Center for the Study of Drug Development Pegs Cost of a New Prescription Medicine at \$802 Million (Nov. 30, 2001) (on file with author); see also Tufts Center: Average New Drug Costs $\$ 802$ Million, Bos. Bus. J. (Nov. 30, 2001, 3:26 PM), http://www.bizjournals.com/boston/ stories/2001/11/26/daily48.html (stating that the press release announced that "the average cost to develop a new prescription drug is $\$ 802$ million”).

145. E.g., Naomi Aoki, R\&D Costs for Drugs Skyrocket, Study Says Tufts Center Estimates Amount Up Threefold From a Decade Ago, Boston GLOBE, Dec. 1, 2001, at C1; Terence Chea, Low Fliers Behind the Drugs; Bioinformatics Firms, Essential to Research, Sag on Wall St., WAsh. Post, Jan. 3, 2002, at E1; Andrew Pollack, Despite Billions for Discoveries, Pipeline of Drugs is Far from Full, N.Y. TimEs, Apr. 19, 2002, at $\mathrm{C} 1$.

146. DiMasi 2003, The Price of Innovation, supra note 129, at 158.

147. A Lexis search for articles that mentioned the "Tufts" study or the published article in the two months after the DiMasi paper was published did not reveal any news stories.

148. For example, a recent report in Australia noted that "[i]n their submission, Medicines Australia quotes an average cost of \$1.5 billion and 12 to 15 years to bring a new drug to market.” AUSTRALIAN REPORT, supra note 61, at 33. Although it is duly noted who provides this cost figure, there is no contrary figure provided, or acknowledgment that Medicines Australia has an incentive to provide the highest number possible. Moreover, 
There is relatively little press coverage of information that contradicts the cost schema. For example, although Light and Warburton published a related article in 2011 challenging the cost schema, ${ }^{149}$ it received relatively little public media attention. ${ }^{150}$ In contrast, the cost schema was presented as an undisputed fact in a 2012 Wall Street Journal article, ${ }^{151}$ as well as in a 2012 Forbes magazine article. ${ }^{152}$ Moreover, although a 2011 academic study notes that there is, in fact, no "gold standard" concerning the cost of drug discovery despite decades of research, this important finding has received virtually no press. ${ }^{153}$

the report suggests that there is a consensus that the cost of drug development is rising and references a study by the UK Office of Health Economics that purports to support this. Id. at 37 (citing JORGE MESTRE-FERRANDIZ ET AL., supra note 125, at v).

149. Light \& Warburton, Demythologizing, supra note 135, at 34.

150. Timothy Noah, The Make-Believe Billion: How Drug Companies Exaggerate Research Costs To Justify Absurd Profits, SLATE (Mar. 3, 2011, 9:19 PM), http://www. slate.com/articles/business/the_customer/2011/03/the_makebelieve_billion.html. In addition, there were a few blogs that reported it. E.g., Derek Lowe, The Costs of Drug Research: Beginning a Rebuttal, CORANTE BLOG (Mar. 7, 2011), http://pipeline.corante.com/archives/ 2011/03/07/the_costs_of_drug_research_beginning_a_rebuttal.php; Scott Gavura, What Does a New Drug Cost?, Science-BASEd Medicine (Apr. 14, 2011), http://www.science basedmedicine.org/index.php/what-does-a-new-drug-cost; John Mack, A New Estimate of Drug Development Cost, Pharma Marketing News (Apr. 23, 2011), http://www.news. pharma-mkting.com/pmn108-article03.htm; Jennifer Ringler, Fact Versus Fact: When Will the Numbers Add Up?, PHARMAEXEC (Mar. 15, 2011), http://blog.pharmexec.com/2011/ 03/15/fact-versus-fact-when-will-the-numbers-add-up. Of course, there are some that question the cost schema without referring to academic sources. E.g., Mike Masnick, Drug Companies Overestimate Cost of Developing a New Drug by Merely \$1.26 Billion, TECHDIRT (Mar. 30, 2011, 8:07 AM), http://www.techdirt.com/articles/20110329/02440013670/drug-companiesoverestimate-cost-developing-new-drug- merely-126-billion.shtml.

151. Josh Bloom, Should Patents on Pharmaceuticals Be Extended To Encourage Innovation?, WALL ST. J. (Jan. 23, 2012), http://online.wsj.com/news/articles/SB1000 1424052970204542404577156993191655000 ("[B]ringing one new drug to market takes roughly 14 years, at a cost of about $\$ 1.3$ billion.”).

152. Herper, supra note 125 , at 38.

153. Morgan et al., supra note 136, at 11. Although not a reliable academic source, Wikipedia does reflect common beliefs, and this study is notably missing in the references listed for the cost of drug discovery. Drug Development, WiKIPEDIA, http://en.wikipedia.org/ wiki/Drug_development (last updated Apr. 27, 2014). In addition, a 2012 study of 100 pages that aimed to be a comprehensive analysis of the cost of drug development did not cite this study. JORGE MESTRE-FERRANDIZ ET AL., supra note 125, at 85 (lacking citation to Morgan et al. in the list of references). This could be because this study is a review of prior studies. However, considering that this study aimed to be comprehensive, its omission is notable. 
A high cost of drug discovery may also seem believable based on information that is readily available in our memory. In particular, the popular press repeatedly reports when late stage drug trials are terminated after millions have been spent or when the FDA declines to approve a drug. ${ }^{154}$ These examples are vivid and thus easily recalled in comparison to the generally unreported fact that only a fraction of drugs cost what the cost schema suggests. In addition, as noted earlier, stories with emotional resonance are more likely to be communicated and remembered. Because most people know that researchers have been searching for decades to find cures for diseases like AIDS or even the common cold, it may seem logical that drug discovery is exorbitantly expensive. The contrary story that only a minority of drugs are expensive and that it is in fact unclear how much most drugs cost to develop is a complex story with little emotional appeal.

Based on all of the above, perhaps it is logical that even sources presumed to be impartial, such as the Congressional Budget Office (Budget Office), might be vulnerable to adopting the industry schema. For example, when the Budget Office did a study of drug development, it acknowledged that the cost of drugs could be much less than the frequently touted $\$ 800$ million-the number that preceded the current $\$ 1$ billion estimate. ${ }^{155}$ However, it seemed to give support to the higher number when it stated that it was the "widely circulated estimate" without acknowledging that it is circulated by those sympathetic to pharmaceutical companies. ${ }^{156}$ In addition, although the report recognized both that the high number excluded some drugs with lower costs and that it was based on proprietary data that could not be independently verified, the Budget Office still seemed to endorse the high number by suggesting that it was consistent with other reports. ${ }^{157}$

More recent policy reports also seem vulnerable to promoting the industry schema. For example, the 2013 report of the pharmaceutical

154. E.g., Andrew Pollack, F.D.A. Fails to Approve Diet Drug, N.Y. Times, Feb. 2, 2011, at B1 (noting the FDA has "declined to approve yet another prescription diet pill," making it the third obesity drug in three months that the FDA failed to approve); Jonathan D. Rockoff \& Mia Lamar, Firms Halt Alzheimer's Drug Work, WALL ST. J., Jan. 18, 2012, at B7 (noting the companies' decision to abandon development of a drug during a phase three trial); Robert Weisman, Biogen Idec's ALS Drug Falls Short in Trials, Bos. GloBE, Jan. 4, 2013, at A1 (noting Biogen Idec's halt of a late-stage clinical trial after spending more than $\$ 80$ million).

155. CBO STUDY, supra note 66, at 2.

156. Id.

157. See id. at 20-21. 
industry in Australia at one point noted that the submission of Medicines Australia, which represents companies that develop and manufacture new drugs, ${ }^{158}$ quoted an average cost of $\$ 1.5$ billion to bring a new drug to market but later simply asserted as fact that "[t]he total cost of developing new drugs has been reported as being more than $\$ 1$ billion," without citation, let alone qualification that this number is disputed. ${ }^{159}$

Scholars may be similarly susceptible to adopting the industry schema, especially when it is considered that patent scholars may have some selfinterest bias in a high number that would better justify the belief that patents work well for pharmaceutical innovation. Indeed, scholars often repeat the earlier ${ }^{160}$ and current version of the cost schema. ${ }^{161}$ There are some scholars that are cognizant that the number may not be accurate, but they tend to focus on the fact that it is controversial and generally do not recognize the most important problem that the number represents a minority of drugs. For example, leading patent scholar Professor Rebecca Eisenberg noted that the figure is based on self-reported data, such that

158. About Us, Medicines Australia, http://medicinesaustralia.com.au/about-us/ (last updated Dec. 2009).

159. Australian REPORT, supra note 61, at 33, 207.

160. E.g., Daniel R. Cahoy, Patent Fences and Constitutional Fence Posts: Property Barriers to Pharmaceutical Importation, 15 Fordham Intell. Prop. Media \& Ent. L.J. 623, 635 (2005) (citing \$800 million figure); Carmelo Giaccotto et al., Drug Prices and Research and Development Investment Behavior in the Pharmaceutical Industry, 48 J.L. \& ECON. 195, 196 (2005) (citing \$802 million figure); Goldman et al., supra note 6, at 85 (echoing the cost schema without questioning its veracity or citing contrary figures); Oskar Liivak, Maintaining Competition in Copying: Narrowing the Scope of Gene Patents, 41 U.C. DAVIS L. REV. 177, 235 n.250 (2007) (repeating the figure); Michael J. Malinowski, Choosing the Genetic Makeup of Children: Our Eugenics Past-Present, and Future?, 36 Conn. L. Rev. 125, 174 n.250 (2003) (repeating the figure). But see Stuart Minor Benjamin \& Arti K. Rai, Who's Afraid of the APA? What the Patent Law System Can Learn from Administrative Law, 95 GEO. L.J. 269, 308 n.207 (2007) (citing DiMasi 2003, The Price of Innovation, supra note 129) (noting high cost of innovation but not repeating cost schema); C. Scott Hemphill, Paying for Delay: Pharmaceutical Patent Settlement as a Regulatory Design Problem, 81 N.Y.U. L. REV. 1553, 1564 n.36 (2006) (citing the DiMasi study, but using the noncapitalized costs that are not touted by the industry).

161. E.g., Peter Lee, Toward a Distributive Commons in Patent Law, 2009 WIs. L. Rev. 917, 920 n.7; Benjamin N. Roin, The Case for Tailoring Patent Awards Based on Time-to-Market, 61 UCLA L. REV. 672, 728 (2014); Sean B. Seymore, Rethinking Novelty in Patent Law, 60 DuKE L.J. 919, 926-27 nn.36, 41 (2011); see also Emily Michiko Morris, The Myth of Generic Pharmaceutical Competition Under the Hatch-Waxman Act, 22 Fordham InTELl. Prop. MEdia \& ENT. L.J. 245, 268 (2012) (citing both numbers). 
critics have challenged the estimate. ${ }^{162}$ Although self-reported data is a problem, the much bigger problem, as noted above, is that the figure is based on a minority of the most expensive drugs developed. Professor Eisenberg does not, however, address this point, nor do other scholars that have noted that the number is controversial. ${ }^{163}$ Moreover, some simply cite the cost schema without contrary numbers or any suggestion that the number is controversial. ${ }^{164}$

Although the most important issue is that scholars often do not seem to recognize that the schema represents the small minority of the most expensive drugs developed, there is an additional problem. In particular, although many scholars may recognize that the study supporting the schema may provide an inflated number, they still lend credence to it by

162. Rebecca S. Eisenberg, The Role of the FDA in Innovation Policy, 13 Mich. TELECOMM. \& TECH. L. REV. 345, 350, n.15 (2007); see also WENDY H. SCHACHT \& JOHN R. Thomas, Cong. Research Serv., R41114, The Hatch-Waxman Act: A Quarter CENTURY LATER 7 (2012) (evidencing the schema in a publication co-authored by an academic and a specialist in science and technology policy).

163. E.g., Burk \& Lemley, supra note 6, at 1616 (noting that the figure is "almost certainly inflated"); Donald P. Harris, TRIPS' Rebound: An Historical Analysis of How the TRIPS Agreement Can Ricochet Back Against the United States, 25 Nw. J. INT'L L. \& Bus. 99, 140 n.167 (2004) (noting that the figure is "not free from doubt," but not citing a contrary number or study); David W. Opderbeck, Patents, Essential Medicines, and the Innovation Game, 58 VAND. L. REV. 501, 518 n.86 (2005) (acknowledging the number is debatable, but nonetheless not providing a contrary number or citations); Michael D. Rawlins, Cutting the Cost of Drug Development?, 3 NATURE 360, 360 (2004) (stating "reluctance in view of incomplete disclosure of the data," but nonetheless accepting the figure); Joseph E. Stiglitz \& Arjun Jayadev, Medicine for Tomorrow: Some Alternative Proposals To Promote Socially Beneficial Research and Development in Pharmaceuticals, 7 J. GENERIC MED. 217, 222 (2010) (noting the disputed estimate but not citing alternative estimates or criticisms); see also Rebecca S. Eisenberg, Lecture, Patents, Product Exclusivity, and Information Dissemination: How Law Directs Biopharmaceutical Research and Development, 72 FoRDHAM L. REV. 477, 481 (2003) (citing cost schema and noting it "may err on the generous side" without citing a lower number).

164. E.g., SсHACHT \& THOMAS, supra note 162, at 7 (stating that the cost has doubled and citing the current cost schema without qualification); Cahoy, supra note 160, at 635 (referring to the "widely cited" estimate from the Tufts Center); Goldman et al., supra note 6, at 85 (affirmatively stating a current cost of drug development that uses the earlier version of the cost schema); Morris, supra note 161, at 254 (citing the two cost schema figures). As noted in the earlier section, repeated information is presumed more credible, such that scholars are simply following predictions of social scientists in referring to a commonly repeated number. This may be particularly true for articles that mention the cost of drugs in passing to compare the higher expenses of drugs versus other patented products. See, e.g., Malinowski, supra note 160, at $174 \mathrm{n} .250$ (mentioning the cost schema only in a footnote of an article that is not focused on patents or drugs but rather, eugenics); Seymore, supra note 161, at $926 \mathrm{n} .36$ (focusing on the novelty of all inventions in general and only citing the cost schema figures in a footnote reference). 
simply repeating it. As discussed earlier, repeated information tends to be remembered over time - even if what is repeated is that the information is false. ${ }^{165}$ Accordingly, if leading patent scholars Professors Burk and Lemley note that " $[\mathrm{t}]$ he pharmaceutical industry reports that it spends as much as $\$ 800$ million on R\&D for each new drug produced," as well as the fact that the number "is almost certainly inflated," 166 what is likely to be remembered is that the industry spends $\$ 800$ million per drug, rather than that the number is inflated. Problematically, this example is typical of most scholarly discussions; even those that recognize the number may not be accurate may nonetheless reinforce it by not only repeating it but failing to cite any contrary figures. ${ }^{167}$

\section{B. Innovation Schema}

This subpart documents the existence of the high innovation schema strongly held by pharmaceutical companies and also presumed by some scholars. Basically, companies believe that the drugs they produce are highly innovative, such that they play a critical social role. ${ }^{168}$ For example, one report by the Canadian Intellectual Propery Council, a Canadian business coalition whose stated objective is to increase intellectual property rights consistent with the position of the pharmaceutical

165. See supra Part II.C.1.

166. Burk \& Lemley, supra note 6, at 1616; see also Basheer, supra note 6, at 310 (noting contrary figures and studies, but nonetheless repeating the most current cost schema); Amy Kapczynski \& Talha Syed, The Continuum of Excludability and the Limits of Patents, 122 YALE L.J. 1900, 1922 n.62 (2013) (citing earlier figure of approximately \$800 million and accurately noting that the cost is controversial); Wood, supra note 36, at 618 (noting that the industry figure has been accused of being "inflated," but providing no citation contrary to the situation for the industry figure, which seems to suggest that the industry schema is in fact valid).

167. See, e.g., supra notes 60-63 and accompanying text.

168. See, e.g., PhrMA, New Medicines Yield Significant Progress Against SERIOUS DiSEASE (2012), available at http://phrma.org/sites/default/files/pdf/medical_ advances_final_9.4.12.pdf (suggesting that new drugs have been "helping patients live longer, healthier lives”); PhRMA Statement on PCAST Innovation Report, PHRMA (Dec. 3, 2012), http://phrma.org/media/releases/phrma-statement-pcast-innovation-report (stating that PhRMA is responsible for over 300 new medicines in the past decade that "provided tremendous and immeasurable value to millions of patients and families around the world"). 
industry, ${ }^{169}$ stated that " $[w]$ ithout the dedication of the research-based pharmaceutical companies investing billions in trying to find new medicines, our lives would be tremendously different, our life expectancy would be much shorter and bloodletting and enemas might still be the favoured techniques to treating almost everything."170 Although such a statement might be mere puffery, it is consistent with the high innovation schema, as explained below.

The industry repeatedly emphasizes that it is highly innovative and may be particularly inclined to emphasize its role in developing innovative drugs whenever there are proposals that would impact its profits, such as possible price regulation of drugs. ${ }^{171}$ At the same time, consistent with studies on confirmation bias, when it comes to studies contradicting this schema, the industry either criticizes the underlying research methodology or ignores them entirely. This subpart provides evidence of both approaches.

The industry response to a 2002 report on pharmaceutical innovation provides an excellent example of confirmation bias. ${ }^{172}$ The report, entitled Changing Patterns of Pharmaceutical Innovation, by the National Institute for Health Care Management (NIHCM), addressed a number of

169. See CANAdian Intell. Prop. Council, http://www.ipcouncil.ca/about-us.cfm (last visited May 20, 2014).

170. Canadian Intell. Prop. Council, InNovation for a BetTer TOMORROW: Closing Canada's Intellectual Property Gap in the Pharmaceutical Sector 5 (2011) (emphasis added), available at http://www.ipcouncil.ca/uploads/Innovation\%20for \%20a\%20Better\%20Tomorrow.pdf.

171. For example, in arguing against price regulation, the president of PhRMA stated "voters do not want to jeopardize the miracle of life-saving innovation in modern medicines," which suggests that PhRMA is responsible for such miracles. Vicki Kemper, Drug Industry Poised To Reap Political Dividends, L.A. Times, Nov. 8, 2002, at A15 (emphasis added). In addition, PhRMA tends to minimize the role of many others, including government and academics that are responsible for developing roughly half of all new drugs. See, e.g., Kneller, supra note 134, at 867, 869-70.

172. In addition, the industry response is consistent with studies that show that providing a defense can reinforce schemas. PhRMA first stated that the National Institute for Health Care Management (NIHCM) "arbitrarily" excludes biologics and later accused NIHCM of arbitrarily excluding large numbers of biologics. Compare PHRMA, NIHCM's REPORT ON PHARMACEUTICAL INNOVATION: FACT VS. FICTION 1 (2002) [hereinafter FACT vs. FICTION] ("NIHCM arbitrarily excludes through brief references in the text and a footnote all vaccines and other biologic products from its report.”), with PHRMA, NIHCM REPORT ON PHARMACEUTICAL INNOVATION: NIHCM RESPONSE TO PHRMA REButTAl Is SiLENT ON THE REAL IsSUES 2-4 (2002) (accusing NICHM of "arbitrarily excluding large numbers of medicines from the data”) [hereinafter NIHCM Is SILENT]. 
issues, including innovation. ${ }^{173}$ It concluded that, from 1989-2000, only $15 \%$ of new drugs were highly innovative and the percentage of new drugs that were highly innovative was decreasing over time, ${ }^{174}$ with companies mostly developing drugs that were incremental modifications to existing drugs. ${ }^{175} \mathrm{PhRMA}$, the lobbying group for major pharmaceutical companies, strongly criticized not only the report's conclusions but also its methodology as inherently flawed. ${ }^{176}$ PhRMA's reaction is consistent with confirmation bias studies; after all, the report challenged, rather than confirmed, the industry's preferred schema. ${ }^{177}$ PhRMA's confirmation bias can be seen in its two rebuttals; one to the NIHCM's original report ${ }^{178}$ and another to NIHCM's defense of its original report. ${ }^{179}$

Before considering whether PhRMA's challenges to the NIHCM's methodology are justified, it is necessary to first understand the methodology. Essentially, to evaluate the innovativeness of the drug industry, NIHCM evaluated most new drugs that entered the domestic market from 1989-2000. ${ }^{180}$ The study excluded vaccines and other biologic products, which although considered important, were a more recent phenomenon such that they were neither consistently present during the entire time frame nor considered to be relevant to a retrospective study. ${ }^{181}$ Once such products were excluded, NIHCM assessed drug innovativeness using the FDA's classification system for drug review. ${ }^{182}$ That system first classifies a drug as either a NME-having an active ingredient never previously approved—or as a IMD—a new combination

173. See Nat’l Inst. for Health Care Mgmt., Changing Patterns of PHARMACEUTICAL INNOVATION (2002) [hereinafter NIHCM REPORT], available at http://www.nihcm.org/pdf/innovations.pdf.

174. Id. at 9 .

175. Id.

176. FACT VS. FICTION, supra note 172, at 12-13.

177. See NIHCM REPORT, supra note 173.

178. FACT VS. FICTION, supra note 172.

179. NIHCM Is SILENT, supra note 172 ; see also NIHCM, THE NIHCM FOUNDATION RESPONDS TO PHRMA's CRITICISMS OF THE REPORT, “CHANGING PATTERNS OF PHARMACEUTICAL INNOVATION” (2002) [hereinafter NIHCM RESPONSE TO PHRMA], available at http://archives.who.int/prioritymeds/report/append/8343.pdf (NIHCM's defense of its original report).

180. NIHCM REPORT, supra note 173, at 2.

181. Id. at $22 \mathrm{n} .3$.

182. Id. at 2 . 
of known active ingredients or a new dosage of known drug. ${ }^{183}$ In addition, whether a NME or IMD, the FDA categorizes a drug for a standard or priority review, with priority reviews getting swifter examination because of stronger patient benefits. ${ }^{184}$ The priority review is granted for drugs that are alleged to provide increased effectiveness, reduce side effects, enhance patient compliance, or be useful in a new subpopulation of patients. ${ }^{185}$ Even a drug that is an IMD can be granted a priority review if it, for example, shows increased effectiveness compared to prior treatments. ${ }^{186}$ Consistent with this framework, the drugs marketed as Celebrex and Vioxx received priority review status as painkillers based solely on the fact that they had allegedly improved side effects, even though there was no claim that they treated pain better than prior drugs. ${ }^{187}$

Based on these criteria, NIHCM classified the most innovative drugs as those that are not only NMEs, but NMEs granted priority review. ${ }^{188}$ The descending order of degree of innovation after NMEs granted priority review was: standard NMEs, priority IMDs, and then standard IMDs. ${ }^{189}$ Notably, the report considered drugs in all categories to have potential value to doctors and patients, but used this framework as a proxy for innovation. ${ }^{190}$

\section{Contesting the Methodology of a Study that Challenges This Schema}

PhRMA attacked the methodology underlying the study, consistent with confirmation bias studies that consistently show that the methodology of studies that provide information inconsistent with a preferred schema is questioned. 191 PhRMA's challenges focused on two primary issues. PhRMA claimed that using the FDA classification system for reviewing drug applications was an improper way to evaluate innovation and also that excluding biologics from the sample was improper. ${ }^{192}$ As explained

183. Id.

184. Id. Applications designed for priority review are evaluated in six months, rather than the ten months for standard reviews. Thaul, supra note 50, at 3.

185. NIHCM REPORT, supra note 173 , at 6 .

186. Id.

187. Id.

188. Id. at 7 .

189. Id.

190. Id.

191. See FACT Vs. Ficton, supra note 172.

192. See id. at 3. 
below, each of these issues is not only unfounded but reflects confirmation bias.

PhRMA strongly rejected the use of the FDA classification system as a method of assessing innovation, even though a number of other studies, including some not criticized by PhRMA, have used this metric. ${ }^{193}$ In particular, PhRMA suggested that the FDA classification was simply an "FDA management tool," such that it makes sense that not all drugs can be granted priority status, even if they offer clinical benefit. ${ }^{194}$ Although it is true that not all drugs can be granted priority status, this statement is incorrect. It ignores the fact that a drug would be granted priority status if it offered any one of an array of possible clinical benefits. This criticism likely reflects confirmation bias in not only rejecting the methodology that reached a conclusion inconsistent with the innovation schema but even misstating the methodology in an attempt to bolster the preferred schema.

PhRMA also argued that the FDA classification method was irrelevant because it does not relate to drug value. ${ }^{195}$ PhRMA claimed that the FDA's own guidelines state that the designation of priority determinations is not intended to predict a drug's "ultimate value or its eventual place in the market." 196 The change in focus from innovation to value can be explained by confirmation bias. After all, confirmation bias studies would predict that unhelpful information is ignored in favor of information that supports a belief, even if the information is tangential to the original point.

Furthermore, although PhRMA contested the use of the FDA classification system, its substantive comments focused almost exclusively on contesting the priority determination without considering that this is only one part of the methodology for assessing innovation. As noted earlier, the most innovative drugs were not simply priority drugs, but priority NMEs. ${ }^{197}$ Nowhere in the PhRMA attack on methodology does

193. E.g., Kneller, supra note 134, at 867; Bhaven N. Sampat \& Frank R. Lichtenberg, What Are the Respective Roles of the Public and Private Sectors in Pharmaceutical Innovation?, 30 HEALTH AFF. 332, 333-34 (2011).

194. FACT VS. FiCTION, supra note 172, at 3.

195. See NIHCM Is SILENT, supra note 172, at 5.

196. FACT VS. FICTION, supra note 172 at 3; see also NIHCM Is SiLENT, supra note 172, at 9-10 (arguing that insurers do not use the FDA system to decide what to cover).

197. NIHCM REPORT, supra note 173 , at 2. 
it dispute whether NMEs are in fact more innovative than IMDs. ${ }^{198}$ Rather, it repeatedly focuses on emphasizing that standard review drugs can be innovative. ${ }^{199}$ As noted earlier, standard review drugs are considered innovative - if they are NMEs. However, in broadly attacking the NIHCM report for giving too much weight to priority drugs, PhRMA fails to distinguish the critical issue that priority NMEs are not interchangeable with priority IMDs. PhRMA considered all standard review drugs the same for purposes of criticizing the methodology, when in fact, that is not the actual methodology used by the FDA. This mischaracterization of the methodology is consistent with confirmation bias in permitting PhRMA to adhere to its belief that IMDs are innovative by selectively ignoring key issues.

In addition to criticizing the use of the FDA's classification scheme for drug approval, PhRMA attacked the methodology for "arbitrarily" excluding biologic drugs and vaccines. ${ }^{200}$ NIHCM's report in fact did explain that these drugs were recent developments that did not lend themselves to a retrospective historical analysis to see how innovation has changed over time. ${ }^{201}$ In addition, although PhRMA's objection seems to suggest that exclusion of such biologics was essential to the undesirable conclusion, subsequent studies suggest otherwise. In particular, the Budget Office found that only one-third of all new drugs, including biologics, were

198. See FACT VS. FiCTION, supra note 172.

199. For example, PhRMA noted as purportedly relevant that the FDA's annual report included many drugs as "[n]otable new drug approvals” that were not solely priority reviewed drugs without addressing whether the standard review drugs were NMEs, which would be the second most innovative drugs according to the study, yet were not acknowledged by PhRMA. See id. at 4.

200. FACT VS. FICTION, supra note 172, at 1; NIHCM Is SILENT, supra note 172, at 2. This would seem to suggest that if biologics were included, PhRMA would be considered innovative.

201. After PhRMA's first criticism of its report, NIHCM added an additional clarification that seventy percent of such drugs were approved within the last six years as reported by the biotechnology industry and also that the drugs were mostly discovered not by the pharmaceutical industry but by the biotechnology industry. NIHCM RESPONSE TO PHRMA, supra note 179, at 2. PhRMA rejected these contentions, claiming that the number of new biologics approved in the two periods was equal based on FDA statistic, but not rejecting the data NIHCM relied on. See NIHCM Is SILENT, supra note 172, at 3. In addition, PhRMA attempted to rebut the assertion that the pharmaceutical and biotechnology industries were separate by arguing that they work together and "jointly" develop such drugs because PhRMA pays for clinical trials and also often provides funding to the biotechnology industry. Id. However, these facts do not establish that PHRMA itself is responsible for such innovations; they demonstrate what PhRMA funds, but not what it invents on its own. 
in fact NMEs, with a growing share of these NMEs as not priority NMEs. ${ }^{202}$ PhRMA did not contest this report, consistent with confirmation bias theory that inconsistent information may be simply ignored.

PhRMA may also not have contested the Budget Office finding because there were other aspects of the report consistent with the innovation schema, such that there was no need to be critical of the discussion of the limited number of NMEs and priority NMEs. ${ }^{203}$ In particular, the Budget Office report reinforced the industry schema by referring to a focus on NMEs as "misleading,"204 even while admitting that it is a "[c]onventional" measure of performance. ${ }^{205}$ The report instead suggested that the "value" of drugs is more important, again echoing the rebuttal to the NIHCM report that reflected confirmation bias in suggesting value was more important. ${ }^{206}$

\section{Supporting and Reinforcing Schema via Selective Listening}

Since the 2002 NIHCM and 2006 Budget Office reports, those who hold the innovation schema are likely to continue to hold that schema by selectively relying on a few recent studies that perpetuate the schema while simultaneously ignoring studies that contradict the schema.

202. CBO STUDY, supra note 66, at 7, 12. In fact, the CBO Report recognized that the majority of new drugs are simply "modified forms of — or new uses for-existing drugs." Id. at 7.

203. In fact, in the Introduction, the first major section is titled "The Cost of Developing a New Drug," which begins with the subheading "Innovative Drugs," seeming to suggest that drugs produced by the industry are in fact innovative. Id. at 1-2.

204. Id. at 35.

205. Id. This report was criticized for coming "close to reading as if it were written by the industry for its lobbying effort," including its agreement with the industry view of innovation. Donald W. Light, Misleading Congress About Drug Development: Research and Development in the Pharmaceutical Industry-A CBO Study, 32 J. HeALTH POL. POL'Y \& L. 895, 895 (2007). Interestingly, the formal rebuttal completely ignored the criticism of innovation. Joseph A. DiMasi et al., Commentary, Misleading Congress about Drug Development: Reply, 33 J. Health Pol. Pol'y \& L. 319 (2008). This is consistent with the fact that confirmation bias may lead to ignoring information consistent with a schema.

206. The report also noted that lower NME productivity is not of concern if those NMEs are very important, relying on an article authored by someone known to be sympathetic to the interests of drug companies and who likely holds the innovation schema. CBO STUDY, supra note 66, at 37 (citing Henry G. Grabowski \& Y. Richard Wang, The Quantity and Quality of Worldwide New Drug Introductions, 1982-2003, 25 HEALTH AFF. 452 (2006)). 
Those who hold the innovation schema and reject use of NME can rely on a few articles that support that schema, written by those who likely support the schema and display their own confirmation bias. For example, Management Professor Iain Cockburn shows confirmation bias in rejecting use of NME output ${ }^{207}$ and instead shifting the focus to "quality" output to conclude that industry quality output could be rising because new products can obtain premium prices in the face of competition from existing drugs and generate substantial sales. ${ }^{208}$ This shift to a focus on supposed quality is similar to PhRMA's earlier claim that drug "value," rather than NME, is relevant. In both cases, this could easily reflect confirmation bias in ignoring unfavorable information, such as low levels of NME, in favor of supposedly helpful information, even if the helpful information may not be entirely supported. As explained later, the pharmaceutical market is an imperfect market, such that the claim that drugs are valuable because they can command premium prices is not a strong one.

In addition to objecting to the use of NME to evaluate innovation, there may be a tendency to suggest a host of other factors responsible for low drug output that similarly reflects confirmation bias in selectively focusing on information that seems to support the innovation schema. For example, an article financially supported by the industry not only reiterates an objection to the use of NME as a metric but asserts that the static number of NME is a function of a focus on riskier targets with low probability of success. ${ }^{209}$ Although it is possible that scientific factors play a role, an emphasis on something other than output is still consistent with confirmation bias.

On the other hand, articles that conclude the industry is not innovative that do not use the disputed NME methodology are ignored, consistent with confirmation bias theory that inconsistent information may be selectively ignored. For example, a study that concluded that the industry is

207. He does, however, concede that NME is a "popular way to measure innovative output.” Iain M. Cockburn, Is the Pharmaceutical Industry in a Productivity Crisis?, in 7 INNOVATION POLICY AND THE ECONOMY 5 (Jaffe et al. eds., 2006).

208. Id. at 3, 7 .

209. Fabio Pammolli et al., supra note 31, at 428 (arguing that NME counts are an “imperfect measure” of outcome); see also K.I. Kaitin \& J.A. DiMasi, Pharmaceutical Innovation in the 21st Century: New Drug Approvals in the First Decade, 2000-2009, 89 Clinical Pharmacology \& Therapeutics 183, 184 (2011) (“[D]rug developers have been buffeted by a host of formidable threats, including patent expirations for a large number of top-selling products, growing reimbursement pressures, increasing regulatory demands, intense market competition, loss of public confidence, and the relentless rise in research and development (R\&D) costs.”). 
not that innovative, without using FDA criteria and instead relying on patent citation counts, is not rebutted by PhRMA or by any scientists associated with the Tufts Center. ${ }^{210}$ Similarly, studies that have found that only about a third of new drugs are therapeutically valuable-consistent with the 2002 NICHM report-are also seemingly ignored. ${ }^{211}$

Interestingly, although some strongly contest the use of the FDA classifications, this appears to be the case only if the overall conclusion is that the industry is not innovative. One recent article, published by authors associated with the same Tufts Center that propagated the cost schema, claimed that the industry is actually at a high point of innovation and embraced the use of NME, as well as priority versus standard classifications, when it was able to selectively use these classifications to achieve a conclusion consistent with the innovation schema. ${ }^{212}$ That article claimed that the percentage of priority products - the ones the FDA considers to have some clinical benefit-is at a thirty-year high. ${ }^{213}$ However, to achieve this result, the study eliminated most drugs that would be incremental innovations and thus likely categorized as standard review drugs. ${ }^{214}$ This skewed methodology is consistent with confirmation

210. Aaron S. Kesselheim \& Jerry Avorn, Using Patent Data To Assess the Value of Pharmaceutical Innovation, 37 J.L. MED. \& ETHICS 176, 176, 182 (2009) (finding that the industry is not innovative based on patent citation counts).

211. E.g., Domenico Motola et al., An Update on the First Decade of the European Centralized Procedure: How Many Innovative Drugs?, 62 BRIT. J. ClinICAL PHARMACOLOGY 610, 610 (2006) (concluding that only a third of drugs were important therapeutic innovations based on an algorithm); Johan C.F. van Luijn et al., Superior Efficacy of New Medicines?, 66 Eur. J. Clinical Pharmacology 445, 445 (2010) (finding only ten percent of new drugs introduced between 1999 and 2005 to be clinically superior over existing medicine); Agnes I. Vitry et al., Assessment of the Therapeutic Value of New Medicines Marketed in Australia, J. PHARMACEUTICAL POL'y \& Prac. 4-5 (June 13, 2013), http://www.joppp.org/ content/pdf/2052-3211-6-2.pdf (assessing the therapeutic value of medicines in Australia and finding similar results as the Motola study). There are no known published rebuttals or criticisms to these studies, consistent with confirmation bias theory that suggests inconsistent evidence may be completely ignored.

212. Kaitin \& DiMasi, supra note 209, at 184.

213. Id. at 183.

214. The study excluded salts, esters, new formulations and new indications. Id. at 184. Although some of these could be rated priority drugs, these drugs are generally considered less innovative. See infra notes 329-30 and accompanying text (discussing India's patent law that does not permit protection of such similar drugs without proof of increased clinical significance). 
bias theory in terms of selective use of NME when it can be manipulated to support a schema. ${ }^{215}$

\section{Strong Patent Schema}

The final schema emphasizes that strong patent protection ${ }^{216}$ of drugs is essential in promoting pharmaceutical innovation and that all innovation is valuable, such that there is no need to consider whether the innovation is more incremental or radical. ${ }^{217}$ In fact, not only is strong protection embraced but also stronger protection is advocated without recognizing that this is likely to result in more incremental innovation. In addition, to the extent that those with this schema sometimes acknowledge incremental innovation, supposed benefits are trumpeted while ignoring social costs of duplicative innovation. For example, in a statement to the Federal Trade Commission (FTC), a representative of PhRMA stated that "[s]trong intellectual property protection is essential" to innovation of the industry, and while broadly claiming credit for "cost-effective treatments that continue to increase life expectancy," 118 the statement claimed that incremental innovation is not only a normal part of pharmaceutical innovation ${ }^{219}$ but also a method for creating competition among brand name companies, resulting in increased therapeutic options

215. Another article by an industry scientist also relied on NME, but to arrive at a conclusion that industry output is constant, rather than of concern, claiming that any problems with the disconnect between increasing expenditures and static output is a reflection of limitations of the existing model of research and development. Munos, supra note 31, at 959.

216. Although patents are indeed the primary focus of this schema, it also extends to related protections of drugs, such as data exclusivity, which is a different form of protection provided through regulatory laws, but still considered part of intellectual property protection.

217. This subpart addresses this schema without addressing the question of whether patents are in fact the optimal method of promoting pharmaceutical innovation because it is clear that patents on drugs will not be eliminated due to international obligations. However, for a discussion of other mechanisms, see AidAN Hollis, INCENTIVE MECHANISMS FOR INNOVATION 2 (2007), available at http://ccg.merit.unu.edu/prizefund/resources/Background \%20reading/Hollis.Aidan.2007_Incentive.Mechanisms.pdf; Amy Kapczynski et al., supra note 7, at 1045; see also Agreement on Trade-Related Aspects of Intellectual Property Rights art. 27, Dec. 15, 1993, 33 I.L.M. 93-94 (1994) (requiring patents on all inventions).

218. Gregory J. Glover, PhRMA, Statement Before the Federal Trade Commission and the Department of Justice Antitrust Division: Competition in the Pharmaceutical Marketplace 2 (Mar. 19, 2002); see also Gerald J. Mossinghoff \& Thomas Bombelles, The Importance of Intellectual Property Protection to the American Research-Intensive Pharmaceutical Industry, Colum. J. World Bus., Spring 1996, at 38, 43 ("[W]ithout adequate and effective patent protection, the research-based pharmaceutical industry would not exist.”).

219. Glover, supra note 218, at 3. 
to the benefit of consumers. ${ }^{220}$ Although this statement may arguably reflect self-interest bias of the industry, it does not mean that this is not a schema. Moreover, as this subpart will demonstrate, this schema is also held by academics and policymakers and is sustained through confirmation bias. For example, a recent article by a group of public policy scholars that argues for stronger protection of drugs takes as a given that all new drugs are equal in value in calculating an estimate of how much money is required for development of each drug. ${ }^{221}$ However, as discussed earlier, not all drugs have the same development time, and the assumption that the time is equivalent may reflect confirmation bias for the schema that strong protection is necessary to promote any and all innovation.

This subpart provides evidence of confirmation bias for the strong patent schema in three parts. The subpart first emphasizes confirmation bias for strong patents that promote any type of innovation at the domestic level. Then, the subpart provides examples of confirmation bias for the strong patent schema with respect to claims about international or comparative levels of innovation. Finally, this subpart concludes with examples of confirmation bias in emphasizing supposed benefits of incremental innovation that are overstated while ignoring the real social cost of duplicative innovation.

\section{The Assumption That Strong Patents Are Desirable To Promote Any Drugs}

Academics have endorsed the strong patent schema with statements supporting the value of strong patents for innovation without consideration of the type of innovation that is produced. For example, leading patent scholars Professors Burk and Lemley affirmatively stated that "[s]trong patent rights are necessary" to provide an incentive for companies to invest time and money to develop drugs, as if this assertion were so obvious to justify no supporting citations. ${ }^{222}$ Although they note in a footnote that companies may obtain multiple patents on the same invention, which suggests lack of innovation, they dismiss this as "a failure of the

220. Id. at 9 .

221. Goldman et al., supra note 6, at 85 .

222. Burk \& Lemley, supra note 6, at 1617. 
system, not its normal function."223 However, the quick dismissal of what is an acknowledged industry practice could be consistent with confirmation bias. In particular, consistent with confirmation bias theory that inconsistent information is ignored, the phenomenon of incremental patenting could be labeled as not relevant because that is not the goal of the patent system, even though the result is equally important as the goal.

Two articles by Professor Benjamin Roin provide another example of how the argument for strong patent rights is often made without considering what type of innovation will be promoted. In 2009, he argued that existing patent standards "suppress" innovation and thus more protection was necessary to promote innovation. ${ }^{224}$ In making this argument, he seemed to assume that all new drugs are valuable. ${ }^{225}$ Although Roin at one point acknowledged that some drugs offer "little or no therapeutic advantage over existing drugs," he quickly dismissed that by claiming that new drugs on the whole yield substantial net benefits. ${ }^{226}$ More recently, in an article focusing on tailoring patent terms to the time necessary to develop a marketable invention, he suggests that certain types of drugs, such as early stage and preventative treatments for cancer and Alzheimer's are not developed because the patent term is inadequate. ${ }^{227}$ Although Roin's candidly admits in his recent article that it is unclear whether more protection would promote more drug development, he says that "it is very likely that it would have this effect."228 This assumption, without strong evidence seems consistent with confirmation bias in that evidence is not scrutinized when it is consistent with an existing schema.

\footnotetext{
223. Id. at 1617 n.135.

224. Roin, supra note 6, at 557.

225. Id. at 508 .

226. Id. at 514-15.

227. Roin, supra note 161 , at $678,752$.

228. Roin, supra note 161, at 752. Interestingly, an earlier draft posted on the Social Science Research Network (SSRN) seems to suggest greater support for the strong patent schema than the published article. In particular, the draft specifically stated that the difference in the cost of developing versus copying a drug supported the conclusion that "strong " protection is essential for drug development, citing the author's own prior work. Benjamin Roin, The Case For Tailoring Patent Awards Based on the Time-to-Market Inventions (Nov. 4, 2013) (draft manuscript at 28, nn.138), available at http://papers.ssrn.com/sol3/papers.cfm? abstract_id=2235354. This statement may reflect confirmation bias in suggesting that the alternative is "weak (or no) protection," suggesting that weak and zero protections are equivalent. Id. In the published article, Roin instead states that "[m]ore so than in any other industry, the revenues that pharmaceutical companies earn from their patents appear to have a significant effect on their willingness to invest in R\&D." Roin, supra note 161, at 752.
} 
Another example of confirmation bias for the strong patent schema is a focus on a false choice. For example, Professors Burk and Lemley argued that pharmaceuticals deserve stronger protection and based this on the assumption that "innovation would drop substantially in the pharmaceutical industry in the absence of effective patent protection," ${ }^{229}$ citing a study that examined the difference between patent protection and no patent protection at all. ${ }^{230}$ Their general argument for stronger protection reflects the strong patent schema, and the reliance on a study that compares patent protection versus none at all may reflect confirmation bias in that the focus of the discussion is shifted to a nonissue that better supports the strong patent schema. ${ }^{231}$ By emphasizing the dramatic impact of no patent protection-even if wholly irrelevant - the strong patent schema may seem to be a logical choice. Indeed, the fact that there is an economics study that exists to calculate the economic cost to society of patent protection versus no patent protection when this is not a legal or political reality reflects confirmation bias for the strong patent schema. After all, there is no empirical need for such a study when no one is suggestingor could legally suggest — eliminating patents on drugs, and most suggestions are only to strengthen protection.

Similar to academics, policymakers may hold the strong patent schema, or at least be susceptible of reinforcing the schema. This may in part be due to the fact that the industry frequently presents its positions to those that create policy reports. For example, in a 2003 report by the FTC, the summary section on innovation noted that "strong patent protection is essential to innovation," without qualifying that the innovation is incremental, even though the section documents that most FDA-approved drugs are incremental innovations. ${ }^{232}$ In addition, although the report

229. Burk \& Lemley, supra note 6, at 1617 (emphasis added); see also Daniel J. Gervais, The Internationalization of Intellectual Property: New Challenges from the Very Old and the Very New, 12 Fordham Intell. Prop. Media \& Ent. L.J. 929, 940 n.63 (2002) ("[W]ithout strong patent protection, there would be no research-based pharmaceutical industry — and few new drugs would be developed .....”).

230. James W. Hughes et al., "Napsterizing” Pharmaceuticals: Access, Innovation, and Consumer Welfare 3 (Nat'l Bureau of Econ. Research, Working Paper No. 9229, 2002).

231. There are other possible explanations. For example, it may be that there are inadequate studies comparing strong versus moderate patent protection or that such studies are hard to create.

232. Fed. Trade Comm'N, supra note 43, ch. 3, at 1. 
aims to present two sides to the benefits or detriments of incremental drugs, it seems to ultimately side with the strong patent schema in stating as fact that a modification of patent laws that permitted generic drugs to more easily achieve regulatory approval "forced brand-name firms to come up with new products to replenish their revenue streams," citing PhRMA's testimony to the FTC. ${ }^{233}$ Although a few pages earlier in the report, the FTC acknowledged that some generic companies were skeptical of innovation, the report seems to suggest that it is reasonable for companies to focus on incremental innovation. ${ }^{234}$

Confirmation bias supporting the strong patent schema is also reflected in selective reliance and consideration of economics literature. Academics who hold this schema often cite a few economics articles to support the claim that strong, or stronger patents are necessary for pharmaceutical innovation. ${ }^{235}$ One frequently cited study by Edwin Mansfield finds that the pharmaceutical industry is one of the rare fields where the industry relies on patents and suggests that without any patents, there would be less pharmaceutical innovation. ${ }^{236}$ However, this study is simply about whether firms value patents and does not attempt to consider whether more protection would result in more innovation or what type of innovation, let alone whether there might be social costs to doing so. Other economists have found that stronger patent protection does in fact result

233. Id. at 11 (citing Glover, supra note 218, at 7).

234. Id. at 8, 11 .

235. E.g., Craig Allen Nard, Toward a Cautious Approach to Obeisance: The Role of Scholarship in Federal Circuit Patent Law Jurisprudence, 39 Hous. L. Rev. 667, 673 (2002) (citing Edwin Mansfield, supra note 29, at 180) (noting that it has been historically accepted that a stronger patent right will result in more innovation and that although this is not generally true, the study by Edwin Mansfield suggests that it may be true for pharmaceuticals); Lisa Larrimore Ouellette, Do Patents Disclose Useful Information?, 25 HARV. J.L. \& TECH. 545, 555 n.57 (2011) (citing Mansfield, supra note 29, at 174); Arti K. Rai \& Rebecca S. Eisenberg, Bayh-Dole Reform and the Progress of Biomedicine, 66 LAW \& Contemp. Probs. 289, 289 n.1 (2003) (citing Cohen et al., supra note 29, at 2); see also F. Scott Kieff, Property Rights and Property Rules for Commercializing Inventions, 85 MinN. L. REV. 697, 699 n.4 (2001) (citing Mansfield, supra note 29, for the proposition that there is a link between patents and innovation).

236. Mansfield, supra note 29, at 175 Table 1. In addition, there are studies that note that patent protection is correlated with more research spending in the pharmaceutical industry, although not necessarily for other areas. E.g., Kendall W. Artz et al., A Longitudinal Study of the Impact of R\&D, Patents, and Product Innovation on Firm Performance, 27 J. PRODUCT InNOVATION MGmT. 725, 725-26 (2010). However, more spending does not necessarily result in more innovation. 
in more patenting, but not necessarily an increase in innovation. ${ }^{237}$ In addition, some note that above a certain level of patent protection, innovation may in fact be reduced. ${ }^{238}$ These economic studies with important caveats are selectively but predictably ignored by those who hold the strong patent schema because they are not helpful to maintaining that schema.

Consistent with confirmation bias, those who adhere to the strong patent schema may selectively ignore statements in the economics literature that are inconsistent with the schema. For example, although scholars cite an article by Richard Levin et al., entitled Appropriating the Returns from Industrial Research and Development, for the argument that patents are necessary for pharmaceuticals, ${ }^{239}$ most fail to note that this article does not endorse strong patents without limits. ${ }^{240}$ In one key passage, the article states that

\footnotetext{
"it should not be taken for granted that ... better protection necessarily leads to more innovation .... . Better protection may yield more innovation at the cost of incrementally increasing resources devoted to producing the innovation: the larger prize may merely encourage duplicative private effort to capture it."241
}

Indeed, this appears to reflect what happens in the pharmaceutical industry where multiple firms compete to address the same problem, resulting in duplicative research. ${ }^{242}$ Similarly, another economics article that explicitly takes on what it describes as "[t]oday's conventional wisdom ... that strong and broad patent rights are conducive to economic progress" is also not

237. E.g., Bronwyn H. Hall, Patents and Patent Policy, 23 Oxford Rev. Econ. Pol’y 568, 574 (2007).

238. E.g., Yi Qian, Do National Patent Laws Stimulate Domestic Innovation in a Global Patenting Environment? A Cross-Country Analysis of Pharmaceutical Patent Protection, 89 REV. ECON. \& STAT. 436, 436 (2007).

239. Levin et al., supra note 29.

240. E.g., Molly A. Holman \& Stephen R. Munzer, Intellectual Property Rights in Genes and Gene Fragments: A Registration Solution for Expressed Sequence Tags, 85 IowA L. Rev. 735, 831 n.259 (2000); A. Samuel Oddi, Un-Unified Economic Theories of Patents-The Not-Quite-Holy Grail, 71 Notre Dame L. ReV. 267, 305 n.244 (1996); Arti K. Rai, Engaging Facts and Policy: A Multi-Institutional Approach to Patent System Reform, 103 Colum L. REV. 1035, 1073 n.167 (2003); Rai \& Eisenberg, supra note 235, at 289 n.1.

241. Levin et al., supra note 29, at 787 (emphasis added).

242. See Roin, supra note 6, at 513. 
cited by those who favor strong patent rights for pharmaceuticals. ${ }^{243}$ The article states that "[i]n view of the fact that patents entail social and economic costs, it would seem wise not to push for stronger patent protection, unless the evidence indicated that the economic benefits were significant."244 Although this article is admittedly not focused on pharmaceuticals, its more balanced consideration of the costs of patent protection, which are generally ignored in discussions of strengthening patent protection for drugs, is still consistent with confirmation bias. ${ }^{245}$

\section{Supporting the Schema Through Selective Consideration of International Evidence}

Those who adhere to the strong patent schema argue that stronger patent protection resulted in more domestic innovation in certain countries; however, the evidence is in fact more ambiguous. ${ }^{246}$ An article by economist Henry Grabowski provides a good example. He claims that in both Japan and Canada, stronger patent protection resulted in more pharmaceutical research. ${ }^{247}$ However, there are studies that provide a

243. Roberto Mazzoleni \& Richard R. Nelson, The Benefits and Costs of Strong Patent Protection: A Contribution to the Current Debate, 27 RES. POL'Y 273, 273 (1998).

244. Id. at 274.

245. See id. at 279-81. Of course, I could be influenced by my own confirmation bias in citing this article, which focuses more on the problem that increased patents have on cumulative innovation, which is largely inapplicable to pharmaceuticals. Nonetheless, as discussed in the next subpart, even if cumulative innovation does not apply to pharmaceuticals, there are other negative social implications that are generally minimized or discounted entirely by those who hold the strong patent schema.

246. This discussion focuses primarily on countries that were at a level of economic development where patents might potentially impact innovation. However, there is also confirmation bias by those who fail to acknowledge studies showing that patent protection is irrelevant for countries that are not at a state of development to innovate. See, e.g., Frederick M. Abbott, The WTO Medicines Decision: World Pharmaceutical Trade and the Protection of Public Health, 99 AM. J. INT'L L. 317, 325 (2005) (“Stronger patent protection in developing countries will increase total research and development.”). Studies actually show that stronger patents do not induce more domestic innovation - they may simply result in increased patents by foreigners. Josh Lerner, Patent Protection and Innovation Over 150 Years 19-20 (Nat'l Bureau of Econ. Research, Working Paper No. 8977, 2002); see also Shamnad Basheer \& Annalisa Primi, The WIPO Development Agenda: Factoring in the "Technologically Proficient" Developing Countries, in IMPLEMENTING WIPO's DEVELOPMENT AGENDA 100-01 (Jeremy De Beer ed., 2009) (noting that patent protection is ineffective in promoting innovation unless a country is at a certain level of economic development).

247. Henry Grabowski, Patents, Innovation and Access to New Pharmaceuticals, 5 J. INT'L ECON. L. 849, 854-55 (2002). In both cases, full patent protection for drugs was provided and Canada also eliminated compulsory licensing. Id. 
contrary conclusion. ${ }^{248}$ Moreover, although Canada did increase research after changes in its patent laws in 1987, the industry actually promised to spend more on pharmaceutical development in Canada. ${ }^{249}$

Similarly, Brian Ferguson, a professor of economics, contests the work of economists Michelle Boldrin and David Levine that suggests that many countries that did not provide patents on pharmaceuticals nonetheless had pharmaceutical activity. ${ }^{250}$ Ferguson exhibits confirmation bias in contesting their methodology, claiming that Boldrin and Levine fail to address that the pharmaceutical industry advanced from one of secrecy to protect intellectual property into one where reverse engineering was possible, such that patents were needed. ${ }^{251}$ However, Ferguson's critique does not reconcile with the historical fact that not all countries adopted patent protection of drugs at the same time; scientific advancement is insufficient to explain why countries like Italy did not adopt patents on drugs until 1978 while other countries did so earlier. ${ }^{252}$

Admittedly, stronger domestic patent protection may not have much of an impact on an individual country's overall research given that most companies today are multinational. ${ }^{253}$ Nonetheless, even if that is the case, the above discussion still shows confirmation bias in that this issue

248. E.g., Lee Branstetter, Do Stronger Patents Induce More Local Innovation?, 7 J. INT’L. ECON. L. 359, 361-63 (2004); Mariko Sakakibara \& Lee G. Branstetter, Do Stronger Patents Induce More Innovation? Evidence from the 1988 Japanese Patent Law Reforms, 32 RAND J. ECON. 77, 78, 88, 98 (2001).

249. Although Grabowski acknowledges in a footnote that the industry promised to locate research in Canada proportional to Canada's share of world sales, there is no cite for this fact. Instead, he cites articles about the different issue of Canadian price regulation that appeared after stronger patent protection was introduced. See Grabowski, supra note 247, at 855 n.18 (citing PAtricia M. DANZON, Pharmaceutical Price Regulation: NAtional Policies Versus Global Interests (1997); Sheila R. Shulman, The Canadian Patented Medicine Review Board: New Rules and New Status, PharmacoEconomics, Nov. 1994, at 71).

250. See Brian Ferguson, The Role of Patents in the Pharmaceutical Sector: A Primer, in Pills Patents \& Profits II 12 (2012).

251. Id.

252. Michelle Boldrin \& David K. Levine, Against Intellectual Monopoly 244-45 (2008).

253. This point is well made by Lisa Ouellette, who argues that studies of a single country's patent laws will understate the impact of the change. Lisa Larrimore Ouellette, Patent Experimentalism, 101 VA. L. REV. (forthcoming 2015) (manuscript at 7-16) (on file with SSRN), available at http://papers.ssrn.com/sol3/papers.cfm?abstract_id=2294774. 
is ignored and there is selective citation of studies or statements without any relevant cites. In addition, consistent with the studies on confirmation bias, when there is ambiguity-in this case, studies with differing conclusions - scholars may find it easier to cite articles that support their desired position. ${ }^{254}$

The pharmaceutical industry can be expected to be even less vigorous in making such claims and being prone to confirmation bias. For example, although studies indicate that Italy did not increase its level of innovation after patent laws were strengthened, ${ }^{255}$ PhRMA claimed that it had a four-fold increase in R\&D. ${ }^{256}$ Not surprisingly, PhRMA did not cite the contrary studies and only relied on its own industry profile. ${ }^{257}$ Similarly, the United States Trade Representatives Office, which often echoes the interests of the industry, also seems to display confirmation bias in how it considers comparative data; it has claimed that Jordan's domestic research was stimulated after entering into a free trade agreement with the United States that required stronger patent protection. ${ }^{258}$ However, although Jordan had improved economic growth, there was no increase in pharmaceutical investment or patent filings by local manufacturers. ${ }^{259}$

\section{Supporting the Schema Through Selective Reliance on Supposed Value of Incremental Innovation}

The last important aspect of the strong patent schema is an emphasis on the fact that there are no net negative social implications to stronger patents. To those that subscribe to the strong patent schema, confirmation bias may result in overly defending incremental innovation without

254. See supra Part II.B.2.

255. E.g., Pablo M. Challu, Effects of the Monopolistic Patenting of Medicine in Italy Since 1978, 10 InT'L J. TeCH. MgMT. 237, 245-46 (1995); F.M. Scherer \& Sandy Weisburst, Economic Effects of Strengthening Pharmaceutical Patent Protection in Italy, 26 INT'L REV. INDUS. PROP. \& COPYRIGHT L. 1009, 1024 (1995).

256. PhrMA, Delivering on the Promise, supra note 62, at 10 (2002) (citing PhRMA, 2001 Industry Profile 105); see also Harvey E. Bale, Jr., Patent Protection and Pharmaceutical Innovation, 29 NYU J. INT'L L. \& PoL. 95, 105 (1996-1997) (claiming that predictions of disastrous results for countries that adopted stronger patent protection were incorrect, without any citations).

257. PhRMA, supra note 62, at 10 (citing PhRMA, 2001 Industry Profile 105).

258. Marilyn Chase \& Sarah Lueck, In New Trade Pacts, U.S. Seeks To Limit Reach of Generic Drugs, WALL ST. J., July 6, 2004, at A1.

259. See Hamed El-Said \& Mohammed El-Said, TRIPS-Plus Implications for Access to Medicines in Developing Countries: Lessons from Jordan-United States Free Trade Agreement, 10 J. WORLD InTELL. PROP. 438, 453-57 (2007). 
acknowledging social costs. ${ }^{260}$ Social costs include the cost of duplicative research, as well as the cost of higher priced products of minimal therapeutic value. ${ }^{261}$ These costs are not necessarily unique to drugs, but overlooking these costs while simultaneously emphasizing benefits when innovation is more modest is consistent with confirmation bias. ${ }^{262}$

There are a number of defenses of incremental innovation that show confirmation bias in attempting to focus on dubious benefits of such innovation while simultaneously ignoring clear social costs. The first one is that what seems incremental is actually simultaneous development; this fundamentally highlights duplicative research without acknowledging that such duplication is an undesirable social cost. ${ }^{263}$ Second, incremental innovation is defended as typical of all industries and also not a problem because it is permissible under the patent system. ${ }^{264}$ However, even if legal and typical, raising these facts reflects confirmation bias in selectively ignoring the social costs of providing patent protection on less important innovation. Third, incremental innovation is defended by those that subscribe to the strong patent schema by citing some supposed social benefits that upon closer inspection are debatable. ${ }^{265}$

One example of a defense of incremental innovation that fails to acknowledge social costs of duplicative research is an article by economists DiMasi and Paquette, who are associated with the same Tufts Center that propagated the cost schema. ${ }^{266}$ The fundamental thesis of this article is that what appears to be "follow-on" innovation ${ }^{267}$ is in fact simultaneously

260. See, e.g., Burk \& Lemley, supra note 6, at 1616-17; Hemphill, supra note 30, at 1563-64. Critics sometimes refer to incremental innovation as me too or follow on drugs. See Joseph A. DiMasi \& Cherie Paquette, The Economics of Follow-on Drug Research and Development, PharmacoEconOMICS, Oct. 2004, at 1, 2. Not surprisingly, the industry disputes the me too term as unduly critical and inaccurate. Id.

261. See Michael A. Sartori, An Economic Incentives Analysis of the Jury’s Role in Patent Litigation, 79 J. PAT. \& TRADEMARK OfF. SOC’y 331, 337-38, 346 (1997).

262. See supra Part II.B.2.a.

263. See Sartori, supra note 261, at 346-47.

264. See Burk \& Lemley, supra note 6, at 1619-20.

265. See Roin, supra note 6, at 513-14.

266. DiMasi \& Paquette, supra note 260.

267. The term follow-on is used in contrast to a drug that is the first in a class. Id. at 2. For example, the drug sold as Prozac was the first in a class of antidepressants commonly referred to as selective serotonin reuptake inhibitors (SSRI) that all operate in the same way, albeit with different chemical compounds, and the drug Zoloft was a follow-on SSRI. Id. at 6 . Some critics refer to these as me too drugs. 
developed, such that the label follow-on is misleading. ${ }^{268}$ However, the data they use to support this conclusion is limited to NMEs and excludes other incremental innovation, such as reformulations - slight modificationsof existing compounds, or sequential patents on multiple aspects of a drug. ${ }^{269}$ The focus on solely NMEs may reflect confirmation bias in focusing on a narrow part of incremental innovation that may be more easily defended. In addition, although other economists have recognized that there are social costs to strong patent rights that result in duplicative research, this article seems to applaud such duplicative research simply because the duplication occurred simultaneously. ${ }^{270}$ However, even if firms did not copy each other in developing similar research, that does not negate the fact that there is still duplicative research, which is a social cost.

A common refrain by those that support incremental innovation and strong patent protection is that this is typical innovation, such that it should be supported just as much as breakthrough innovation so long as the invention is patentable. Incremental innovation is defended by the industry, ${ }^{271}$ as well as by some scholars, ${ }^{272}$ and policymakers. ${ }^{273}$ Those

268. See id. at 2; see also Joseph A. DiMasi \& Laura B. Faden, Competitiveness in Follow-on Drug R\&D: A Race or Imitation?, 10 NATURE REV. DRUG DisCOVERY 23, 2526 (2011) (“[N]ew drug development is better characterized as a race to market among drugs in a new theraputic class, rather than a lower risk imitation of a proven breakthrough.”). In addition, even if this is true in part, there are still follow-on drugs approved long after the initial drug that do not fit this phenomenon. E.g., Joshua J. Gagne \& Niteesh K. Choudhry, Commentary, How Many “Me-Too” Drugs Is Too Many?, 305 J. AM. MED. Ass’N 711, 711 (2011).

269. For example, patents can be obtained on not only the main active ingredient but methods of manufacture, intermediates, and packaging. See, e.g., JoHn R. THOMAS, Pharmaceutical Patent Law 39-42, 410 (2d ed. 2010); Aaron S. Kesselheim, Think Globally, Prescribe Locally: How Rational Pharmaceutical Policy in the U.S. Can Improve Global Access to Essential Medicines, 34 AM. J.L. \& MED. 125, 136 (2008) (noting patents on peripheral aspects of drugs can lead to "extensions in market exclusivity"). Other terms include stockpiling, lawyering, or line extensions. See, e.g., JoHN R. THOMAS, Cong, RESEARCH SERV., R40917, PATENT "EVERgREENING": IsSUES IN INNOVATION AND COMPETITION 1 (2009) [hereinafter THOMAS, PATENT EVERGREENING].

270. This study could be alternatively explained as responding to the term me too that is often used by critics of follow-on innovation that seems to suggest copying. However, confirmation bias still seems to be a sound explanation for justifying an academic paper to prove simultaneous development.

271. E.g., GlaxoSmithKline Government Affairs, Public Policy and Patient Advocacy, Global Public Policy Issues: Evergreening, GlaxoSmithKLine (Aug. 2011), http://www. gsk.com/content/dam/gsk/globals/documents/pdf/GSK-and-evergreening.pdf; see also Scott Parker \& Kevin Mooney, Is "Evergreening” a Cause for Concern? A Legal Perspective, 13 J. Com. Biotechnology 235 (2007) (expressing the view of attorneys for the industry); 
who hold the strong patent schema that endorses incremental innovation equally with breakthrough innovation emphasize that the patent standards are neutral, ${ }^{274}$ but selectively ignores evidence that many patents on incremental innovation have actually been later found invalid ${ }^{275}$ and the fact that the patent system as a whole is criticized as too lenient in granting patents. ${ }^{276}$

Confirmation bias is also seen in that supporters of the strong patent schema raise incomplete rebuttals to criticisms that the industry develops and promotes mostly incremental drugs whose expense is less justified than more innovative drugs. ${ }^{277}$ For example, they suggest that the patent system adequately recognizes different types of innovation with a narrower scope of rights for incremental innovations, such that patents

The Degree to Which Patenting, and in Particular Secondary Patenting, Protect Pharmaceutical Products During Their Lifecycle Is Often Misconstrued, Eur. FED'N PHARMACEUTICAL INDUSTRIES \& ASS'N (Nov. 28, 2012), http://www.efpia.eu/blog/ 9/71/The-degree-to-whichpatenting-and-in-particular-secondary-patenting-protect-pharmaceutical-products-during-their -lifecycle-is-ofsten-miscontrued [hereinafter EEPIA Study] (noting that “'incremental innovation' is in no way lesser innovation either legally or scientifically").

272. E.g., DiMasi \& Paquette, supra note 260, at 12; Albert Wertheimer et al., Too Many Drugs? The Clinical and Economic Value of Incremental Innovations, in INVESTING IN Health: The Social and ECONOMic BenEFits of Health CaRe InNOVATION 79 (Irina Farquhar et al. eds., 2001) (claiming that most technology is incremental, rather than breakthrough).

273. E.g., CBO Study, supra note 66, at 16; Thomas, Patent Evergreening, supra note 269, at 8 (citing Ivar M. Kaardal, The American Invetnros Protection Act, the Independent Inventor's Interest \& Consumer Choice in the Market, 84 J. PAT. \& TRADEMARK OFF. SOC'Y 503 (2002)) (claiming that “patent law experts" consider incremental innovation to be typical and potentially beneficial, although what is cited is not specific to the pharmaceutical industry). Notably, although the CBO Report largely defended incremental innovations, some aspects of the report nonetheless recognized that the cost of such innovation might not be justified. See CBO STUDY, supra note 66, at 2 (noting higher prices for reformulations "may not be commensurate with the additional value that those drugs provide").

274. E.g., ThOMAs, PATENT EVergreEning, supra note 269, at 8.

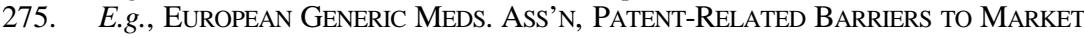
ENTRY FOR GENERIC MEDICINES IN THE EUROPEAN UNION 13 (Kristof Roox ed., 2008), available at http://www.egagenerics.com/images/publication/PDF/IP_Barriers_web.pdf.

276. See NAT'L ReSEARCH CounCIL, supra note 5, at 47-51; Carlos María Correa, Ownership of Knowledge-The Role of Patents in Pharmaceutical R\&D, 82 BULL. WORLD HEALTH ORG. 784, 784-85 (2004).

277. See PCAST REPORT, supra note 14, at 73; see also Aaron S. Kesselheim, supra note 7 , at 1855 (cautioning that careful tailoring is required to promote socially desirable innovation). 
on incremental innovations do not block competition from patents that have expired by selectively ignoring key information. ${ }^{278}$ Technically, a patent that has expired cannot block others from making what is patented; however, a key piece of missing information that is selectively left out of this defense is that companies generally have multiple patents that cover a drug and also obtain these sequentially, such that the expiration of one patent on a drug will not necessarily result in generic competition because it is still protected by other unexpired patents. ${ }^{279}$ Indeed, at times, the industry not only acknowledges this practice but, in fact, defends it as legitimate "lifecycle management" of a drug to continue to sustain profits. ${ }^{280}$

Finally, rather than address the negative repercussions of duplicative research, defenders of incremental innovation focus on alleged social benefits. ${ }^{281}$ Defenders claim that such innovation is valuable because of some data that shows some incremental innovations to be valuable, providing selective evidence of therapeutic benefits of incremental innovation and suggesting that such innovation is responsible for overall reductions in medical expenditures. ${ }^{282}$ In addition, defenders claim that innovation is valuable if consumers purchase it. ${ }^{283}$ Defenders also note that incremental innovation is valuable in providing increased competition that lowers costs. ${ }^{284}$ However, each of these defenses is problematic, as explained below.

Although adherents of the strong patent schema may suggest that independent evidence from the World Health Organization (WHO) supports the value of incremental innovation, a closer look at this evidence still shows confirmation bias. Those that endorse this schema have noted that half of the drugs on WHO's list of essential drugs were actually

278. E.g., GlaxoSmithKline Government Affairs, Public Policy and Patient Advocacy, supra note 271 (alleging that the medical community and paying authorities decide whether the patent premium for the newer version is justified).

279. See Amy Kapczynski et al., Polymorphs and Prodrugs and Salts (Oh My!): An Empirical Analysis of "Secondary" Pharmaceutical Patents, PLOS ONE (Dec. 5, 2012), http://www.plosone.org/article/info\%3Adoi\%2F10.1371\%2Fjournal.pone.0049470.

280. EFPIA Study, supra note 271. Indeed, there are books dedicated to this approach. E.g., Tony Ellery \& Neal Hansen, Pharmaceutical Lifecycle Management: MaKing the Most of Each and Every Brand (2012); Martin A. Voet, The Generic Challenge: Understanding Patents, FDA and Pharmaceutical Life-Cycle Management (3d ed. 2011).

281. E.g., Ernst Berndt et al., The Impact of Incremental Innovation in Biopharmaceuticals, PharmacoEconomics, Dec. 2006, at 69, 71.

282. See id.

283. See id.

284. Wertheimer et al., supra note 272, at 108. 
incremental, rather than the first in the class, ${ }^{285}$ relying on an academic article authored by scientists affiliated with the Tufts Center responsible for the cost schema discussed above. ${ }^{286}$ However, this claim selectively ignores the fact that this study does not include the most problematic type of incremental innovations-reformulations, which are very minor changes to existing compounds - and instead focuses solely on NMEs that are follow-on inventions.

Defenders of incremental innovation also attempt to establish the value of such innovation by citing specific examples that provide therapeutic benefit. ${ }^{287}$ However, there may still be confirmation bias in failing to provide any data on the percent of incremental innovations that provided therapeutic benefit. Without such data, the articles supporting incremental innovation can selectively choose examples that support the claim of therapeutic benefit - even if there are many more contrary examples. Such an approach is, of course, consistent with confirmation bias.

The claim that the cost of incremental drugs is worthwhile based on overall reductions in medical expenditures due to the utility of such drugs is also questionable. The economist Frank Lichtenberg has indeed authored a number of papers that make this claim, ${ }^{288}$ and his papers have been cited to support the claim that newer drugs result in increased longevity and reductions in medical expenditures - to the extent that drugs might substitute more expensive treatment such as surgery. ${ }^{289}$

285. E.g., id. at 82; Albert I. Wertheimer \& Thomas M. Santella, PharmaCeutical EVOlUtion: The AdVANTAgES OF INCREMENTAL INNOVATION IN DRUG DEVELOPMENT 9 (2009), available at http://cei.org/sites/default/files/Wertheimer\% 20and\%20Santella\%20-\%20Pharmaceutical\%20Evolution.pdf; Harvey E. Bale \& Boris Azais, Pharmaceutical Innovation Is Evolutionary and Incentive-Driven, 82 BULL. WORLD HEALTH ORG. 788, 788 (2004); Joshua Cohen \& Kenneth Kaitin, Follow-on Drugs and Indications: The Importance of Incremental Innovation to Medical Practice, 15 AM. J. THERAPEUTICS 89, 89-90 (2008).

286. J. Cohen et al., Role of Follow-on Drugs and Indications on the WHO Essential Drug List, 31 J. CliniCAL PhARMACY \& ThERAPEUTICS 585 (2006).

287. E.g., Wertheimer et al., supra note 272, at 86-98.

288. E.g., Frank R. Lichtenberg, Are the Benefits of Newer Drugs Worth Their Cost? Evidence From the 1996 MEPS, 20 HEALTH AFF. 241 (2001); Frank R. Lichtenberg, The Impact of New Drug Launches on Longevity (Nat'l Bureau of Econ. Research, Working Paper No. 9754, 2003).

289. See, e.g., DiMasi \& Paquette, supra note 260, at 12. 
However, his studies do not support the claim that this is due exclusively to incremental innovation because he considers both brand new and incremental drugs together. Moreover, others have contested his claims ${ }^{290}$ or failed to replicate his conclusion. ${ }^{291}$ In fact, a recent study that focused solely on incremental innovation found that in the long term, incremental innovations may cost consumers more money by impeding low cost, generic alternatives. ${ }^{292}$ This has obvious consequences because even if a newer patented version might have some therapeutic value, that value may be theoretical for patients who cannot afford the expense. ${ }^{293}$

In addition, the claim by defenders of the strong patent schema that the marketplace is the proper place to assess the value of a drug also selectively ignores information-consistent with cognitive biasconcerning the fact that the pharmaceutical market operates in a unique manner. ${ }^{294}$ For example, a doctor may give a patient a "free" sample of a new, patented version and also prescribe that new version without the patient ever realizing that there is a less expensive and equally effective generic drug available. ${ }^{295}$ Alternatively, a patient may demand a newer, patented version that is not a therapeutic improvement based on advertising. Accordingly, the marketplace is not necessarily deciding whether the higher costs associated with a marginally different improvement are

290. E.g., Paul Grootendorst et al., Life-Expectancy Gains from Pharmaceutical Drugs: A Critical Appraisal of the Literature, 9 ExPert Rev. PHARMACoECONOMics OuTCOMES REs. 353 passim (2009).

291. Yuting Zhang \& Stephen B. Soumerai, Do Newer Prescription Drugs Pay For Themselves? A Reassessment Of The Evidence, 26 HeALTH AfF. 880, 880 (2007).

292. Stephane Régnier, What Is the Value of “Me-too" Drugs?, 16 Health CARE MGMT. ScI. 300, 300 (2013).

293. E.g., Kesselhiem, supra note 7, at 1855; Economic Problems Facing Families, The Henry J. KAISER FAMILY Found. 3-4 (April 2008), http://kaiserfamilyfoundation. files.wordpress.com/2013/01/7773.pdf.

294. E.g., GlaxoSmithKline Government Affairs, Public Policy and Patient Advocacy, supra note 271.

295. Studies show that samples provided to doctors influence their prescribing choices and also that companies usually only provide samples of the most expensive drugs. E.g., Richard F. Adair \& Leah R. Holmgren, Do Drug Samples Influence Resident Prescribing Behavior? A Randomized Trial, 118 AM. J. MED. 881 (2005); Lisa D. Chew et al., A Physician Survey of the Effect of Drug Sample Availability on Physicians' Behavior, $15 \mathrm{~J}$. Gen. Internal Med. 478 (2000); K.E.M. Groves et al., Prescription Drug Samples Does this Marketing Strategy Counteract Policies for Quality Use of Medicines?, $28 \mathrm{~J}$. Clinical Pharmacy \& Therapeutics 259 (2003); Adriane Fugh-Berman \& Shahram Ahari, Following the Script: How Drug Reps Make Friends and Influence Doctors, PLoS MED. 621 (Apr. 24, 2007), http://www.ncbi.nlm.nih.gov/pmc/articles/PMC1876413/pdf/ pmed.0040150.pdf. 
"worthwhile expenditures"296 or that they necessarily reflect the superiority of a drug. ${ }^{297}$

The suggestion that all incremental innovation is socially valuable because incremental innovation results in increased competition and lower costs is also problematic. ${ }^{298}$ Competition among patented drugs may modestly reduce costs for consumers, but the price reduction is negligible compared to the more dramatic cost differential between patented and generic drugs. Even those that assert that multiple entrants reduce price do not necessarily cite strong price competition-one study asserted that thirteen of twenty drugs were priced at discounts of "at least 5\%." contrast, the differential between a patented drug and a generic drug is dramatic; when there are multiple entrants, the price drop may be far more than fifty percent. ${ }^{300}$

In conclusion, although there may be some value to incremental innovation in drug development, the problem is that such innovation is overly defended by those who hold the strong patent schema. This has serious consequences because those who hold this schema often argue for more protection of drugs, which would likely further exacerbate the current situation of producing mostly incremental drugs that have social costs that are often given undue consideration.

296. Thomas, Patent Evergreening, supra note 269, at 9.

297. In recent years, this problem may be somewhat lessened by the fact that insurers are becoming more resistant to covering all new medication. However, what is covered is subject to complex negotiations that still reflect an imperfect market.

298. There is a related claim that incremental innovation reduces costs because if no such innovation were permitted, drugs would be more expensive. E.g., COMM'N ON INTELLECTUAL PROP., INT'L CHAMBER OF COMMERCE, THE IMPORTANCE OF INCREMENTAL InNOVATION FOR DEVELOPMENT (2005). However, this reflects confirmation bias as a false choice because no one is suggesting barring all such innovation but simply questioning whether more such innovation is on balance socially desirable. Moreover, drug prices do not seem to be correlated with the cost of development, as reflected by the fact that marketed drugs may have sudden and substantial price increases. E.g., John Carreyrou, Inside Abbott's Tactics to Protect AIDS Drug, WALL ST. J., http://online.wsj.com/news/articles/SB11677 8411362865429 (last updated Jan. 3, 2007, 12:00 AM) (reporting a 400\% price increase); see also U.S. GOv'T ACCOUNTING OFFICE, GAO-10-201, BRAND-NAME PRESCRIPTION DRUG PRICING: LACK OF THERAPEUTICALLY EQUIVALENT DRUGS AND LIMITED COMPETITION MAY CONTRIBUTE TO EXTRAORDINARY PRICE INCREASE (2009) (discussing a Congressionally mandated study to investigate sudden price increases).

299. Wertheimer et al., supra note 272, at 108-09.

300. See supra notes 57-58 and accompanying text. 


\section{ADDRESSING THE POLICY IMPLICATIONS OF PHARMACEUTICAL INOVATION SCHEMAS}

This Part explores the implications of the schemas unveiled in Part III. Subpart A discusses how to address current schemas and the fact that repetition has unfortunately made them seem true. Subpart B argues that patent and related laws should be modified to better promote important drug innovation, including specific suggestions of how to do so. Subpart $\mathrm{C}$ suggests additional related schemas for future exploration.

\section{A. Addressing Existing Schemas}

This subpart suggests a three-step approach to addressing the existing schemas. The most fundamental first step is simply acknowledging that previously recognized beliefs are in fact schemas. Hopefully, Part III was effective in establishing this. However, even if it was, studies show that schemas are difficult to change. Accordingly, there is a need for additional work beyond a single article to address long-held schemas by academics, policymakers, and the general public. To that end, the next step is for scholars and policymakers that recognize the schemas to take steps to avoid unintentionally perpetuating them. This may seem modest, but it is nonetheless a critical step because anytime a schema is perpetuated, it is reinforced as true. The final step is for scholars and policymakers to directly challenge the schemas through further studies and broadly disseminate these to not only other scholars but also the popular press.

\section{Avoiding Unintentionally Propagating Problematic Schemas}

It is simple to say that problematic schemas should not be propagated but much more difficult to implement. Typical writing techniques for journalists and law professors usually suggest focusing on extremes. Indeed, in writing this Article, this Author struggled with how to explain the schemas without reinforcing them. This Author attempted to give schemas neutral abbreviations and also attempted to avoid repeating schemas in explanatory footnotes. However, it is unclear whether these efforts were successful. Moreover, even if successful in this Article, these approaches are not broadly applicable. Accordingly, this subpart will attempt to outline more broadly applicable suggestions.

There are specific things that scholars can do to avoid propagating the cost schema. For example, in articles that simply want to reference the cost of drug discovery, scholars can more ambiguously note that the cost is in the millions and provide a cite to the source of the industry cost 
schema without repeating it. ${ }^{301}$ Moreover, scholars can and should cite contrary studies and numbers to reinforce the fact that the actual cost is unclear.

Avoiding propagating the innovation schema will likely be more challenging. There seems to be a tendency to defer to industry beliefs because the industry is seen as largely responsible for producing new drugs on which society relies. ${ }^{302}$ However, the goal of any responsible pharmaceutical company is to maintain and improve its profits. ${ }^{303}$ This is consistent with how any business that is responsible to its shareholders

301. Scholars sometimes do this, at least in part, by not repeating the cost schema in the text. However, oftentimes the cost schema is still given undue representation if sources or parentheticals reinforce the schema.

302. See, e.g., Holman, supra note 6, at 648-49 ("[W]e should take seriously concerns voiced by those within the industry since we as a society rely upon this industry to generate continuing advances in medicine and healthcare.”). In addition, others rely on industry representations without expressly explaining why they should be considered, let alone considering that the industry representations might be unreliable. See, e.g., supra notes 160-61 and accompanying text (demonstrating reliance by scholars).

303. See Lawrence Perkins, Commentary, Pharmaceutical Companies Must Make Decisions Based on Profit, 175 W. J. MED. 422, 422 (2001). Although some may suggest that pharmaceutical companies have more of a social responsibility to those in need of drugs, this ignores the fact that companies are responsible not to the public in general but to their shareholders, who demand a focus on the bottom line. Id. at 423. Nonetheless, companies are still sometimes evaluated and companies attempt to address this as a public relations issue. See, e.g., ACCESS to MEDICINE FOUNDATION, THE ACCESS TO MEDICINE IndEX 2012 811(2012), available at http://www.accesstomedicineindex.org/sites/www. accesstomedicine index.org/files/2012-access-to-medicine-index-clickable.pdf; CONSUMERS INT’L, BRANDING the Cure: A Consumer Perspective on Corporate Social Responsibility, Drug Promotion and the Pharmaceutical Industry in Europe 5-7 (2006); Hans V. Hogerzeil, Big Pharma and Social Responsibility-The Access to Medicine Index, 369 NEW. ENG. J. MED. 896, 897-99 (2013); Paul Hunt \& Rajat Khosla, Are Drug Companies Living Up to Their Human Rights Responsibilities? The Perspective of the Former United Nations Special Rapporteur (2002-2008), PLoS MED. 1-2 (Sept. 28, 2010), http://www.ncbi.nlm.nih.gov/ pmc/articles/PMC2946950/pdf/pmed.1000330.pdf; Harvey Bale Jr., The Pharmaceutical Industry and Corporate Social Responsibility, CORPORATE RESPONSIBILITY, http://www. responsible practice.com/english/insight/ifpma (last visited May 20, 2014). In addition, universities, which often discover drugs that companies then develop, have also been evaluated on the extent to which they are addressing neglected health needs. See, e.g., Rachel Marusak Hermann, North American Universities Seen Failing To Promote Socially Responsible Licensing, INTELL. PROP. WATCH (Apr. 5, 2013, 7:22 PM), http://www.ip-watch.org/2013/04/05/ north-american-universities-found-failing-to-promote-socially-responsible-licensing; University Global Health Impact Report Card, U. AlLIED FOR EsSENTIAL MED., http://globalhealth grades.org (last visited May 20, 2014). 
operates. Although the industry is often criticized for valuing profits over patients, it nonetheless has financial and fiduciary obligations. ${ }^{304}$ Remembering the goal of companies is important to considering whether their claims relating to the schemas here should be viewed more skeptically.

The strong patent schema is the most difficult to avoid propagating, and yet the most important one to focus on. As discussed in Part III, there are serious social costs to providing more patent protection for drugs. ${ }^{305}$ Moreover, not only is stronger protection often trumpeted as a solution to inadequate drug development but also as a politically easy solution to follow because there is no clear "cost" in terms of taxpayer dollars. $^{306}$ However, as discussed, there are in fact social costs; society may be paying for more expensive drugs that are not of clinical significance. ${ }^{307}$ Scholars should more consistently recognize that although the industry relies on patent protection, providing more protection should not be a knee-jerk reaction and assumption if the most socially desirable innovation-NMEs that provide improved therapeutic value-is inadequate. $^{308}$ Although companies tend to suggest that any innovation is valuable, if all innovation is priced the same to consumers and they are unable to choose cheaper drugs of equal value, more protection will most likely promote more of the same type of mostly incremental innovation. ${ }^{309}$ Studies of countries that increased patent protection of drugs do not unambiguously support the claim that more protection leads

304. See Perkins, supra note 303, at 422-23.

305. See supra Part III.C.3.

306. For example, Congress would not need to request appropriation spending to extend the term of a patent.

307. See supra Part III.C.3.

308. There is of course some evidence that more protection can help promote innovation where none existed before, which has arguably happened with legislation for orphan drugs. See, e.g., Christopher-Paul Milne \& Joyce Tait, Evolution Along the Government-Governance Continuum: FDA's Orphan Products and Fast Track Programs as Exemplars of "What Works" for Innovation and Regulation, 64 FoOD \& DRUG L.J. 733, 740 (2009) (noting that before the Orphan Drug Act, only two or three drugs for orphan type diseases were approved per year, whereas an average of over eight such drugs per year were approved in the decade thereafter). But see Robert Rogoyski, The Orphan Drug Act and the Myth of the Exclusivity Incentive, Colum. ScI. \& TECH. L. Rev., Apr. 15, 2006, at 1, 2 (suggesting that the patent system, rather than the Orphan Drug Act, remains the most important motivator of drugs to address orphan diseases); David Duffield Rohde, The Orphan Drug Act: An Engine of Innovation? At What Cost?, 55 FoOD \& DRUG L.J. 125, 133 (2000) (suggesting that the costs of the Orphan Drug Act might not justify the productivity benefits). However, that is a situation of zero innovation, versus trying to optimize the type of innovation to focus more on the most innovative drugs.

309. See Rohde, supra note 308, at 138. 
to more innovation-despite claims to the contrary by the industry. ${ }^{310}$ In addition, there is a lack of data that shows that more protection will result in more innovation of the right type.

Policymakers and advocates can also take steps to avoid repetition of schemas. Information presented to the public is often presented in the format of "myth versus fact." 311 This may seem like a good strategy to clearly and succinctly rebut a schema. However, studies indicate that the targeted myth may actually be reinforced, rather than rebutted, because it is repeated. ${ }^{312}$ Problematically, this myth versus fact approach is often adopted by advocacy groups that attempt to rebut industry views. ${ }^{313}$ In addition, studies show that even when individuals are informed that a source may be biased, repetition is more influential. ${ }^{314}$ Accordingly, even though consumers are generally skeptical of the pharmaceutical industry, they are nonetheless susceptible to believing its claims because of repetition.

\section{Combating Current Schemas}

Each noted schema could be better challenged by not only additional studies that rebut the schema but also greater dissemination of studies that challenge those schemas. Notably, although there are some studies that challenge these schemas, they often receive a mere fraction of the attention that the schemas do. This subpart explains how each schema could be better challenged.

Scholars and policymakers can challenge the cost schema through contrary studies. This, admittedly, may be difficult because companies zealously guard their cost data, such that the only researchers with access to substantial data are those associated with the industry-supported Tufts Center that perpetuates the cost schema. However, the tide of public and political opinion seems to be shifting to require more public disclosure

310. See supra Part III.C.2.

311. E.g., Brook K. Baker, Debunking Pharma's Cant Against the Novartis Judgment: Myth and Fact, HeAlth Global ACCESs Project (Apr. 3, 2013), http://healthgap.org/blog/ 2013/4/3/debunking-pharmas-cant-against-the-novartis-judgment-myth-and-fact; Myth-Buster, TREATMENT ACTION CAMPAIGN, http://www.fixthepatentlaws.org/wp-content/uploads/2013/

10/TAC_MythBuster_Patent_Reform.pdf (last visited May 20, 2014).

312. See supra note 109 and accompanying text.

313. E.g., Baker, supra note 311.

314. See supra note 110 and accompanying text. 
of industry data, such that perhaps cost data may ultimately be accessible to robust research. ${ }^{315}$ In the meantime, scholars and policymakers can challenge the schema by better citing and propagating contrary numbers that have a sound empirical basis. Although some have criticized the industry numbers in the past, if the criticism is accompanied by overly critical views of the industry or not vigorously supported, those criticisms can be easily dismissed. ${ }^{316}$

315. For example, there is increasing pressure to require companies to provide all clinical data, including unpublished studies. E.g., Trial and Experimental Studies Transparency (TEST) Act of 2012, H.R. 6272, 112th Cong. (2012); Daniel Cressey, Drug-Company Data Vaults To Be Opened: European Agency Will Publish Firms' Clinical-Trial Results, 495 NATURE 419, 419-20 (2013), available at http://www.nature.com/polopoly_fs/ $1.12679 ! / \mathrm{menu} / \mathrm{main} / \mathrm{topColumns/topLeftColumn/pdf/495419a.pdf;} \mathrm{Jeffrey} \mathrm{M.} \mathrm{Drazen,}$ Transparency for Clinical Trials-The TEST Act, 367 NEW ENG. J. MED. 863, 863-64 (2012); Fiona Godlee, Clinical Trial Data for All Drugs in Current Use Must Be Made Available for Independent Scrutiny, BRIT. MED. J., Oct. 29, 2012, at 1, 2; Katie Thomas, Breaking the Seal on Drug Research, N.Y. TIMES, June 30, 2013, at BU1. Not surprisingly, the industry is resistant. E.g., PhRMA Statement on Clinical Trials and Bad Pharma, PHRMA (Feb. 4, 2013), http://phrma.org/media/releases/phrma-statement-clinical- trials-badpharma; Ian Sample, Big Pharma Mobilising Patients in Battle over Drugs Trials Data, GUARDIAN (July 21, 2013, 2:44 PM), http://www.theguardian.com/business/ 2013/jul/21/bigpharma-secret-drugs-trials. However, the pressure has been effective in resulting in a voluntary agreement to release some clinical data. E.g., PHRMA, PRINCIPLES FOR RESPONSIBLE Clinical Trial Data Sharing: Our Commitment to Patients and Researchers (2013), available at http://phrma.org/sites/default/files/pdf/PhRMAPrinciplesForResponsible ClinicalTrialDataSharing.pdf; Katie Thomas, Drug Companies Promise More Data Transparency, N.Y. Times, July 25, 2013, at B6; Hester Plumridge, Proposed Law Would Require More Drug-Trial Transparency, WALL ST. J. (Mar. 21, 2014, 5:01 PM), http:// online.wsj.com/news/articles/SB10001424052702303802104579449160147006896; Note from the Gen. Secretariat, Council of the European Union, to Delegations (Dec. 20, 2013), available at http://www.parlament.gv.at/PAKT/EU/XXV/EU/00/78/EU_07823/imfname _10428837.pdf.

316. For example, although a doctor questioned the cost of drug discovery in a book highly critical of the industry, the general tenor of the book made it easy for the industry to quickly dismiss it. See Marcia Angell, The Truth About the Drug Companies (2003); see also Richard A. Epstein, Pharma Furor: Why Two High-Profile Attacks on Big Drug Companies Flunk the Test of Basic Economics, LEGAL AFF., Jan/.Feb. 2005, at 56 (criticizing Angell's "extended indictment" as reflecting an "inability to grasp fundamental economic principles"). Similarly, a recent book by two economists that challenged the importance of patents on pharmaceuticals contained some overstatements that perhaps made it predictably ignored by most patent scholars. See BoLDRIN \& LEVINE, supra note 252. For example, although others have noted that many drugs are not innovative, the approach that these authors take seems not duly tailored. Id. at 228. They claim that it is reasonable to ask medical doctors about innovative medicines; however, the study that they cite is not limited to medicine and in fact also discusses medical discoveries. Id. (citing Petra Moser, How Do Patent Laws Influence Innovation? Evidence from Nineteenth-Century World Fairs (Nat'l Bureau of Econ. Research, Working Paper No. 9909, 2003)). Although they 
More study and dissemination are also needed to address the innovation and strong patent schemas. Some scholars are beginning to provide empirical analysis of the impact of so-called "secondary" patents that cover not the original active ingredient in a new drug but alternative formulations or methods of administration. ${ }^{317}$ These secondary patents are less innovative yet may nonetheless bar approval of generic drugs. ${ }^{318}$ Two researchers recently evaluated two key HIV drugs and found that there were 108 related patents, which together could delay generic competition until at least 2028 - twelve years after the expiration of the patents on the original active ingredients. ${ }^{319}$ Similarly, a different group of researchers, including Law Professor Amy Kapczynski, recently published an empirical study that revealed that the majority of drugs are protected by multiple secondary patents. ${ }^{320}$ These studies also echo findings of the

claim that only two of the fifteen innovations were patented, the list includes many nondrug discoveries, such as x-rays, tissue culture, public sanitation, evidence-based vaccines, and even computers. Id. at 229. Similarly, they claim that the U.S. Centers for Disease Control and Prevention's top ten list of public health achievements in the twentieth century yielded no medical patents, but this list is for the broad category of public health, and not pharmaceuticals. Id. They may perhaps realize that these numbers are misrepresentative because they ultimately do consult a "List of Top Pharmaceuticals" from the Chemical and Engineering News magazine, which they claim should "stack the odds in favor of patents." Id. Of this list of forty-six best selling drugs at the time of the 2005 survey, they claim that for almost half, "[p]atents had pretty much nothing to do with the development," whereas the remaining products "somehow owe their existence to the availability of drug patents." Id. at 230. However, this list suffers the same problems as the others in not being focused solely on pharmaceuticals - despite its title. See id. The top-selling “drugs" include medical marijuana and vitamins. Id. In addition, they provide no evidence for their claim of why patents had no connection to certain drugs, such as Allegra, Prozac, Viagra and Vioxx. Id. Similarly, although certain drugs were discovered by chance and patented, or made in university labs, this does not discount the fact that the availability of patent protection, although perhaps not essential to initial creation, could have been essential to commercialization of the product.

317. See, e.g., Tahir Amin \& Aaron S. Kesselheim, Secondary Patenting of Branded Pharmaceuticals: A Case Study of How Patents on Two HIV Drugs Could Be Extended for Decades, 31 HeAlth AfF. 2286, 2291 (2012); Kapczynski et al., supra note 279.

318. See Kapczynski et al., supra note 279, at 1.

319. Amin \& Kesselheim, supra note 317, at 2291.

320. Kapczynski, supra note 279, at 4; see also Andrew F. Christie et al., Patents Associated with High-Cost Drugs in Australia, PLoS ONE 6 (Apr. 5, 2013), http://www. plosone.org/article/fetchObject.action?uri=info\%3Adoi\%2F10.1371\%2Fjournal.pone.00608 12 \&representation=PDF (discussing similar results with a focus on Australian patents). In contrast to the widely cited figure that the effective patent term of a drug is only about 
European Union's comprehensive 2009 study of the pharmaceutical industry. ${ }^{321}$

However, these critical research results do not garner much public attention. ${ }^{322}$ This may in part be because the story of secondary patents is a nuanced and complex one that includes uncommon terms, such as polymorphs and prodrugs, that have less resonance than the simple and emotionally powerful schemas of the industry.

Beyond considering secondary patents, research on the cost of drugs focusing on drugs that are not NMEs, or at least not lumping together such molecules with IMD, is definitely needed. It is unclear to this Author why there seems to be a paucity of such research. In the past two decades, the Budget Office suggested that such drugs cost a third of NMEs, but there seems to be no recent data on this issue. ${ }^{323}$ However, whereas the cost schema is repeated as the cost of all drugs when it is at best representative of a minority of drugs, there exists no solid data on the cost of the majority of new drugs, which are in fact incremental innovations. Of course, there could be challenges in considering all incremental drugs together because some may be slower or faster to develop. However, that seems equally true of NMEs. At a minimum, some comparative data is necessary to help drive home the point that the oft-repeated figure is at best accurate for only one part of the cost spectrum.

In addition, patents are not the only protection relied on by the industry to protect drugs. Other protections include patent linkage and data exclusivity, which are explained in more detail in the next subpart. Given that the industry also relies on these, research that addresses them in addition to patents is a priority to understand the full impact of pharmaceutical protectionism. One team of Canadian scholars has begun to

ten years, this study suggests that secondary patents may result in an additional four or five years of protection, which would make the effective patent term of pharmaceuticals much closer to that of other inventions and argue against providing additional protection. Compare Kapczynski et al., supra note 279, with Henry G. Grabowski \& John M. Vernon, Effective Patent Life in Pharmaceuticals, 19 InT’L J. TeCh. Mgmt. 98 (2000).

321. EUROPEAN COMM’n, Pharmaceutical SECTOR INQUiRY: Final REPORT 521 (2009).

322. The study of HIV drugs does not seem to have captured much attention in the United States beyond a few blogs. E.g., Jessica Bylander, The Indian Supreme Court Weighs in on "Patent Evergreening," HeALTH AFF. BLOG (April 3, 2013), http://healthaffairs.org/ blog/2013/04/03/the-indian-supreme-court-weighs-in-on-patent-evergreening; Lisa Larrimore Ouellette, Kapczynski, Park \& Sampat on Secondary Pharma Patents, WRITTEN DESCRIPTION (Jan. 10, 2013), http://writtendescription.blogspot.com/2013/01/kapczynski-park-sampat-onsecondary.html.

323. See supra note 66 and accompanying text. 
do this and found that the nexus of patents and patent linkage promotes more incremental drugs of modest clinical significance. ${ }^{324}$ However, the work of this team of Canadian scholars is minimally cited by U.S. scholars, and there do not appear to be any parallel U.S. studies that focus on both patents and patent linkage. ${ }^{325}$

A more challenging task is changing the popular discourse in the media that to date has largely reinforced the schemas. Admittedly, the schemas may be easy to reinforce because they tend to be simple and memorable stories - which make for good journalism - when the reality is more nuanced. Although journalists are unlikely to change their methods, perhaps schemas can nonetheless be challenged by providing journalists with press releases and other information that they can easily rely on.

Another challenging task is to change the discourse of scholars and policymakers. As noted in Part II, there are already scholars that recognize the schemas, but their work has generally not infiltrated or influenced most patent scholarship and policymaking. This may be in part because the group of scholars that recognize the schemas-without calling them as such - may be so focused on the goal of promoting access to lower cost medicine that most patent scholars view these scholars as an opposing group that is against patents and thus reject what they have to

324. Ron A. Bouchard et al., Empirical Analysis of Drug Approval-Drug Patenting Linkage for High Value Pharmaceuticals, 8 NW. J. TECH. \& INTELL. ProP. 174, 174-75, 22527 (2010); Ron A. Bouchard et al., The Pas de Deux of Pharmaceutical Regulation and Innovation: Who's Leading Whom?, 24 BERKELEY TECH. L.J. 1461, 1463-64 (2009).

325. A Westlaw search revealed only two scholarly articles that cite Bouchard's conclusions; however, neither of these articles focuses primarily on the issue of the role of patent or regulatory laws on drug innovation. See C. Scott Hemphill \& Mark A. Lemley, Earning Exclusivity: Generic Drug Incentives and the Hatch-Waxman Act, 77 ANTITRUST L.J. 947, 950-51, 954 n.30 (2011); Benjamin P. Liu, Fighting Poison with Poison? The Chinese Experience with Pharmaceutical Patent Linkage, 11 J. MARSHALL REV. INTELL. PROP. L. 623, 625-27, 671-72 (2012). In addition, Bouchard's empirical studies are cited for different issues. See, e.g., Kali Murray \& Esther van Zimmeren, Dynamic Patent Governance in Europe and the United States: The Myriad Example, 19 CARDOZO J. INT'L \& Comp. L. 287, 335 n.186 (2011) (general pharmaceutical patent litigation); Joshua D. Sarnoff, Government Choices in Innovation Funding (with Reference to Climate Change), 62 EMORY L.J. 1087, 1131 n.184 (2013) (environmental law). Although there is a dearth of empirical data on the intersection of patents and patent linkage on U.S. drug innovation, the problems of patent linkage in general are recognized. See, e.g., Brook K. Baker, Ending Drug Registration Apartheid: Taming Data Exclusivity and Patent/Registration Linkage, 34 AM. J.L. \& MED. 303 (2008). 
say. Accordingly, perhaps some scholars and advocates who recognize problems with patent laws in pharmaceuticals can and should be careful not to take a strident tone. ${ }^{326}$ However, broader steps likely need to be taken to change the discussion to ensure that the problems caused by stronger patent protection on pharmaceuticals do not continue to be an issue addressed by an isolated group of scholars. One possibility is an institutional change to focus on such policy implications of patents, such as innovation, that are not captured by the industry. ${ }^{327}$

\section{B. Less Is More: Patent Policy Should Consider Promoting More Innovative Drugs}

One implication of the schemas is that scholars and policymakers should take a more skeptical view of popular claims for additional protection to promote pharmaceutical innovation. After all, more protection may simply lead to an exacerbation of the existing situation: promoting mostly incremental innovation of minimal clinical value. At a time when

326. Some recent books that raise valid points about patents on pharmaceuticals may be easily discounted because of their strident tone. For example, the book by economists Boldrin and Levine is not only antagonistic in its title, which refers to intellectual monopoly instead of intellectual property, but the content of the text is also very slanted. BOLDRIN \& LEVINE, supra note 252, at 234 ("[A] monopolized industry, where patents are the core and foundation of the business method adopted, must end up practicing rent seeking and bribery, it must conceal or suppress relevant research findings, it must monitor doctors' prescription behavior, it must employ a sales force three times the size of its research team, and it must, finally, become one of the top donors of political campaign contributions.”). It is perhaps unsurprising that the insights of this book are generally not included in scholarly discussions, except as an example of a contrary view on eliminating intellectual property. See, e.g., Scott Baker, Can the Courts Rescue Us from the Patent Crisis?, 88 Tex. L. REv. 593, 599 n.39 (2010)

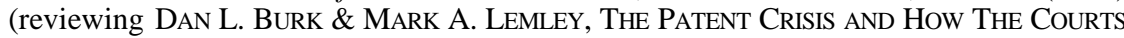
CAN SOLVE IT (2009)) (citing the book as a "but see" cite to the normally accepted premise that patents do in fact work); Mark A. Lemley, The Myth of the Sole Inventor, $110 \mathrm{MiCH}$. L. REV. 709, 738, 750 (2012); see also Ron A. Bouchard et al., Structure-Function Analysis of Global Pharmaceutical Linkage Regulations, 12 MinN. J.L. SCI. \& TECH. 391, 394 n.3 (2011) (including the book in a string cite about how patent law is controversial for stimulating drug development, but also including other cites that tend to suggest that patents are beneficial to drug discovery); Brian J. Love, Interring the Pioneer Invention Doctrine, 90 N.C. L. REV. 379, 414 n.144 (2012) (citing book as a "see also" cite to the cost of drug discovery).

327. See Stuart Minor Benjamin \& Arti K. Rai, Fixing Innovation Policy: A Structural Perspective, 77 GEO. WASH. L. REV. 1 (2008) (proposing a new agency to analyze innovation policy); see also Salomeh Keyhani \& Alex Federman, Fact or Fiction: The Need for Independent Pharmaceutical Policy Research, 24 J. GEN. InTERnAl Med. 692, 693 (2009) (suggesting the need for independent policy research to provide neutral information to policymakers now that the Office of Technology Assessment has been disbanded). 
the pharmaceutical industry is producing fewer new drugs and claiming that its ability to fund new drug development is compromised by increased competition from generics, the industry should be expected to seek more protection. Accordingly, a more skeptical view is particularly important now.

Although probably difficult to implement, it is relatively straightforward to outline how to modify, or at least contradict, the current schema that favors more protection. Essentially, the current presumptions should be reversed. So, for example, instead of a lenient standard of patentability to arguably encourage more innovation - of any type-the standard of patentability could be applied more rigorously by the U.S. Patent and Trademark Office (USPTO). This would be a major change to not only existing law but also what most patent scholars have advocated. ${ }^{328}$ Although arguably iconoclastic with respect to domestic policy, there is precedent in the international arena. In particular, India, as well as some other developing countries do not permit patents on new uses of existing compounds or even "new" compounds that are slight variations of existing compounds, unless there is proof of increased clinical significance. ${ }^{329}$ The Indian Supreme Court recently affirmed application of this law to deny Novartis a patent. ${ }^{330}$ This decision has prompted widespread discussion and consideration of modifying patent laws, even among wealthy countries. ${ }^{331}$ In addition, although this decision shines a spotlight on this issue, some countries had already been considering this problem. ${ }^{332}$

328. Although U.S. patent scholars have generally not advocated a heightened level of scrutiny for pharmaceutical patents, others have. See, e.g., Molly F.M. Chen, Note, Reconsidering the U.S. Patent System: Lessons from Generics, 45 VAND. J. TRANSNAT'L L. 1249, 1253 (2013).

329. The Patents (Amendment) Act, 2005, No. 15, Acts of Parliament, 2005, § 3(d); Divya Rajagopal, EU, Australia, Canada May Follow India's Patent Law, ECON. TIMES (April 4, 2013, 4:00 AM), http://articles.economictimes.indiatimes.com/2013-04-04/news/ 38278712_1_patent-act-patent-protection-patent-quality.

330. Novartis AG v. Union of India, (2013) _ _.C.R. __ (India), available at http:// indiankanoon. org/doc/165776436.

331. Rajagopal, supra note 329.

332. Canadian courts have in fact recently recognized the "promise doctrine," as a subset of the utility requirement, which has been used to limit patentability of drugs in cases of evergreening by requiring the patent application to disclose any claimed utility in the application. See Apotex Inc. v. Pfizer Canada Inc., [2011] F.C.A. 236 (Can.), available at http://decisions.fca-caf.gc.ca/site/fca-caf/decisions/en/item/37251/index.do; Eli Lilly Canada Inc. v. Novopharm Ltd., [2012] 1 F.C.R. 349 (Can.), available at http://decisions.fca-caf.gc. 
India's particular approach does have some practical problems in that it may be difficult to evaluate clinical significance when a patent application is filed. Similarly, Canada's current approach of imposing a stringent utility doctrine to pharmaceutical inventions could possibly be better tailored to address fairness concerns. However, logistical challenges alone in crafting an appropriate standard to promote the right type of innovation should not completely thwart consideration of how to best promote drug innovation. Moreover, this should not be a new phenomenon. After all, for years, scholars and policymakers have been discussing how to better tailor patent standards to ensure that patents are granted for deserving innovations. ${ }^{333}$

In addition, although patent law is traditionally a "one size fits all” reward, perhaps there could be better tailoring of patent rewards. In other words, perhaps more innovative drugs should get a longer patent term. The current law already permits some deviations of the standard patent term, although those are largely to compensate for delays in

ca/site/fca-caf/decisions/en/item/36863/index.do. At least one commentator has criticized this doctrine. See Norman Siebrasse, The False Doctrine of False Promise, 29 CANADIAN INTELLECTUAL PROPERTY REVIEW 3 (2013), available at http://papers.ssrn.com/sol3/papers. cfm?abstract_id=2171762. Eli Lilly filed a formal challenge in September, seeking monetary damages pursuant to an international investment arbitration based on its claim that Canada's law is inconsistent with international law, although a number of commentators have cast doubt on the validity of Eli Lilly's claim. Notice of Arbitration, Eli Lilly \& Co. v. Gov't of Canada (Sept. 12, 2013), available at http://infojustice.org/wp-content/uploads/2013/09/Eli-LillyNotice-of-Arbitration-September-12-2013.pdf; see PUBLIC CitIZEN, U.S. PHARMACEUTICAL CORPORATION USES NAFTA ForeIgn INVESTOR PRIVILEGES REgime TO ATtaCK CANADA's PATENT Policy, Demand \$100 Million FOR InVALIDATION OF A PATENT (2013), available at http://www.citizen.org/documents/eli-lilly-investor-state-factsheet.pdf; Brook K. Baker, Corporate Power Unbound: Investor-State Arbitration of IP Monopolies on MedicinesEli Lilly and the TPP, PIJIP RESEARCH PAPER SERIES (May 1, 2013), http://digitalcommons. wcl.american.edu/cgi/viewcontent.cgi?article=1038\&context=research. Regardless of how the arbitration is resolved, Canada's promise doctrine remains an example of a country besides India that has attempted to restrict patents on drugs that seem not particularly innovative. Australia also seems to agree. AUSTRALIAN REPORT, supra note 61, at x, xvi (noting that although "it is logical that patentees will seek further patents for improvements to their drugs - so called follow-on patents - with an eye to extending the market life of the original drug," there is a need for more rigorous review of attempts to patent that do not in fact meet patentability standards).

333. Discussions have focused on the "nonobvious" standard of patent law. See, e.g., DAN L. BURK \& MARK A. LEMLEY, supra note 326, at 21-22 (noting that the patent system is broken and it is highly likely that the USPTO has been too lenient in granting patents in recent decades); FED. TRADE COMM'N, supra note 43, at 4-8; NAT'L RESEARCH COUNCIL, supra note 5, at 87-101 (recommending a reinvigoration of the nonobviousness standard and a post-grant review procedure). However, these reports focus primarily on areas outside the pharmaceutical arena. 
evaluation by the USPTO or the inevitable lag time between patent application and usual approval by the FDA that cuts into the effective patent term. ${ }^{334}$ So, the concept of modifying the patent term is on its face not novel. Of course, the suggestion to modify patent terms based on the level of innovativeness is dramatically different than current patent term adjustments that are based on clear cut situations. Admittedly, there are challenges to determining what inventions are more worthwhile and thus deserving of a longer term, especially at the stage of a patent application, which often occurs earlier than the clinical tests that would establish the value. However, logistical problems alone are not a sound justification for not considering how to improve the current system. ${ }^{335}$ Rather, they simply suggest that a new method is perhaps necessary.

Although firm details of a new method are beyond the scope of this Article, a brief discussion may help to show that such a method need not be beyond consideration. For example, perhaps for patented drugs, the time to apply for an extension would not happen when the patent application is filed, or even when granted, but when application for FDA approval occurs. At that time, clinical data would exist because that is a pre-requisite to obtaining regulatory approval to sell drugs. ${ }^{336}$ In addition, one possibility is to grant more time to priority NMEs. Of course, such a proposal is likely to be strenuously opposed by the industry; indeed, the objections would likely mirror past objections to the use of FDA criteria in evaluating innovativeness. ${ }^{337}$ However, this is simply an example of what would be administratively easy. If there were a different way that innovativeness could be assessed that the industry agreed with, that could of course be used. However, the bigger problem is that because the industry has confirmation bias that everything it produces is innovative, it would strongly object to any and all suggestions of innovativeness that change the current system. ${ }^{338}$ Nonetheless, because

334. 35 U.S.C. §§ 155-156 (2012).

335. It is also possible to promote this goal without touching the patent term. For example, innovative drugs could be granted more market protection through data exclusivity. Congress has previously used data exclusivity to incentivize desired innovation in specific areas, such as drugs for children and antibiotics. See 21 U.S.C. §§ 355, 801 (2012).

336. See How Drugs Are Developed and Approved, FDA, http://www.fda.gov/drugs/ developmentapprovalprocess/howdrugsaredevelopedandapproved (last updated Feb. 13, 2014).

337. See supra notes $210-15$ and accompanying text.

338. See supra Part III.B. 
the proposal is to provide more patent term, as a carrot, perhaps there is some possibility - even if slim-that this is something that could be framed in a way that would be acceptable.

Even if patent laws are not modified, they could be better policed by the USPTO to ensure that patents are not improperly granted. Although invalid patents can be challenged in litigation, such litigation is expensive and may be practically difficult. Once issued, a patent is given a presumption of validity. ${ }^{339}$ As a matter of public policy, there seems to be no compelling case against a more rigorous application of existing requirements of patentability before a patent is issued. ${ }^{340}$

One traditional mechanism to reinforce existing patentability requirements is to permit third parties to challenge patent applications before they issue as patents with a presumption of validity. European countries have followed this policy for years. ${ }^{341}$ However, there are serious practical challenges to incorporating such an approach in the United States because of international agreements — often prompted by PhRMA - that preclude the United States from doing so. ${ }^{342}$ Even if there is not political will to overcome these agreements, that does not mean that this approach is sound policy.

In addition, even if post-grant review is not possible, that does not mean that review within the USPTO cannot be enhanced. For example, following public outcry about business method patents of questionable quality, the USPTO instituted a second level of review. ${ }^{343}$ This type of review could easily be extended to patents beyond business methods.

339. 35 U.S.C. § 282 (2012). Some have questioned this presumption. See, e.g., Fed. Trade Comm'N, supra note 43, at 26-28; Doug Lichtman \& Mark A. Lemley, Rethinking Patent Law's Presumption of Validity, 60 StAN. L. ReV. 45, 47 (2007). Nonetheless, that is the current law and unlikely to change.

340. Indeed, in discussions leading up to the recent major overhaul of patent laws, a major criticism was that the standard of obviousness was too leniently applied. See, e.g., NAT'L RESEARCH COUNCIL, supra note 5, at 59-63.

341. See Convention on the Grant of European Patents art. 115, Oct. 5, 1973, 1065 U.N.T.S. 199 (as amended Sept. 2013) (permitting the public to comment on patentability of pending patent applications); see also Jay P. Kesan, Carrots and Sticks To Create a Better Patent System, 17 BERKELEY TECH. L.J. 763, 780 (2002) (advocating pregrant oppositions).

342. See, e.g., Free Trade Agreement, U.S.-Morocco, art. 15.9(5), June 15, 2004, 44 I.L.M. 544 [hereinafter U.S.-Morocco FTA]; Free Trade Agreement, U.S.-S. Kor., art. 18.8(4), Mar. 15, 2012, available at http://www.ustr.gov/trade-agreements/free-tradeagreements/korus-fta/final-text.

343. See Richard Maulsby, Under Secretary Dickinson Initiates Action Plan for Business Method Patents, USPTO TODAY, Apr. 2000, at 5-7 (outlining the USPTO's Business Method Patent Initiative action plan). 
This is not to suggest that this is the only solution to improve drug innovation. Rather, it is simply an example of how some structural changes, even without changing the law, could potentially be beneficial and even have some precedence.

Similarly, another possibility could be to change how drug patents are considered after issuance. In particular, given the statistics that many challenged drug patents that are found invalid or not infringed, ${ }^{344}$ perhaps such patents should not be entitled to a presumption of validity. This may sound completely radical, but it was actually proposed at one point to address the problem of business method patents. ${ }^{345}$ In addition, any such proposal would need to be considered in conjunction with other types of protections that companies rely on and that are also relevant to the schema that currently promotes more protection of drugs.

In particular, regulatory laws provide important complementary protection to patents for the pharmaceutical industry. As discussed below, "patent linkage" and "data exclusivity" could be modified to reduce overprotection of incremental innovation to promote more breakthrough innovation.

Patent linkage bars the FDA from approving a proposed generic drug that is linked or associated with a patent that relates to an already approved drug, such that a proposed generic drug would arguably infringe the linked patent if made and sold. ${ }^{346}$ This helps protect existing patented drugs from competition and is justified by the industry as an efficient means to prevent patent infringement. ${ }^{347}$ Importantly, the FDA makes such decisions based solely on information provided by the drug companies. ${ }^{348}$ The FDA has taken the position that it is not legally required to determine whether the linked patents are valid, and courts have thus

344. See supra note 275 and accompanying text.

345. See Business Method Improvement Act of 2001, H.R. 1332, 107th Cong. (2001).

346. CYNTHIA M. Ho, ACCESS TO MEDICINE IN THE GLOBAL ECONOMY: INTERNATIONAL AgREEMENTS ON PATENTS AND RELATED RightS 273 (2011).

347. Id.

348. The information is listed in what is referred to as the "Orange Book" and is based on information submitted to the FDA as part of new drug applications concerning what patents are associated with the drug. See 21 U.S.C. § 355(b)(1) (2012); FDA, APPROVED Drug Products With Therapeutic Equivalence Evaluations iv (33d ed. 2013), available at http://www.fda.gov/ucm/groups/fdagov-public/@fdagov-drugs-gen/documents/ document/ucm071436.pdf. 
far blessed this approach. ${ }^{349}$ This has resulted in a system that has been abused to preclude generic competition. Proposed generics can challenge the validity or arguable infringement of the listed patents but only in a limited window and at great cost because patent litigation is notoriously expensive. ${ }^{350}$ Notably, generic companies win more than seventy percent of such challenges, suggesting that the patent linkage system is not only flawed but also provides overprotection of patented drugs at great social cost. $^{351}$ Even more problematically, although generics can challenge patents, they sometimes choose not to because they are paid by patent holders not to do so, which has been dubbed "pay for delay." ${ }^{352}$ The U.S. Supreme Court recently held that this can violate antitrust laws, but it remains to be seen whether this will reduce such socially problematic settlements. $^{353}$

Patent linkage is a concept that is well known to those who advocate for better access to lower cost generic drugs, but it is almost never discussed by patent scholars who advocate for stronger protection of drugs. However, patent linkage exacerbates overly strong patent rights in that it provides a de facto injunction against generic companies before any commercial sales ever take place and without a judicial hearing that would evaluate the likelihood of success of a patent suit or a consideration of the equities. ${ }^{354}$

Patent linkage could be eliminated, or at least modified, to minimize its harms. Politically, eliminating patent linkage is unlikely, not only because of expected resistance from the pharmaceutical industry but also because the industry has successfully lobbied the government to enact

349. See, e.g., Alphapharm Pty Ltd. v. Thompson, 330 F. Supp. 2d 1, 9 (D.D.C. 2004).

350. See 21 U.S.C. $\S 355(j)(5)(F)(i i)$ (2012) (prohibiting a generic manufacturer from submitting an application to the FDA until five years after approval of the pioneer NME); Maurice Ross, Leveling the Playing Field-The Role of Venture Capital in Hatch-Waxman Patent Litigation, 79 PAT. TRADEMARK \& COPYRIGHT J. 730, 730-31 (2010).

351. E.g., Fed. TRADE COMM’N, GENERIC DRUg ENTRY PRIOR to PATENT EXPIRATION 13 (2002); Adam Greene \& D. DeWey Steadman, RBC Capital Markets CoRP., PhaRmaCEUTICALS: ANALYZING LitigATION SuCCESS RATES 4 (2010), available at http:// amlawdaily.typepad.com/pharmareport.pdf.

352. E.g., Fed. Trade Comm’n, PAy-For-Delay: How Drug Company Pay-OFFs COST CONSUMERS BILLIONS 1 (2010).

353. Fed. Trade Comm’n v. Actavis, Inc., 133 S. Ct. 2223, 2234-35 (2013).

354. For a discussion of the public policy concerns, see, for example, Ho, supra note 346, at 253-81; World HeAlth ORG., Briefing Note ON ACCESS TO MEDiCiNes: DATA EXCLUSIVITY AND OTHER “TRIPS-Plus” MEASURES 3 (2006), available at http:// www. searo.who.int/entity/intellectual_property/data-exclusively-and-others-measures-briefing-note-on -access-to-medicines-who-2006.pdf. 
international agreements that require linkage. ${ }^{355}$ However, it could nonetheless be modified to minimize harm. For example, the FDA could permit the list of patents to be periodically audited based on information from third parties and perhaps involve the USPTO or another entity to help evaluate this information. ${ }^{356}$ In addition, generic companies could be permitted to challenge the validity or claimed infringement of drugs earlier. ${ }^{357}$

The second type of regulatory protection that is important to protecting incremental innovation is data exclusivity. Essentially, the first company to seek and obtain approval for a new drug can prevent a generic company from relying on its supporting clinical data for a certain period of time. ${ }^{358}$ This is important because generic companies generally do not have the financial resources to replicate the large clinical trials necessary to obtain approval; moreover, apart from cost, it is arguably unethical to subject patients to unnecessary clinical trials. Accordingly, it is well accepted in the United States and many other countries that a generic version of a previously approved drug will be approved if the generic company can provide more limited and far less expensive studies to show that its proposed generic is bioequivalent to the previously approved drug; rather than doing extensive clinical tests

355. E.g., Free Trade Agreement, U.S.-Cent. Am.-Dom. Rep., art. 15.10(3), Aug. 5, 2004, available at http://www.ustr.gov/trade-agreements/free-trade-agreements/caftadr-dominican-republic-central-america-fta/final-text; U.S.-Morocco FTA, supra note 342, at art. 15.10(4); Free Trade Agreement, U.S.-Austl., May 18, 2004, 43 I.L.M. 1248, art. 17.10(5); Free Trade Agreement, U.S.-Chile, art. 17.10(2), June 6, 2003, 42 I.L.M. 1026; Free Trade Agreement, U.S.-Sing., art. 16(8)(4)(c), May 6, 2003, 42 I.L.M. 1026; see also PHRMA, SpeCIAL 301 SuBMISSION 201212 (2012) (recommending that countries prevent marketing of products that would potentially infringe, which is patent linkage); Ruth Lopert \& Deborah Gleeson, The High Price of "Free" Trade: U.S. Trade Agreements and Access to Medicines, 41 J.L. MED. \& ETHICs 199, 199-200 (2013) (discussing the strategy of using free trade agreements to address issues not in the Agreement on Trade Related Aspects of Intellectual Property Rights (TRIPS)).

356. See, e.g., Health Canada, Guidance Document: Patented Medicines (Notice OF COMPLIANCE) REgulATIONS (2012) (permitting third parties to challenge patents).

357. Currently, generic companies must wait to be sued before they can challenge a linked patent. See 21 U.S.C. § 355 (j)(5)(C)(ii)(I) (2013). Only if sued can a generic manufacturer challenge whether the patent was inappropriately listed, an issue that the Court recently addressed in Caraco Pharm. Labs. Ltd. v. Novo Nordisk, 132 S. Ct. 1670, 1688 (2012).

358. See 21 U.S.C. § 355(j)(5)(F)(ii) (2012). 
to establish safety and efficacy of the proposed generic, the limited bioequivalence testing is used in conjunction with reliance on the extensive data submitted by the original manufacturer to infer that the proposed generic would be similarly safe and effective. ${ }^{359}$ Data exclusivity can be rationalized as granting the originator necessary protection to prevent freeriding by a second entrant who does not bear the costs. ${ }^{360}$ However, in the United States, not only is there data exclusivity for a brand new molecule but also an additional period of data exclusivity for each new use of the molecule after the exclusivity ends for the new molecule. ${ }^{361}$ Essentially, this additional exclusivity encourages companies to look for new uses. The exclusivity for a new use is shorter than for new drugs - three versus five years. ${ }^{362}$ However, if new uses are substantially less costly to develop than a new drug, it would seem logical to focus on these new uses; indeed, such new uses are the majority of newly approved drugs in the United States. ${ }^{363}$

Resisting more protection is especially important with respect to data exclusivity. The United States recently granted a much longer period of data exclusivity for so-called biologics, ${ }^{364}$ which are the newest and generally most expensive type of pharmaceuticals and are prevalent in the treatments for important conditions such as cancer. ${ }^{365}$ Unlike most drugs that get a five-year term of exclusivity, biologics get a twelve-year term. ${ }^{366}$ This is true even though empirical studies do not show that biologics have vastly different development costs than traditional drugs. ${ }^{367}$ Moreover, some have suggested that this twelve-year term be expanded to all drugs; this is likely driven by the same motivation for increased patent protection because exclusivity provided by the FDA is an independent method for companies to maintain a competitive

359. See 21 U.S.C. § 355(j)(5)(F)(i)-(iv) (2012).

360. See, e.g., InT'L FED'N Pharm. MFrs. \& Ass'Ns, EnCOURAGEMENT of NEW Clinical Drug Development: The Role of Data Exclusivity 1-2 (2000), available at http://www.who.int/intellectualproperty/topics/ip/en/DataExclusivity_2000.pdf.

361. 21 U.S.C. \& 355(j)(5)(F)(iii)-(iv) (2012). By contrast, there is no such additional period provided in Europe.

362. See id.; 21 U.S.C. § 355(j)(5)(F)(ii) (2012).

363. See CBO STUDY, supra note 66, at 7.

364. 42 U.S.C. § 262(k) (2012).

365. See Alex M. Brill, Proper Duration of Data ExClusivity for Generic BIOLOGICS: A CRITIQUE 5 (2008).

366. 42 U.S.C. $\S 262(\mathrm{k})(7)(A)(2012)$.

367. See, e.g., BRILL, supra note 365, at 4, 11 (suggesting seven years of data exclusivity for biologics); DiMasi \& Grabowski, supra note 128, at 470 (noting that both biologics and conventional drugs cost about $\$ 1$ billion to develop). 
advantage. ${ }^{368}$ However, even for conventional drugs, there is no clear economic case suggesting that five years is the appropriate time; in the past, some have suggested that Congress consider a shorter term because of the social costs to society. ${ }^{369}$ Accordingly, resisting a longer period of data exclusivity for conventional drugs is another important issue to be considered in conjunction with changing defaults for patent protection.

\section{Schemas for Further Consideration}

Although this Article has focused primarily on cognitive biases that stem from a self-interest bias, there may be additional cognitive biases at a cultural level that deserve further consideration and evaluation. This subpart briefly sketches these issues.

\section{Is There a Cultural Belief That Newer Is Better?}

The first possible schema is an assumption that newer is necessarily better. ${ }^{370}$ This is arguably related to the industry self-interest bias that it

368. E.g., Goldman et al., supra note 6, at 89.

369. Legislative Proposal To Increase Funding for Medical Research: Hearing Before Subcomm. on Dep'ts of Labor, Health and Human Services, and Education, and Related Agencies of the S. Comm. on Appropriations, 105th Cong. 18 (1997) (statement of James P. Love, Director, Consumer Project on Technology).

370. This Article focuses on newer medical treatments, although there could be a general preference for new products. More importantly, there could also be a schema that assumes that unless newer treatments are favored, there is improper rationing or government interference, or both. However, the term rationing seems inappropriate with respect to not spending money on expensive goods that are not clearly better. This approach may seem radical in the context of a freewheeling market economy that drug manufacturers prefer. However, given that patients have inaccurate information to compare drugs, even assuming they have a role in which drug they take, this is not necessarily either rationing or government interference. To the contrary, some governments consider this entirely rational. See, e.g., Ruth Lopert, Evidence-Based Decision-Making Within Australia's Pharmaceutical Benefits Scheme, CommonweAlth Fund, July 2009, at 7; Jane Merrick, “Too Expensive” Cystic Fibrosis Drug is Blocked Due to Expense, InDEPENDENT (Oct. 21, 2012), http:// www.independent.co.uk/life-style/health-and-families/health-news/too-expensive-cystic-fibrosisdrug-is-blocked-due-to-expense-8219524.html; Helen Pidd, Avastin Prolongs Life but is Too Expensive for NHS Patients, Says Nice, GUARDIAN (Aug. 23, 2010), http://www. theguardian.com/society/2010/aug/24/avastin-too-expensive-for-patients. Of course, skeptics might question whether these countries have comparable levels of innovation. However, as noted above, even in an environment where pharmaceutical companies have their desired conditions, the level of innovation is not so impressive. 
is developing innovative new drugs. There also may be a cultural bias among the health care sector, or society as a whole, that also fosters this belief. ${ }^{371}$ For example, as many consumers know, doctors often suggest trying newer drugs. This may be complicated by the fact that there are often free samples of newer drugs and doctors sometimes have relations with companies that make them biased towards promoting new drugs. ${ }^{372}$ However, society as a whole may still seem to have a general presumption that newer is better. ${ }^{373}$

A recent story suggests that some doctors believe there may be such a schema. Doctors from the renowned Memorial Sloan Kettering Cancer

371. See Francisco Javier Garjón et al., Adoption of New Drugs by Physicians: A Survival Analysis, BMC HEALTH SERvs. Res. 1 (Mar. 8, 2012), http://www.biomed central.com/content/pdf/1472-6963-12-56.pdf (noting that new drugs often substitute for cheaper ones). In addition, although doctors may recognize that new drugs might have risks, there is some indication that patients do not. WAYNE D. HOYER ET AL., CONSUMER BEHAVIOR 422 (6th ed. 2013). This can be a problem because newer drugs with the same therapeutic value may have unknown side effects that expose patients to greater safety issues compared to drugs already on the market. After all, although drugs must establish a basic level of safety to be approved by the FDA, that is based on much more limited data than years or even decades of knowledge that develop after a drug is approved. See Garjón et al., supra, at 6 (noting that new drugs are adopted before safety is well established because clinical trials involve limited patients for short duration that are unlikely to be representative of all patients and suggesting that some recommend waiting at least seven years before using a new drug to better identify adverse effects). In the 1990s, all the drugs withdrawn from the market for safety reasons were drugs that did not fill new medical needs. E.g., Daniel Sigelman, Dangerous Medicine, Ам. РROSPECT (Sept. 5, 2002), http://prospect.org/article/dangerous-medicine.

372. See, e.g., Cong. Budget Office, Promotional Spending for Prescription DRUGS 2 (2009), available at http://www.cbo.gov/sites/default/files/cbofiles/ftpdocs/105xx/ doc10522/12-02-drugpromo_brief.pdf; David Grande, Limiting the Influence of Pharmaceutical Industry Gifts on Physicians: Self-Regulation or Government Intervention?, 25 J. GEN. Internal Med. 79, 79 (2010); Daniel Carlat, Dr. Drug Rep, N.Y. Times Mag., Nov. 25, 2007, at E64, available at http://www.nytimes.com/2007/11/25/magazine/25memoir-t.html? pagewanted=all\&_r=0. Moreover, the influence of companies starts in medical school. See, e.g., Melena Bellin et al., Medical Students' Exposure to Pharmaceutical Industry Marketing: A Survey at One U.S. Medical School, 79 ACAD. MED. 1041, 1044 (2004); Pauline W. Chen, For Medical Students, Love from the Drug Rep, N.Y. Times Well Blog (Oct. 3, 2013, 3:24 PM), http://well.blogs.nytimes.com/ 2013/10/03/for-med-students-love-fromthe-drug-rep.

373. E.g., Michael D. Dalzell, Pushback on Zaltrap's Price Highlights Sensitive End-of-Life Issue, MANAGED CARE (Dec. 2012), http://www.managedcaremag.com/archives/ 1212/1212.zaltrap.html ("[T]he culture in medicine — and oncology is no exception —often is 'newer is better,' regardless of a drug's outcomes or costs.”); Vitry et al., supra note 211, at 1 ("[T] he belief that all new medicines bring a therapeutic innovation and better health outcomes is widely shared among the public, health professionals and policy makers.”) (citations omitted). 
Center recently announced that they would not use a cancer drug because it was not better than existing treatments but was priced twice as high. ${ }^{374}$ They noted that because there is a presumption in the medical culture that equates new with better, their decision to reject a new drug that offers no significant benefit and costs twice as much as prior drugs was hard to make. ${ }^{375}$ In addition, other cancer doctors are questioning the cost of many new cancer drugs that offer marginal extensions of life. ${ }^{376}$

There is also some historical evidence that seems to support a schema favoring new drugs. ${ }^{377}$ In particular, in the 1980s, new antihypertensives designed to treat high blood pressure-known as ACE inhibitorsquickly became top sellers whereas sales of older and cheaper treatments, such as diuretics, plummeted despite a strong price differential. ${ }^{378}$ The generic diuretics cost around \$40 compared to $\$ 700$ for the patented ones. $^{379}$ Remarkably, the quick market response happened without any studies to establish that the newer drugs were better. As noted earlier, such studies are not required for FDA approval. Nonetheless, it would seem logical that doctors would not prescribe newer and more expensive drugs unless there was evidence that they were better. This example, however, shows that is not necessarily the case. After nearly two decades, a

374. Peter B. Bach et al., Op-Ed., In Cancer Care, Cost Matters, N.Y. Times, Oct. 15, 2012, at A25.

375. Id

376. See, e.g., Laura Beil, The Cancer "Breakthroughs" that Cost Too Much and Do Too Little, NEwswEEK, http://www.newsweek.com/cancer-breakthroughs-cost-too-muchand-do-too-little-64531 (last updated Aug. 27, 2012, 10:02 PM).

377. The same phenomenon may also be true for medical treatment in general, and not just regarding drugs. For example, a newer "metal on metal" hip replacement was widely adopted, representing a third of all hip replacements in 2007, but was recently discovered to in fact be inferior to prior models, including a 2010 recall of Johnson \& Johnson products, because metal ions leached into the bloodstream and twice as many revisions were needed, even though the product was not recalled completely. E.g., Rupert Shepherd, Metal on Metal Hip Implants Causing Big Problems Again, Med. News Today (June 27, 2012, 8:00 AM), http://www.medicalnewstoday.com/articles/ 247151.php; see also Vinay Prasad \& Adam Cifu, Medical Reversal: Why We Must Raise the Bar Before Adopting New Technologies, 84 Yale J. Biology \& MED. 471, 471-72 (describing the broad phenomenon that medical therapies and diagnoses are often too quickly adopted and then subsequently reversed).

378. See ANGELL, supra note 316, at 96-97.

379. See Ron Winslow \& Scott Hensley, Dose of Reality: Study Questions HighCost Drugs for Hypertension, WALl ST. J., Dec. 18, 2002, at A1. 
study by the National Institutes of Health (NIH) conclusively determined that the newer drugs were not only not significantly better but, in fact, were worse in some respects, such that generic diuretics were recommended as the preferred first step for treating high blood pressure. ${ }^{380}$

A schema that assumes that newer drugs are necessarily better can have dangerous implications when combined with drug company marketing and testing. In particular, whereas the ACE inhibitor situation establishes that new drugs with no established significant improvements are quickly adopted, in situations where companies tout supposed benefits, doctors should be expected to adopt them. Although this seems reasonable, it may not be if the benefits are based on studies done by the very companies that develop and promote the drugs. Some have noted that companies have a conflict of interest even in the basic studies establishing safety and efficacy, ${ }^{381}$ and have called for such studies to be publicly funded. ${ }^{382}$ There are examples of situations where doctors and patients rely on industry-financed data and only later discover that there are problems; for example, for decades, based on industry data, women took hormone replacement therapy to not only treat menopause but also to prevent heart disease, only to later discover from an NIH study that the drugs actually increased the risk of heart disease. ${ }^{383}$ Moreover, companies

380. Antihypertensive and Lipid-Lowering Treatment To Prevent Heart Attack Trial (ALLHAT) Officers et al., Major Outcomes in High-Risk Hypertensive Patients Randomized to Angiotensin-Converting Enzyme Inhibitor or Calcium Channel Blocker vs Diuretic, 288 J. AM. MED. Ass’n 2981, 2985-86 (2002).

381. See, e.g., Catherine D. DeAngelis \& Phil B. Fontanarosa, Impugning the Integrity of Medical Science: The Adverse Effects of Industry Influence, 299 J. AM. MED. Ass’N 1833, 1833 (2008).

382. See, e.g., Tracy R. Lewis et al., The Case for Public Funding and Public Oversight of Clinical Trials, ECONOMISTS' VOICE, Jan. 2007, at 1; Jerome H. Reichman, Rethinking the Role of Clinical Trial Data in International Intellectual Property Law: The Case for a Public Goods Approach, 13 Marq. InTell. Prop. L. ReV. 1, 49-51 (2009); Marc A. Rodwin \& John D. Abramson, Clinical Trial Data as a Public Good, 308 J. Am. Med. Ass'N 871, 872 (2012); Working Document - Barbados and Bolivia Proposal 6: Clinical Trials on Medicines as Global Public Goods (2008), http://keionline.org/misc-docs/b_b_igwg/ prop6_clinical_trials_as_as_global_public_goods.pdf (last visited May 20, 2014). An alternative proposal is to separate companies that develop drugs from those that do clinical testing and marketing. See, e.g., FINKELSTEIN \& TEMIN, supra note 8; SHELDON KRIMSKY, SCIENCE IN

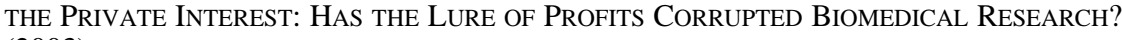
(2003).

383. See, e.g., Catherine Kreatsoulas \& Sonia S. Anand, Menopausal Hormone Therapy for the Primary Prevention of Chronic Conditions, 123 POLISH ARCHIVES OF InTERNAL MED. 112 (2013); Heidi D. Nelson et al., Menopausal Hormone Therapy for the Primary Prevention of Chronic Conditions: A Systematic Review To Update the U.S. Preventive Services Task Force Recommendations, 157 ANNALS InTERNAL MED. 104 (2012); 
have no incentive to do comparative research because it may in fact reveal that their drug is not better; indeed, when Bristol-Meyers Squibb attempted to establish that its cholesterol-lowering drug compared well to Pfizer's Lipitor, it got the bad news on its previously top-selling drug, which the Wall Street Journal reported as a corporate mistake. ${ }^{384}$

At a minimum, there must be awareness of the conflict of interest. Companies obviously have an incentive to reach certain conclusions, which not only has resulted in ghost writing of studies ${ }^{385}$ but in some cases outright fraud and misrepresentation in hiding evidence. For example, in the debacle involving the patented COX-2 anti-inflammatory drug marketed by Merck as Vioxx - the third best-selling drug in 2003 with over $\$ 2$ billion a year in sales_-the drug was pulled off the market when suppressed studies indicated that it was associated with an increase in heart attacks and strokes. ${ }^{386}$ In addition, although doctors widely

Diana Petitti, Commentary, Hormone Replacement Therapy and Coronary Heart Disease: Four Lessons, 33 INT'L J. EPIDEMIOLOGY 461 (2004). After years of research, the benefits of such therapy remain controversial. See, e.g., JoAnn E. Manson et al., Menopausal Hormone Therapy and Health Outcomes During the Intervention and Extended Poststopping Phases of the Women's Health Initiative Randomized Trials, 310 J. AM. MED. Ass'N 1353 (2013); see also Larry Husten, Long Terms Study Results Offer Broad Perspective on Hormone Replacement Therapy for Women, ForBes (Oct. 1, 2013, 4:12 PM), http://www. forbes.com/sites/larryhusten/2013/10/01/long-terms-study-results-offer-broad-perspective-onhormone-replacement-therapy-for-women (noting the results of hormone replacement theory in younger women are still inconclusive).

384. See Ron Winslow, Blood Feud: For Bristol-Myers, Challenging Pfizer Was a Big Mistake, WALL ST. J., Mar. 9, 2004, at A1, available at http://online.wsj.com/news/articles/ SB107876021684949151; see also Trudo Lemmens, Piercing the Veil of Corporate Secrecy About Clinical Trials, 34 Hastings Center ReP. 14, 15 (Sept-Oct. 2004) (discussing Wall Street Journal article).

385. This involves companies providing nearly finished manuscripts to investigators who "author" them without sometimes even seeing the underlying data. E.g., Thomas Bodenheimer, Uneasy Alliance: Clinician Investigators and the Pharmaceutical Industry, 342 NEw ENG. J. MED. 1539, 1542 (2000). There is often also manipulation of study results, or studies written by those who have a conflict of interest as paid consultants of companies. DeAngelis \& Fontanarosa, supra note 381, at 1833.

386. See, e.g., Holly Presley, Institutions in Crisis: Vioxx AND the MERCK TEAM EFFORT (2009), available at https://kenan.ethics.duke.edu/wp-content/uploads/2012/07/ Case-Study-Vioxx.pdf; Margaret Gilhooley, Vioxx's History and the Need for Better Procedures and Better Testing, 37 Seton Hall L. Rev. 941 (2007); Ronald M. Green, Direct-to-Consumer Advertising and Pharmaceutical Ethics: The Case of Vioxx, 35 Hofstra L. ReV. 749 (2006); Jef Feeley, Merck Pays \$23 Million To End Vioxx DrugPurchase Suits, BLOOMBERG (July 18, 2013, 4:05 PM), http://www.bloomberg.com/news/ 
report that they understand that companies market to them and assume that they are not influenced by such marketing, ${ }^{387}$ studies suggest otherwise, ${ }^{388}$ consistent with social science research demonstrating that despite intentions to be objective, doctors are human and fall prey to biases. ${ }^{389}$ This is particularly problematic because there is presently a

2013-07-18/merck-pays-23-million-to-end-vioxx-drug-purchase-suits.html; Peter Loftus \& Brent Kendall, Merck To Pay $\$ 950$ Million in Vioxx Settlement, WALL ST. J. (Nov. 23, 2011), http://online.wsj.com/news/articles/SB10001424052970204531404577054472253737682. There was also intentional suppression of data that showed the antidepressant drug promoted as Paxil was not efficacious and also that the drugs were potentially dangerous for children, which resulted in a lawsuit against GlaxoSmithKline for misrepresentation. See, e.g., Alison Bass, Side Effects: A Prosecutor, A Whistleblower, and A Bestselling ANTIDEPRESSANT ON TRIAL 3-4 (2008); Wayne Kondro \& Barbara Sibbald, Drug Company Experts Advised Staff To Withhold Data About SSRI Use in Children, 170 CANADIAN MED. Ass'N J. 783, 783 (2004). There are also other cases of companies paying millions of dollars in fines because of fraud that focuses on marketing problems, but not necessarily data concerning efficacy of drugs. See, e.g., Gardiner Harris, Pfizer To Pay $\$ 430$ Million over Promoting Drugs to Doctors, N.Y. TIMES (May 14, 2004), http://www.nytimes.com/2004/05/14/ business/pfizer-to-pay-430-million-over-promoting-drug-to-doctors.html; Jeremy Laurance, Drug Giants Fined \$11bn for Criminal Wrongdoing, INDEPENDENT (Sept. 20, 2012), http://www.independent.co.uk/life-style/health-and-families/health-news/drug-giants-fined11bn-for-criminal-wrongdoing-815748 3.html.

387. E.g., Susan Chimonas et al., Physicians and Drug Representatives: Exploring the Dynamics of the Relationship, 22 J. GEN. InTERNAL MED. 184, 184 (2007) (finding that the majority of residents believed that they were not influenced by marketing efforts, but assumed that only sixteen percent of their colleagues would be immune from influence); Mary-Margaret Chren, Interactions Between Physicians and Drug Company Representatives, 107 AM. J. MED. 182, 182 (1999) (suggesting that physicians understand that sales reps can influence them, but they engage in a variety of denials and rationalizations to hold the belief that they are not influenced); see also Kirsten E. Austad et al., Medical Students' Exposure to and Attitudes About the Pharmaceutical Industry: A Systematic Review, PLoS MED. 1 (May 24, 2011), http://www.plosmedicine. org/article/fetchObject.action?uri=info\%3 Adoi\%2F10.1371\%2Fjournal.pmed.1001037\&representation=PDF (finding undergraduate medical students to have positive attitudes about marketing and skepticism about potential for bias).

388. See, e.g., Jerry Avorn et al., Scientific Versus Commercial Sources of Influence on the Prescribing Behavior of Physicians, 73 AM. J. MED. 4, 7-8 (1982); Anthony D. Bower \& Gary L. Burkett, Family Physicians and Generic Drugs: A Study of Recognition, Information Sources, Prescribing Attitudes, and Practices, 24 J. FAM. Prac. 612, 614-16 (1987); T. Shawn Caudill et al., Physicians, Pharmaceutical Sales Representatives, and the Cost of Prescribing, 5 Archives Fam. Med. 201, 201 (1996); Ashley Wazana, Physicians and the Pharmaceutical Industry: Is a Gift Ever Just a Gift?, 283 J. AM. MED Ass’N 373, 373, 375-76, 378-79 (2000) (discussing how increased interactions between physicians and companies led to increased prescription costs and nonrational prescribing).

389. Indeed, some suggest that even small gifts to doctors may result in bias. See, e.g., Jason Dana \& George Loewenstein, A Social Science Perspective on Gifts to Physicians from Industry, 290 J. Am MED. Ass’n 252, 253-54 (2003); Dana Katz et al., All Gifts 
dearth of independent research on comparative effectiveness, such that a great deal of "research" available to doctors is sponsored by drug companies and thus may reflect drug company bias. 390

\section{Exploring Other Patent Schemas?}

There may also be other issues thus far taken as "truth" in patent law that are in fact schemas that should be further explored. This subpart will merely raise a few that stem naturally from the issues discussed above. ${ }^{391}$ At the domestic level, there may be schemas that a single patent covers a single drug and that the patent term for drugs are substantially shorter than for other inventions. ${ }^{392}$ In fact, recent evidence noted above shows that multiple patents tend to cover each drug, usually with sequential expiration dates, such that the effective patent term is not as short as PhRMA, or those with a strong patent schema, typically

Large and Small: Toward an Understanding of the Ethics of Pharmaceutical Industry Gift Giving, 3 Aм. J. BiOETHICS 39, 39-41, 43-44 (2003).

390. See, e.g., Keyhani \& Federman, supra note 327, at 693 (noting that doctors are often exposed to selective promotion of research that may reflect the opinion of the industry).

391. However, there are likely many more. For example, there could be a schema that drugs are better than non-drug methods of treatment. Many people often seek a pill to solve a problem - whether it is high blood pressure, sleeping problems, or depressioninstead of nondrug lifestyle treatments. This is true even when there are studies that suggest that the drug is no more effective than a placebo, as was the case with the highly popular SSRI antidepressants. E.g., Irving Kirsch \& Thomas J. Moore, The Emperor's New Drugs: An Analysis of Antidepressant Medication Data Submitted to the U.S. Food and Drug Administration, Prevention \& TREATMENT 1 (July 15, 2002), http://alphachoices.com/ repository/assets/pdf/EmperorsNewDrugs.pdf (finding that for the six most widely used antidepressant drugs approved between 1987 and 199, including Prozac, placebos were 80 percent as effective). Of course, antidepressants may not be the best example because scientists do not entirely understand how they work. But, there are other examples as well. For example, for many years, women were advised to take hormone replacement therapy based on industry-sponsored studies that suggested it would prevent heart disease; however, the NIH subsequently found this was not effective and recent studies suggest that such therapy should not generally be recommended. See supra note 383 and accompanying text. Nonetheless, current public health focuses predominantly on a "biomedical model," rather than considering social determinants of health, such as socioeconomic status and other lifestyle factors. In addition, this schema is reinforced by companies that can protect patented drugs, but not lifestyle interventions. See Kapczynski \& Syed, supra note 166, at 1928-29, 1946-48.

392. E.g., BURK \& LEMLEY, supra note 326, at 53. 
suggests. ${ }^{393}$ In addition, at the international level, there are likely schemas concerning compulsory licenses, as well as the impact of stronger patent protection for developing countries. ${ }^{394}$ The industry has repeatedly claimed that compulsory licenses are anathema to innovation and that other countries will benefit from stronger patent protection, a claim that the United States Trade Representatives Office has thus far adopted wholesale in demanding that other countries adopt stronger protection. ${ }^{395}$ However, data does not wholeheartedly support stronger patent protection. ${ }^{396}$

In addition to considering these schemas, further consideration of how patents interrelate with cultural cognition may be a prime area for additional exploration. Notably, although schemas and confirmation bias shed some light, they do not necessarily provide a complete solution to how to modify strongly held schemas. Cultural cognition, on the other hand, aims to get at culturally based reasons for different world views, such that there is the potential for modification. ${ }^{397}$ Thus far, those who have worked in this area have not explored patents, but perhaps the time is ripe for such a consideration. ${ }^{398}$

393. See Kapczinski et al., supra note 279.

394. See generally supra notes 246-49 and accompanying text (selective consideration of international evidence)

395. See supra note 258 and accompanying text (noting that USTR often echoes industry).

396. See supra Part III.C.2.

397. See, e.g., Donald Braman \& Dan M. Kahan, Overcoming the Fear of Guns, the Fear of Gun Control, and the Fear of Cultural Politics: Constructing a Better Gun Debate, 55 EMORY L.J. 569, 570-71, 579, 606-07 (2006); John Gastil et al., Deliberation Across the Cultural Divide: Assessing the Potential for Reconciling Conflicting Cultural Orientations to Reproductive Technology, 76 GEO. WASH. L. REV. 1772, 1773-74, 1797 (2008); Dan M. Kahan, The Cognitively Illiberal State, 60 STAN. L. REV. 115, 117, 12628, 130, 154 (2007). In addition, cultural cognition supports different inferences based on the same fact. E.g., Dan M. Kahan et al., Motivated Numeracy and Enlightened SelfGovernment 1-4, 24-25 (Yale Law Sch., Pub. Law Working Paper No. 307, 2013), available at http://papers.ssrn.com/sol3/papers.cfm?abstract_id=2319992.

398. See, e.g., The Cultural Cognition Project, YaLE LAw SCHOOL, http://www. culturalcognition.net/projects (last visited May 20, 2014). This may be changing, although there is likely still room for additional research. See Lisa Larrimore Ouellette, Cultural Cognition of Patents, 4 IP THEORY (forthcoming 2014), available at http://papers.ssrn. com/sol3/papers.cfm?abstract_id=2333216 (suggesting that cultural cognition might help to understand conflicts over patents in general, rather than the specific schemas addressed here, or even the subset of patents that relate to drugs). 


\section{CONCLUSION}

This Article hopes to provide a balanced picture of how current patent law and policy promotes mostly modest, yet high priced new drugs, as well as how cognitive biases have perpetuated this situation. This Article highlights the important interplay of cognitive biases not only by the frequently maligned industry but also previously presumed neutral parties, such as academics and policymakers. Most scholars would likely agree that considering how to optimize or at least not distort innovation is an important part of legal scholarship. However, to date, there has been little recognition, let alone robust discussion, of how patent and related laws promote problematic innovation of drugs, resulting in a situation where society is "drugged out" of necessary therapies. Although some scholars and policymakers have recognized that pharmaceutical innovation is mostly incremental, such recognition has thus far focused on proposing solutions outside the patent arena with no challenges to the fundamental patent law dialogue. This Article hopes to provide a first step toward doing so. 
